\title{
CALIPER
}

\section{Report 20.4:}

Lumen and Chromaticity Maintenance of LED PAR38 Lamps Operated in Steady-State Conditions

Prepared for:

Solid-State Lighting Program

Building Technologies Office

Office of Energy Efficiency and Renewable Energy

U.S. Department of Energy

Prepared by:

Pacific Northwest National Laboratory 
PNNL-23988

\title{
DISCLAIMER
}

This report was prepared as an account of work sponsored by an agency of the United States Government. Neither the United States Government nor any agency thereof, nor Battelle Memorial Institute, nor any of their employees, makes any warranty, express or implied, or assumes any legal liability or responsibility for the accuracy, completeness, or usefulness of any information, apparatus, product, or process disclosed, or represents that its use would not infringe privately owned rights. Reference herein to any specific commercial product, process, or service by trade name, trademark, manufacturer, or otherwise does not necessarily constitute or imply its endorsement, recommendation, or favoring by the United States Government or any agency thereof, or Battelle Memorial Institute. The views and opinions of authors expressed herein do not necessarily state or reflect those of the United States Government or any agency thereof.

\author{
PACIFIC NORTHWEST NATIONAL LABORATORY \\ operated by \\ BATTELLE \\ for the \\ UNITED STATES DEPARTMENT OF ENERGY \\ under Contract DE-AC05-76RL01830
}

Printed in the United States of America

Available to DOE and DOE contractors from the

Office of Scientific and Technical Information,

P.O. Box 62, Oak Ridge, TN 37831-0062;

ph: (865) 576-8401

fax: $(865) 576-5728$

email: reports $\boldsymbol{a}$ adonis.osti.gov

Available to the public from the National Technical Information Service

5301 Shawnee Rd., Alexandria, VA 22312

ph: (800) 553-NTIS (6847)

email: orders@ntis.gov <http://www.ntis.gov/about/form.aspx>

Online ordering: http://www.ntis.gov 


\section{Preface}

The U.S. Department of Energy (DOE) CALiPER program has been purchasing and testing general illumination solid-state lighting (SSL) products since 2006. CALiPER relies on standardized photometric testing (following the Illuminating Engineering Society of North America [IES] approved method LM-79-08 ${ }^{1}$ ) conducted by accredited, independent laboratories. ${ }^{2}$ Results from CALIPER testing are available to the public via detailed reports for each product or through summary reports, which assemble data from several product tests and provide comparative analyses. ${ }^{3}$ Increasingly, CALiPER investigations also rely on new test procedures that are not industry standards; these experiments provide data that is essential for understanding the most current issues facing the SSL industry.

It is not possible for CALiPER to test every SSL product on the market, especially given the rapidly growing variety of products and changing performance characteristics. Instead, CALiPER focuses on specific groups of products that are relevant to important issues being investigated. The products are selected with the intent of capturing the current state of the market at a given point in time, representing a broad range of performance characteristics. However, the selection does not represent a statistical sample of all available products in the identified group. All selected products are shown as currently available on the manufacturer's web page at the time of purchase.

CALiPER purchases products through standard distribution channels, acting in a similar manner to a typical specifier. CALiPER does not accept or purchase samples directly from manufacturers, to ensure that all tested products are representative of a typical manufacturing run and not hand-picked for superior performance. CALiPER cannot control for the age of products in the distribution system, nor account for any differences in products that carry the same model number.

Selecting, purchasing, documenting, and testing products can take considerable time. Some products described in CALIPER reports may no longer be sold or may have been updated since the time of purchase. However, each CALiPER dataset represents a snapshot of product performance at a given time, with comparisons only between products that were available at the same time. Further, CALiPER reports seek to investigate market trends and performance relative to benchmarks, rather than as a measure of the suitability of any specific lamp model. Thus, the results should not be taken as a verdict on any product line or manufacturer. Especially given the rapid development cycle for LED products, specifiers and purchasers should always seek current information from manufacturers when evaluating products.

To provide further context, CALiPER test results may be compared to data from LED Lighting Facts, ${ }^{4}$ ENERGY $\mathrm{STAR}^{\circledR}$ performance criteria, ${ }^{5}$ technical requirements for the DesignLights Consortium ${ }^{\circledR}$ (DLC) Qualified Products

\footnotetext{
${ }^{1}$ IES LM-79-08, Approved Method for the Electrical and Photometric Measurements of Solid-State Lighting Products, covers LED-based SSL products with control electronics and heat sinks incorporated. For more information, visit http://www.iesna.org/.

${ }^{2}$ CALiPER only uses independent testing laboratories with LM-79-08 accreditation that includes proficiency testing, such as that available through the National Voluntary Laboratory Accreditation Program (NVLAP).

${ }^{3}$ CALiPER application reports are available at http://energy.gov/eere/ssl/caliper-application-reports. Detailed test reports for individual products can be obtained from http://www.ssl.energy.gov/search.html.

${ }^{4}$ LED Lighting Facts ${ }^{\circledR}$ is a program of the U.S. Department of Energy that showcases LED products for general illumination from manufacturers who commit to testing products and reporting performance results according to industry standards. The DOE LED Lighting Facts program is separate from the Lighting Facts label required by the Federal Trade Commission (FTC). For more information, see http://www.lightingfacts.com.

${ }^{5}$ ENERGY STAR is a federal program promoting energy efficiency. For more information, visit http://www.energystar.gov.
} 
List (QPL), ${ }^{6}$ or other established benchmarks. CALiPER also tries to purchase conventional (i.e., non-SSL) products for comparison, but because the primary focus is SSL, the program can only test a limited number.

It is important for buyers and specifiers to reduce risk by learning how to compare products and by considering every potential SSL purchase carefully. CALiPER test results are a valuable resource, providing photometric data for anonymously purchased products as well as objective analysis and comparative insights. However, photometric testing alone is not enough to fully characterize a product-quality, reliability, controllability, physical attributes, warranty, compatibility, and many other facets should also be considered carefully. In the end, the best product is the one that best meets the needs of the specific application.

For more information on the DOE SSL program, please visit http://www.ssl.energy.gov.

\footnotetext{
${ }^{6}$ The DesignLights Consortium Qualified Products List is used by member utilities and energy-efficiency programs to screen SSL products for rebate program eligibility. For more information, visit http://www.designlights.org/.
} 


\section{Outline of CALiPER Reports on PAR38 Lamps}

This study is part of a series of investigations performed by the CALIPER program on LED PAR38 lamps. Each report in the series covers the performance of up to 44 LED PAR38 lamps (some tests were not performed on all of the available samples) that were purchased in 2012 or 2013. Summaries of the testing are covered in each report, as follows:

Application Summary Report 20: LED PAR38 Lamps (November 2012, addendum September 2013) ${ }^{7}$ A sample of 44 LED PAR38 lamps, as well as 8 halogen and 2 compact fluorescent (CFL) benchmarks, underwent photometric testing according to IES LM-79-08. CALiPER Application Summary Report 20 focuses on the basic performance characteristics of the LED lamps compared to the benchmarks, as well as performance relative to manufacturers' claims. This report follows numerous similar reports on different product types, which have been published by the CALIPER program.

\section{Report 20.1: Subjective Evaluation of Beam Quality, Shadow Quality, and Color Quality for LED PAR38 Lamps (October 2013)}

This report focused on human-evaluated characteristics, including beam quality, shadow quality, and color quality. Using a questionnaire that included rank-ordering, opinions on 26 of the Report 20 PAR38 lamps were gathered during a demonstration event for members of the local IES chapter. This was not a rigorous scientific experiment, and the data should not be extrapolated beyond the scope of the demonstration. The results suggest that many of the LED products compared favorably to halogen PAR38 benchmarks in all attributes considered. LED lamps using a single-emitter design were generally preferred for their beam quality and shadow quality, and the IES members' ranking of color quality did not always match the rank-order according to the color rendering index (CRI).

\section{Report 20.2: Dimming, Flicker, and Power Quality Characteristics of LED PAR38 Lamps (March 2014) ${ }^{9}$} This report focused on the flicker and power quality performance of the Series 20 lamps at full output and various dimmed levels. All of the Series 20 PAR38 lamps that manufacturers claimed to be dimmable (including all halogen lamps) were evaluated individually (one lamp at a time), both on a switch and under the control of a phase-cut dimmer designed for use with "all classes of bulbs." Measurements of luminous flux, flicker, and power quality were taken at 10 target dimmed settings and compared with operation on a switch.

The dimmed performance of many LED lamps is dependent on the phase-cut dimmer used and the number of lamps that are connected to the dimmed circuit. Some manufacturers recommend specific dimmers that work better with their product(s), as well as the minimum and maximum number of dimmers per circuit. Because only a single unit of each product was evaluated on a single dimmer make and model, which may or may not have been recommended by its manufacturer, this report focuses on the performance of the products relative to each other, rather than on the best-case performance of each lamp or variation in performance delivered from each lamp. Despite these limitations, the results suggest that LED performance is improving, and performance trends are beginning to emerge, perhaps due in part to the identification of preferred LED driver strategies for lamp products.

\footnotetext{
${ }^{7}$ Available at: http://apps1.eere.energy.gov/buildings/publications/pdfs/ssl/caliper_20_summary.pdf

${ }^{8}$ Available at: http://apps1.eere.energy.gov/buildings/publications/pdfs/ssl/caliper_20.1_par38.pdf

${ }^{9}$ Available at: http://apps1.eere.energy.gov/buildings/publications/pdfs/ssl/caliper_20-2_par38.pdf
} 


\section{Report 20.3: Robustness of LED PAR38 Lamps $^{10}$}

Most of the Series 20 PAR38 lamps underwent multi-stress testing, whereby samples were subjected to increasing levels of simultaneous thermal, electrical, and mechanical stress. The results do not directly yield expected lifetime or reliability performance, but the LED products can be compared with one another, as well as with benchmark conventional products, to assess the relative robustness of the product designs.

The results showed that there is great variability in the robustness and design maturity of LED lamps. Nonetheless, the LED lamps were generally more robust than the benchmark PAR38 lamps, with a couple exceptions. More than $25 \%$ of the lamps were prone to early failure, indicating that the designs and manufacturing could still be improved.

Almost all of the lamps that failed did so catastrophically rather than parametrically. That is, the lamps stopped working before their lumen output or chromaticity reached unacceptable levels $-L_{70}$ or a $\Delta u^{\prime} v^{\prime}$ of 0.007 , respectively. Although a precise failure analysis examining each failed lamp's components was not conducted, this breakdown of failure modes helps to identify areas of weakness for the lamps. In this case, the electronics tended to fail before performance of the LED packages or optical systems degraded, with a few exceptions.

\section{Report 20.4: Lumen and Chromaticity Maintenance of LED PAR38 Lamps}

The lumen depreciation and color shift of 38 different lamps ( 32 LED, 2 CFL, 1 ceramic metal halide [CMH], 3 halogen) were monitored in a specially developed automated long-term test apparatus (ALTA2) for nearly 14,000 hours. Five samples of each lamp model were tested, with measurements recorded on a weekly basis. The lamps were operated continuously at a target ambient temperature between $44^{\circ} \mathrm{C}$ and $45^{\circ} \mathrm{C}$.

During the test period, 13 LED lamp samples failed catastrophically-although these failures came from only five of the 32 models of LED lamps. Five of the LED-lamp catastrophic failures occurred in conjunction with a system power failure and/or the subsequent restart of the apparatus. All of the halogen lamps failed (but none of the CFL or CMH lamps failed). Importantly, the steady-state test conditions were not optimized for inducing catastrophic failure (to which thermal cycling is a strong contributor) for any of the lamp technologies and are not typical of normal use patterns - which usually include off periods where the lamp cools down. Further, the test conditions differ from those used in standardized long-term test methods (i.e., IES LM-80, IES LM-84), so the results should not be directly compared, although the conditions do match one version of the ENERGY STAR Elevated Temperature Life Test. Likewise, the conditions and assumptions used by manufacturers to generate lifetime claims may vary; the CALIPER long-term data is informative but cannot necessarily be used to discredit manufacturer claims. The test method used for this investigation should be interpreted as one more focused on the long-term effects of elevated temperature operation, at an ambient temperature that is not uncommon in luminaires.

On average, the lumen maintenance of the LED lamps monitored in the ALTA2 was substantially better than the average for the other lamp technologies. After nearly 14,000 hours, the average lumen output for the noncatastrophically failed LED lamps was $94 \%$. In contrast, the CFLs were at $68 \%$ and the CMH lamps were at $62 \%$. The halogen lamps typically reached about $80 \%$ of the initial output before failing.

While the average lumen maintenance for the LED lamps was very good, there was considerable variation from lamp model to lamp model. At the end of the test period, some lamp models had an average lumen output greater than the initial average, whereas two lamp models had an average output less than $80 \%$ of the initial. All

\footnotetext{
${ }^{10}$ Available at: http://energy.gov/eere/ssl/downloads/report-203-stress-testing-led-par38-lamps
} 
but three of the LED lamp models had average relative output between $87 \%$ and $101 \%$ (only including operating lamps).

As with lumen maintenance, on average the LED lamps exhibited superior chromaticity maintenance compared to the conventional benchmark lamps-including the halogen lamps. However, the average $\Delta u^{\prime} v^{\prime}$ of two of the LED lamp models exceeded the ENERGY STAR limit of 0.007 (which is used as a basis of comparison in this report) and would likely be problematic in an application where color stability is important.

Given the methods used for this investigation-most notably, continuous operation-the results should not be interpreted as indicative of a lamp's performance in a typical environment. Likewise, these results are not directly relatable to manufacturer lifetime claims. This report is best used to understand the variation in LED product performance, compare the robustness of LED lamps and benchmark conventional lamps, and understand the characteristics of lumen and chromaticity change. A key takeaway is that the long-term performance of LED lamps can vary greatly from model to model (i.e., the technology is not homogeneous), although the lamp-to-lamp consistency within a given model is relatively good. Further, operation of LED lamps in an enclosed luminaire (or in other settings involving high ambient temperatures) can induce parametric failure of LEDs before the end of their rated lifetime; manufacturer warnings about such conditions should be followed if performance degradation is unacceptable. 


\section{Introduction}

Besides efficacy, one of the major competitive advantages of LED products versus conventional light sources is the promise of longer lifetimes. Given rated lifetimes in the many tens of thousands of hours and the rapid turnover in products, it is impractical for manufacturers to test products for the duration of their lifetime. Some modes of failure, such as lumen depreciation, can be projected based on a relatively small number of measurements taken over a relatively short duration, but other failure modes are much more difficult to predict. There is also an important distinction between data for LED packages and data for integral LED lamps and luminaires; oftentimes, LED package data is applied to complete LED lamps and luminaires by verifying operating conditions similar to the temperatures under which the packages were tested.

The goal of this investigation was to examine the long-term performance of complete LED lamps-in this case, PAR38s - operated continuously at a relatively high ambient temperature of $45^{\circ} \mathrm{C}$. This ambient temperature is above what a lamp would experience in an open fixture, but within the range of what an LED lamp might experience if operated in an enclosed fixture or even in a downlight or track head with only one side open. Importantly, all except three of the Series 20 PAR38 lamps stated in specification sheets or on product packaging that they were not to be used in enclosed luminaires, and none explicitly stated that use in an enclosed fixture was acceptable. Nonetheless, the higher ambient temperatures were used to create a more hostile operating environment, which allows for greater differentiation between the lamp models. Further, $45^{\circ} \mathrm{C}$ is the ambient temperature required for the ENERGY STAR Elevated Temperature Life Test.

This report documents the long-term performance of 32 of the Series 20 LED PAR38 lamps. Specifically, it focuses on lumen maintenance, chromaticity maintenance, and catastrophic failures of the LED lamps and eight benchmark lamps. Importantly, continuous operation does not lead to the most rapid degradation of LED sources, ${ }^{11}$ or of the halogen, $\mathrm{CFL}$, and $\mathrm{CMH}$ benchmarks. More specifically, the steady-state operating conditions eliminate thermal cycling, which can increase the degradation of many types of components within a lamp. Further, it eliminates a primary cause of catastrophic failure, especially for the CFL and halogen benchmarks. Thus, the results must be carefully interpreted and should not be extrapolated to other operating conditions. Even the relationship between the LED lamps and benchmark lamps will not be consistent across different operating conditions/testing protocols, which can be more or less harsh for a given lamp technology (or a given make and model).

There are several key factors to keep in mind when interpreting the results of this study, especially relative to manufacturer lifetime claims:

- The test conditions were not similar to those of most real-world applications. Specifically, the protocol for this study did not involve on/off cycling or dimming, which could lead to thermal cycling of the lamps, is known to increase the rate of lumen and chromaticity change, and is a contributor to catastrophic failure for both LEDs and conventional light sources. Thus, it is important to reiterate that the results are comparative between the included products but do not indicate how long a product will perform as intended when installed in a real application, nor the accuracy of manufacturer claims.

- The lamps were operated for nearly 14,000 hours - 13,925 to be exact, which is more than 18 monthsand were all purchased in 2012. Consequently, they are likely not the same as would be currently available for purchase. This is further reason to evaluate the results only within the context of this study.

\footnotetext{
${ }^{11}$ For more information, see: Narendran N. 2014. Accelerated Life-testing Study to Predict LED System Failure. Strategies in Light. February 27, 2014. Santa Clara, CA.
} 
- In 2013, the IES published LM-84-13, Approved Method for Measuring Lumen and Color Maintenance of LED Lamps, Light Engines, and Luminaires; as well as TM-28-13, Projecting long-term lumen maintenance for LED lamps and luminaires. The investigation covered in the present report was initiated before these documents were published, and uses a different procedure. Data from this report are not comparable to LM-84 data.

The present report is best used to understand the variation in LED product performance, compare the robustness of LED lamps and benchmark conventional lamps, and understand the characteristics of lumen and chromaticity change.

\section{Comparable Long-Term Test Data}

Pacific Northwest National Laboratory (PNNL) developed the automated long-term test apparatus (ALTA) ${ }^{12}$ in order to test products for the L Prize ${ }^{\circledR}$ competition. Beginning in 2010, 200 samples of Philips Lighting's L Prize entry were evaluated in the ALTA; after approximately 30,000 hours of operation, the sample size was reduced to 32 . Through 25,000 hours of testing, the average lumen maintenance of the samples remained at $100 \%$ of the maximum average output, as noted in the report Lumen Maintenance Testing of the Philips 60-Watt Replacement Lamp L Prize Entry. ${ }^{13}$ Besides data analysis, the report also includes detailed information about the test apparatus development and measurement procedures.

While the L Prize long-term testing regimen was underway, a second apparatus with near-identical specifications was constructed. This apparatus - deemed the automated long-term test apparatus 2 (ALTA2) -included minor upgrades to improve performance and a mounting configuration to accept PAR38 lamps. The ALTA2 was used to investigate the long-term performance of the CALiPER Series 20 PAR38 lamps, beginning in early 2013.

The L Prize long-term dataset demonstrates, for all practical purposes, the maximum achievable lumen and chromaticity maintenance for LED products. The tested lamps were pre-commercial, but the design eventually turned into a commercial product, and the technological innovation was used in subsequent products. Still, it is unreasonable to expect all LED lamps to perform to the level of the L Prize lamp, given the considerable tradeoffs between performance and cost, for example. Nonetheless, the L Prize result does provide context for understanding the performance of other lamps that the CALiPER program has subsequently tested.

\footnotetext{
${ }^{12}$ This device was originally named the lumen maintenance test apparatus (LMTA). That name is used in previous reports that relied on the apparatus.

${ }^{13}$ Available at: http://www.lightingprize.org/pdfs/lprize_60w-lumen-maint-testing.pdf
} 


\section{Methods}

The 32 LED lamps and 8 benchmark lamps were simultaneously operated for approximately 14,000 hours in the ALTA2. The lamps are identified in Appendix A. Five samples of each lamp were tested, which allows for some evaluation of the variability in performance for a particular lamp make and model but does not allow for a thorough statistical inference or an extrapolation based on mean performance. In other words, the results were not extrapolated using the TM-28 projection method.

\section{Apparatus $^{14}$}

The ALTA2 (Figure 1) can accommodate up to 204 lamps, arranged in a 12-by-17 array. One space in the 204position array is used as a rest location for the mobile integrating sphere, and another is used for a calibration standard lamp, so the effective capacity is 202 lamps. The PAR38 lamps tested for this investigation were mounted base-up, with their emitting area approximately even with a 5"-diameter opening, which was machined into an aluminum channel. This opening was similar to the maximum diameter of the PAR38 lamps

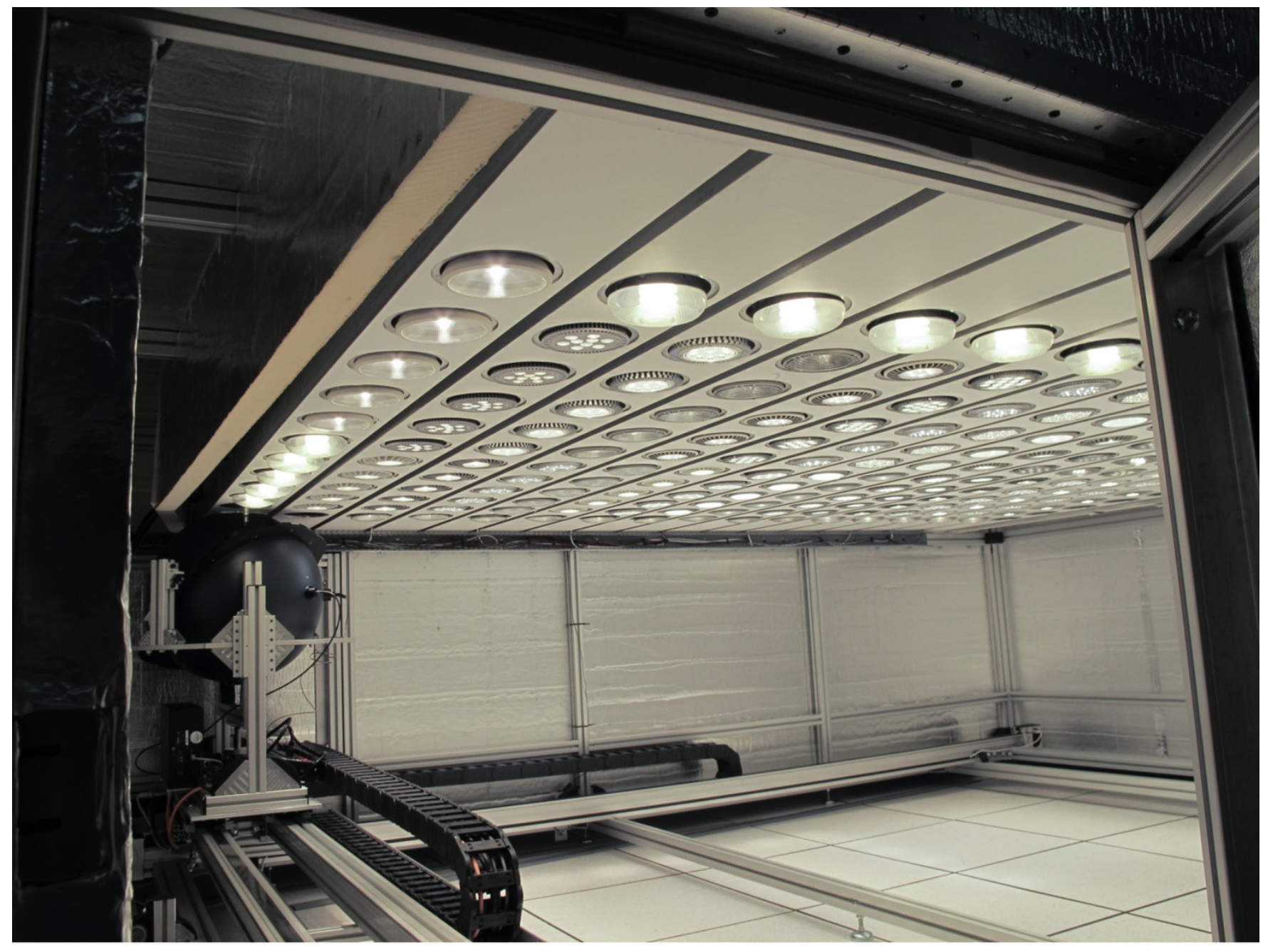

Figure 1. The inside of the ALTA2 apparatus, showing the installed PAR38 lamps and the automated integrating sphere measuring system.

\footnotetext{
${ }^{14}$ The ALTA2 is the sister apparatus to the ALTA1, which was used to test the L Prize submission; for complete details about the design and construction of the ALTA1, see the L Prize long-term testing report.
} 
but was not a perfectly tight fit. Unlike the L Prize lamp testing, in which the lamps fit tightly inside the channel opening, it was not possible to alter the aperture for each of the 38 different PAR38 lamp models, which would completely seal off the emitting area. Also, the LED lamps had irregular surfaces due to integral heatsinks.

Given the small gap surrounding each lamp, a small amount of spill light may have been included in the photometric measurements. The spill light was estimated to be less than 1 lumen (approximately $0.1 \%$ of the typical measured values), based on 13 measurements where an LED lamp had failed and was still measured during regular data collection. Regardless of the absolute or relative quantity, the amount of spill light was generally consistent from measurement to measurement, and did not significantly affect the results of the investigation.

The lamps were operated continuously, with the ambient temperature maintained between $44^{\circ} \mathrm{C}$ and $45^{\circ} \mathrm{C}$. The ambient temperature was monitored with an array of thermocouples and maintained with an exhaust fan that would operate when needed. The thermocouples were located in a plane approximately at the midpoint of the lamp bodies; that is, between the emitting area and the lamp base. Nine thermocouples were evenly spaced throughout one quadrant of the apparatus, which provided a complete characterization of the ambient temperature distribution throughout the apparatus.

Besides some vertical temperature stratification (which was unavoidable), there was some degree of temperature variation within the measurement plane. The coolest area was around the perimeter, and the warmest area was at the center of the apparatus, with an approximate difference of $1-2^{\circ} \mathrm{C}$. The lamp models were distributed as evenly as possible, with 30 of the 32 LED lamp models spanning from the center to the perimeter along the short axis of the array (see Appendix B). The benchmark lamps were all located around the perimeter.

One of the halogen benchmarks, positioned adjacent to the calibration lamp and rest position of the integrating sphere, was removed from the device because it was found to radiate too much heat onto the integrating sphere. The lamp was removed out of concern that this heating might cause issues with the spectrophotometer or data transfer devices.

Photometric measurements were taken by initiating an automated sequence. Besides the computer and control hardware, the measurement setup included an integrating sphere and accompanying spectroradiometer that were mounted to a track system and could be maneuvered to each lamp (see Figure 1). The integrating sphere measured the lamps in a consistent sequence and, at each lamp, raised until contact with the aperture was achieved. At this point, the lamp was emitting directly into the open port of the integrating sphere, consistent with a 2-pi photometric measurement procedure. The measurements were taken and recorded automatically. The entire measurement procedure took approximately 1 hour to complete per measurement cycle.

The apparatus included a working standard calibration lamp, which was itself calibrated based on a NISTcertified calibration standard. Prior to each photometric measurement, a calibration measurement was performed, which adjusted for any long-term degradation of the integrating sphere surface or measurement equipment. The calibration lamp was not operated continuously and was assumed not to degrade over the small amount of time it was operational.

\section{Measurement Sequence and Procedures}

Following a 2-hour temperature stabilization period, the first measurement sequence was initiated on March 21, 2013. This measurement was used as the baseline for relative lumen maintenance measurements in this report, and was denoted as zero hours. Subsequent measurements were initiated the next day, at 22 hours, and 
approximately every 168 hours (weekly) thereafter. At the time of this report, the lamps had been operating for approximately 13,925 hours.

Over the course of the investigation, 13 (8\%) of the LED lamps and all of the 15 halogen benchmark lamps failed. Each failure resulted in at least one measurement where the lamp was not lit, which allowed for detection. After all of the lamps had been measured, the failed lamp was replaced with an $11 \mathrm{~W}$ incandescent placeholder lamp for the remainder of the experiment. The placeholder lamps were used to prevent a delay in the automated measurement sequence and maintain heat balance within the apparatus. The failed lamps were then visually evaluated to gain a better understanding of the failure mode. They were also tested to ensure that it was the lamp, and not the test apparatus, that had failed.

\section{Power Outages}

Over the course of the investigation, two power outages affected the operation of the apparatus. First, an unanticipated building power outage at midnight on June 14, 2013 affected the lamps after approximately 2,000 hours of operation. The unexpected shutdown of the apparatus was not observed until the next scheduled reading, which was on June 18, 2013; so the lamps were not operated for 106 hours. Upon restarting the apparatus, two of the halogen lamps failed; this is further discussed in the Results section. The hours of operation reported in this study were adjusted to account for the 106 hours when the lamps were off.

After approximately 6,000 hours of continuous operation (December 13, 2013), a scheduled outage for building electrical work affected the apparatus for less than three hours. Still, this brief shutdown altered the thermal equilibrium of the system. More importantly, five LED lamps (two different products) failed to relight when the apparatus was restarted. (By this time, all of the initially installed halogen lamps had failed.)

In both cases, measurements were taken immediately after restarting the apparatus. However, the measurements were not included in the analysis, because the ambient temperature was not equivalent to the other measurements. Besides the lamp failures, the effect of the outages on the overall lumen and chromaticity maintenance is not possible to discern.

\section{Reported Metrics \\ Lumen Maintenance}

For this report, lumen maintenance is reported as the relative value compared to the baseline measurement for each lamp. The mean output of all of the LED lamps measured reached a maximum approximately 500 hours into the study; the maximum was less than $0.1 \%$ above the initial value, however. Note that not all LED lamps exhibited this initial rise in output. The maximum for the benchmark lamps was the initial reading. An important threshold is the point at which lumen maintenance reaches $70 \%$ of its initial value, denoted as $L_{70}$. This threshold is often used as an indicator of parametric failure. No lamps reached this threshold during this investigation.

In some instances where the data were averaged over large sets (e.g., the average output of the halogen benchmark), the number of samples included was reduced as the hours increased. That is, once a lamp failed, it was dropped from the average instead of counting as a zero.

\section{Chromaticity Maintenance}

The color appearance of a light source may be described using one of several metrics, all of which relate to the chromaticity of the light. Important characteristics include correlated color temperature (CCT), distance from the black body locus $\left(D_{u v}\right)$, and $\Delta u^{\prime} v^{\prime}$, which characterizes the change in chromaticity using the most uniform 
chromaticity diagram (CIE 1976). For more background on these color metrics, please see the DOE fact sheet LED Color Characteristics, ${ }^{15}$ or the DOE report Color Maintenance of LEDs in Laboratory and Field Applications. ${ }^{16}$

The most relevant color metric for the present report is $\Delta u^{\prime} v^{\prime}$. It is the most accurate and comparable measure of color shift, because it relies on the CIE 1976 chromaticity diagram, which has greater spatial uniformity than its predecessors. This means that a given value of $\Delta u^{\prime} v^{\prime}$ has approximately the same meaning in terms of color difference, regardless of position within the chromaticity diagram (e.g., starting chromaticity). For context, a circle with a radius of 0.001 in the CIE 1976 chromaticity diagram is roughly equivalent to a 1-step MacAdam ellipse. Importantly, $\Delta u^{\prime} v^{\prime}$ is only a measure of the magnitude of change and does not indicate the direction of the shift. To better understand the direction of the shift, $\Delta u^{\prime} v^{\prime}$ can be paired with metrics such as $\Delta C C T$ and $\Delta D_{u v}$, or plots of chromaticity coordinates can be examined directly.

There are no standards that establish an unacceptable color shift for LEDs or any other type of light source. Unlike $L_{70}$ for lumen maintenance, the IES does not suggest that any value of $\Delta u^{\prime} v$ ' constitutes a parametric failure, for example. In this report, the lamps are evaluated in the context of the ENERGY STAR criterion, which is 0.007. Importantly, this level of difference is readily noticeable in many interior lighting settings, ${ }^{17}$ if two lamps with that level of difference are viewed simultaneously. If all the lamps in a room undergo a change of that magnitude-and in the same direction-over the course of several years, the occupants may not detect that the lighting has changed, at least not until one or more of the lamps is replaced.

\footnotetext{
${ }^{15}$ http://ssl.energy.gov/factsheets.html

${ }^{16}$ Available at: http://apps1.eere.energy.gov/buildings/publications/pdfs/ssl/2013_gateway_color-maintenance.pdf

${ }^{17}$ A just-noticeable difference (JND) is dependent on the viewing condition. There is no universal relationship between a value of $\Delta u^{\prime} v^{\prime}$ and a JND.
} 


\section{Lamp Failures}

Over the course of more than 35,000 hours of continuous operation, not a single L Prize lamp experienced catastrophic failure. In contrast, 5 of the 32 LED PAR38 lamp models tested under near-identical conditionswith the notable exception of the power outages-had at least one sample fail during the 14,000-hour test period. Of those five models, the number of failed samples ranged from just one to all five, as shown in Table 1.

In total, 13 of 160 (8\%) of the LED lamps failed during the test period. Based on a preliminary analysis, it is thought that all of the catastrophic LED lamp failures resulted from degradation of electrical components (e.g., the driver). None of the lamps had a visible degradation to the optical materials or LED packages.

In contrast with the LED lamps, none of the CFL or CMH lamps failed, despite rated lifetimes of 10,000 and 15,000 hours, respectively. For the CFLs, all 10 samples exceeded the rated lifetime, even though the lifetime rating is based on the expected point at which $50 \%$ of lamps would have failed $\left(B_{50}\right)$. While the rated lifetime of the $\mathrm{CMH}$ lamps was not reached, it was close, and yet none of the lamps failed. Of course, it is critical to note that the test methods were not suited for inducing failure of CFL or CMH lamps, for which on-off cycling is a primary contributor to degradation and, ultimately, failure to light. Similarly, incandescent lamps most often fail immediately after being switched on, due to the in-rush current. Of the 14 LED lamp samples, six failed before the rated lifetime, and eight failed after. This is expected since, as with CFLs, the lifetime rating is based on $B_{50}$.

Switching itself is not typically considered a contributing factor for LED catastrophic failures, although on-off cycling can induce thermal stresses on lamp components (e.g., electronics, phosphor). As previously noted, the failure rate and performance degradation of both the LED and benchmark lamps in the ALTA2 apparatus are different from what would occur in a typical architectural lighting application that included both on and off cycles as well as potentially different ambient conditions.

Although a small number of LED lamps experienced catastrophic failure, none of the 160 lamps exhibited parametric failure based on the lumen maintenance criterion of $L_{70}$; and only 2 of the 32 LED lamp models exhibited parametric failure based on the average of the chromaticity measurements for a given model, using the chromaticity maintenance criterion of $\Delta u^{\prime} v^{\prime}>0.007$. All five samples for each model were consistent, and each failed based on the chromaticity maintenance criterion. Each of these two parametric failure modes is discussed separately in the following sections.

\section{Lumen Maintenance}

On average, the LED lamps substantially outperformed the benchmark conventional lamps in terms of lumen maintenance, as shown in Figure 2. Note that failed lamps were removed from the calculation as they occurred; thus, the number of lamps being averaged changes as the hours increase. This is particularly relevant to the

Table 1. Number of failures and time to failure for the five LED PAR38 lamp models that experienced catastrophic failure. Note the failures in italics at 6,297 hours, which is the second time the ALTA2 apparatus had to be re-started after a power outage.

\begin{tabular}{|c|c|c|c|c|c|c|}
\hline Product ID & Number of Failures (of 5) & Time of $\mathrm{Fa}$ & re(s) (ho & & & \\
\hline $12-90$ & 1 & 11,910 & & & & \\
\hline $12-96$ & 1 & 2,552 & & & & \\
\hline $12-134$ & 4 & 8,380 & 11,070 & 12,246 & 12,918 & \\
\hline $12-147$ & 2 & 6,297 & 9,894 & & & \\
\hline $12-148$ & 5 & 6,297 & 6,297 & 6,297 & 6,297 & 10,255 \\
\hline
\end{tabular}




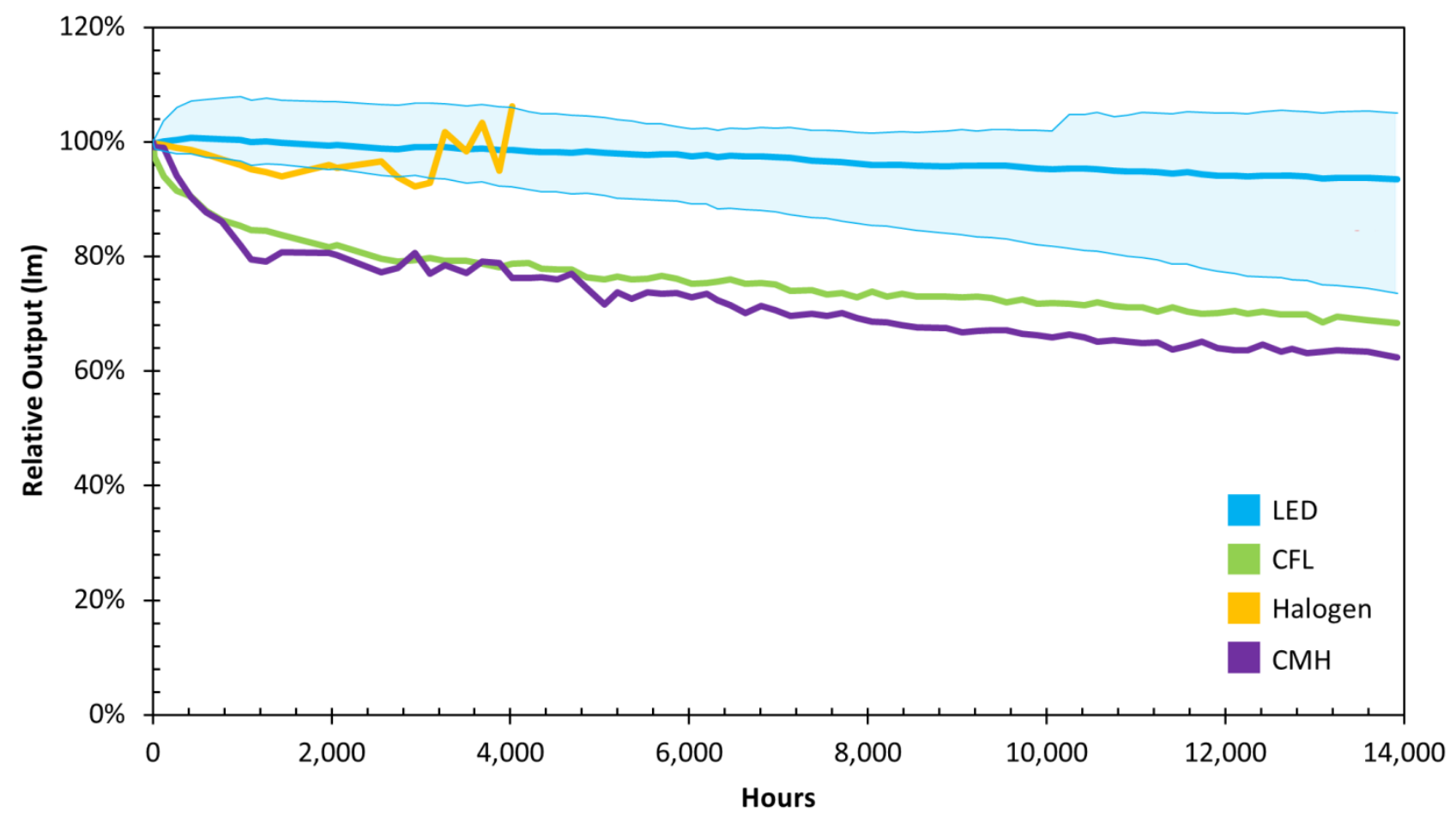

Figure 2. Average lumen maintenance for each source type, with the range in relative output shaded for the LED lamps. Note that the range is for average values for each type at a given time, not for individual samples. Failed lamp samples were dropped from the calculation (rather than included as zeros); this contributes to the inconsistency in relative output for the halogen benchmarks after 2,000 hours.

halogen lamps, all of which had failed in less than 4,100 hours; as a result, the last data points represent only a single lamp.

Of course, the average for each lamp technology only tells part of the story. There was considerable variation in the average lumen maintenance for each of the 32 LED lamp models, which is to be expected, given the level of maturity of the technology. In fact, as shown in Figure 3, four lamp models (12-67, 12-86, 12-92, and 12-99) had average relative lumen output above $99 \%$ for the duration of the study (and above $100 \%$ at the final measurement). In contrast, one product (12-74) showed consistent decline to a minimum of $74 \%$ at the last measurement point (13,925 hours), and another product declined to $76 \%$ of its initial output at the final measurement, after showing an increase in output in the first 500 hours. The other 26 LED products fell somewhere between $86 \%$ and $98 \%$ at the last measurement point.

In general, the rate of change in lumen maintenance was very consistent for the LED products. That is, the results shown in Figure 3 are generally linear-some minor deviations are due to measurement error. Importantly, this indicates that the lumen depreciation for most products did not increase in rate over time, or suddenly change due to failure of a specific component. The latter was the case for a few of the lamps, including one sample of product 12-85 (sudden increase at approximately 10,000 hours) and 12-92, for which all samples had a sudden drop of about $10 \%$ somewhere between approximately 9,900 hours and the final measurement.

Further insight into lumen depreciation performance can be gained by examining the relative performance of each of the five samples for a given model. One interesting statistic is the range in relative lumen output at the end of the investigation, as shown in Figure 4. For a vast majority of the lamps, all five samples performed very similarly, with a range in relative output of less than $5 \%$. A handful of products had a range greater than $5 \%$; 

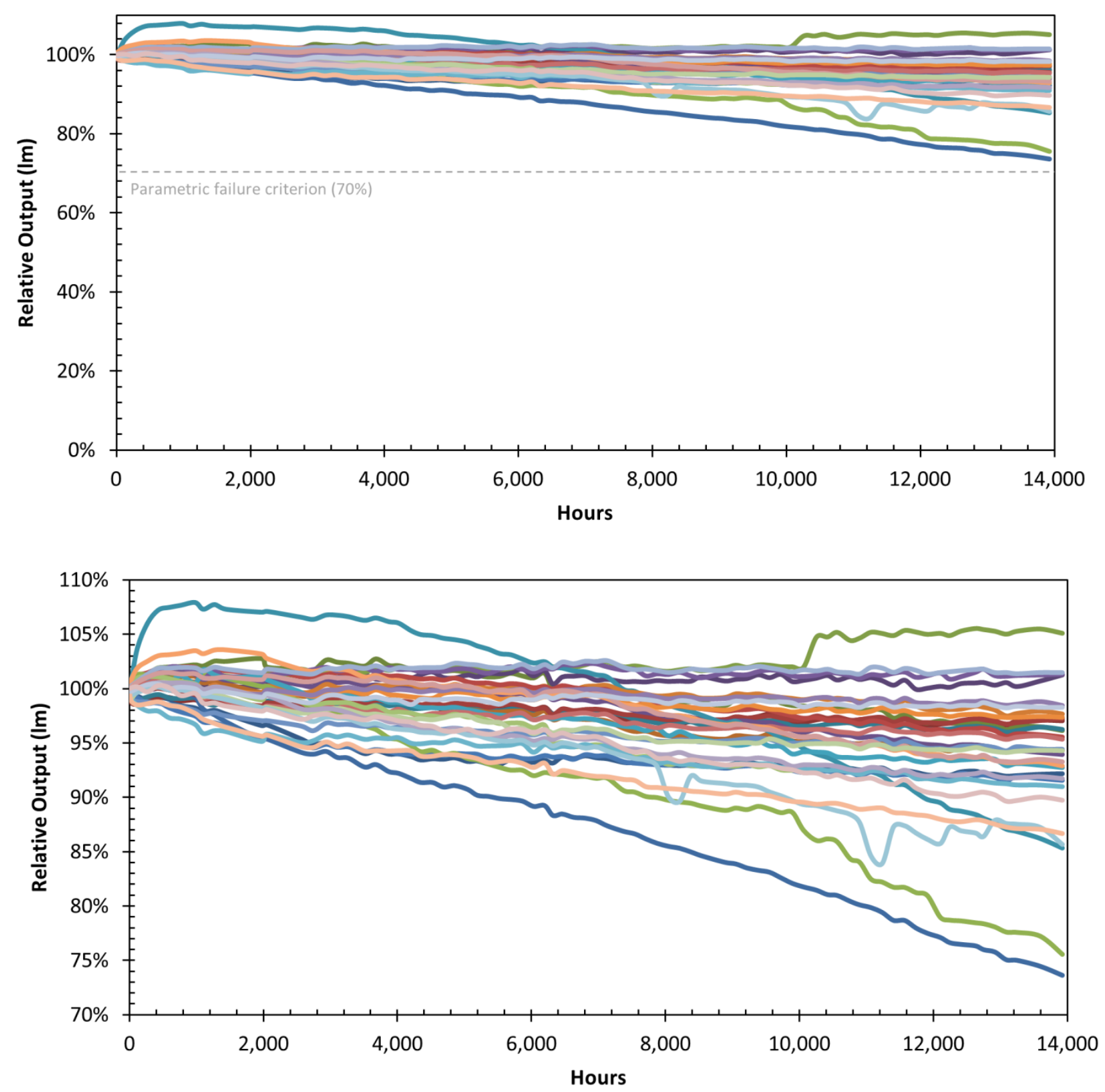

Figure 3. Average lumen maintenance for each of the $\mathbf{3 2}$ LED lamp models. There were a few lamps with better or worse performance, but a majority of the lamp types emitted between 90 and $98 \%$ of their initial lumens at the final measurement point. The cause of the sudden jump for 12-92 (green line) at approximately 10,000 hours was not identified; it occurred for only one of the five lamp samples. The line colors are consistent for each product in all charts throughout this report.

plots of relative output for each sample are shown in Appendix C. Two products showed higher levels of variation, exceeding $25 \%$.

A few products had one or more samples that had a different absolute lumen output, or that performed slightly differently over time. These differences are visible in the plots in Appendix $C$, which show the lumen maintenance for each sample. Differences in absolute output (and chromaticity) are a consistency issue. All products will vary to some degree, but variation that is too large can be problematic. While product-to-product 


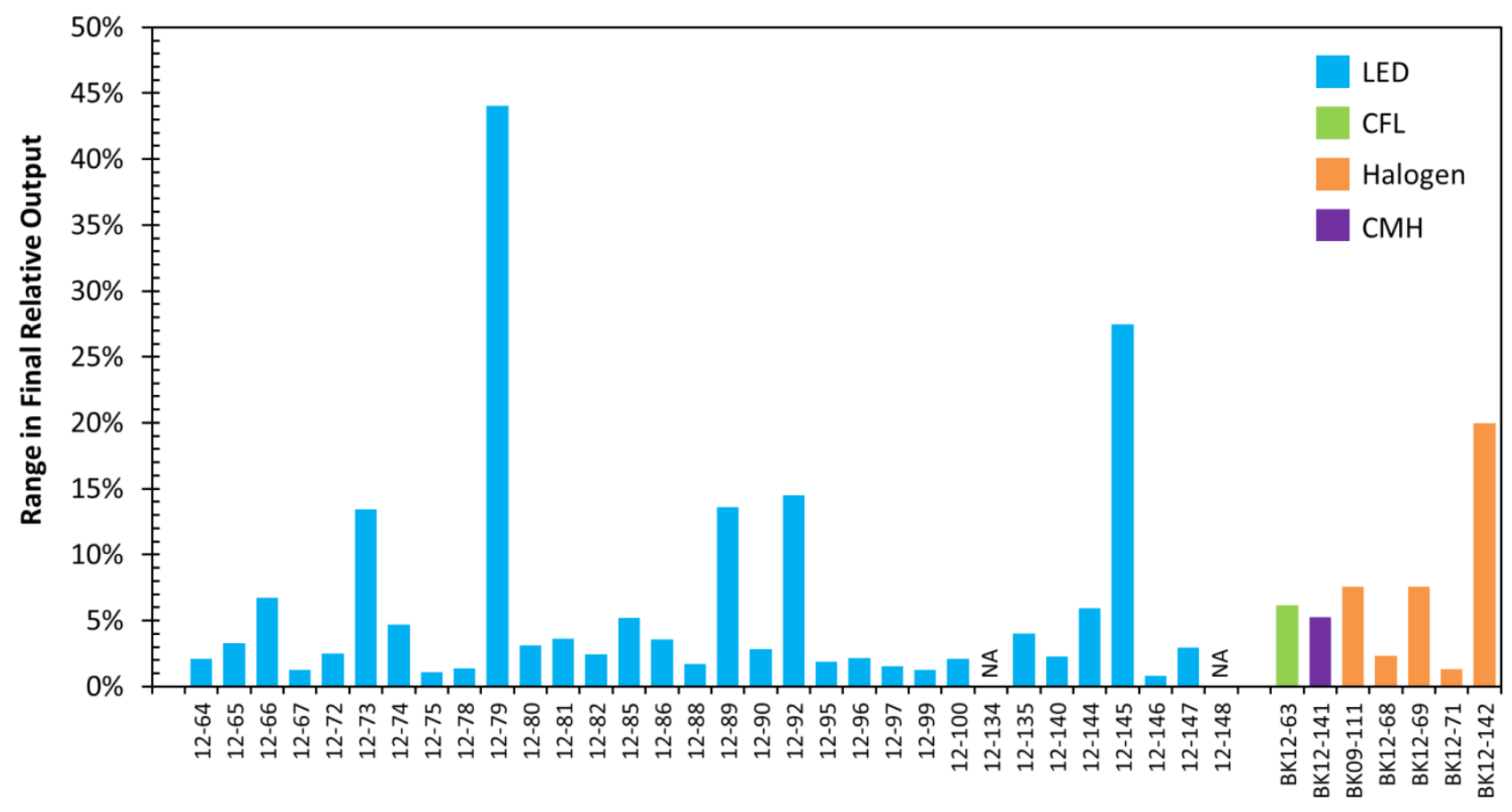

Product ID

Figure 4. Variation in relative output at the final measurement point. Most of the LED products were very consistent across the five samples. This chart does not document differences in absolute lumen output (i.e., product-to-product variation in initial output). Products $12-148$ and $12-134$ had 1 and 0 samples remaining at the final measurement point, so the range could not be calculated.

consistency is an important concern, it was not the focus of this investigation, and the sample size is likely not large enough to truly understand any potential problems.

Figures 5 and 6 explore the relationship between lumen depreciation (using the final measured value for each lamp) and rated lifetime or input power, respectively. Neither of the attribute pairs shows a correlation. That is, there does not appear to be a correlation between the manufacturer's rated lifetime claim and a product's measured relative output at 14,000 hours - at least, under the conditions of this experiment. It is presumed that the manufacturer ratings are based on IES LM-80 and TM-21 data for the LED package used, but this was not verified. There was no officially standardized method for reporting lifetime at the time these products were purchased.

In any case, the conditions under which the products were tested likely do not match those of the ALTA2. Further, a portion of the degradation that the products experienced in this investigation was related to the driver, which would not be characterized with LM-80/TM-21 data. With those caveats in mind, Figure 5 demonstrates that a product's lumen maintenance at 14,000 hours $^{18}$ is not correlated to the manufacturer's rated lifetime. Likewise, the failed lamps were relatively evenly distributed over the range of rated lifetimes. Additional analysis regarding ENERGY STAR thresholds for lifetime claims can be found in the next subsection.

As with rated lifetime, there was no obvious relationship between input power and percent of initial lumen output at the end of the investigation period. That is, the output of those lamps drawing more power-or having

\footnotetext{
${ }^{18}$ All samples of product $12-148$ had failed by approximately 10,000 hours. The last measurement, at 10,061 hours, was used in Figure 4 in lieu of a 14,000-hour measurement.
} 


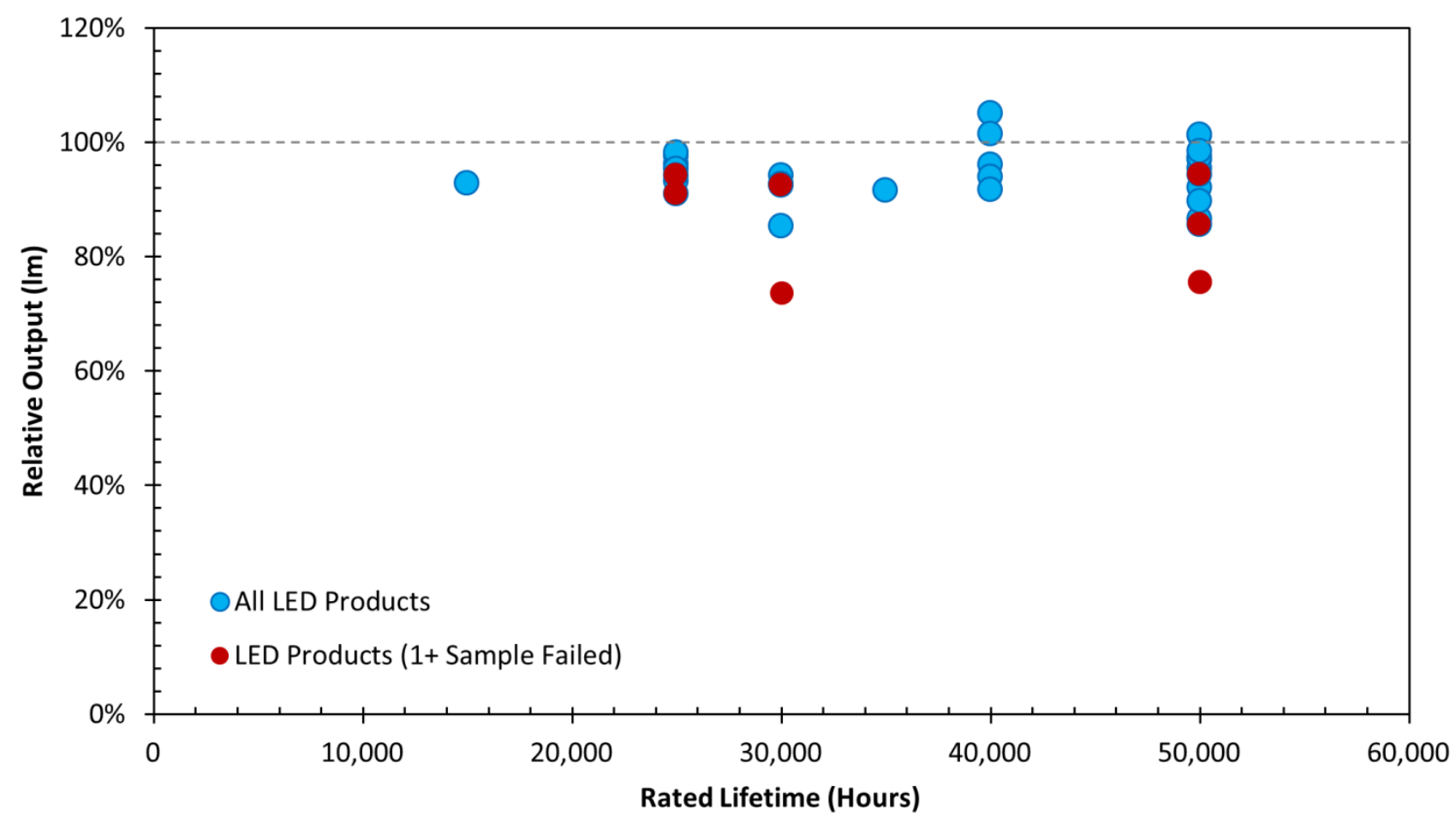

Figure 5. Lumen maintenance (final measurement) versus rated lifetime. There was no correlation between manufacturer rated lifetime and the final measured relative output.

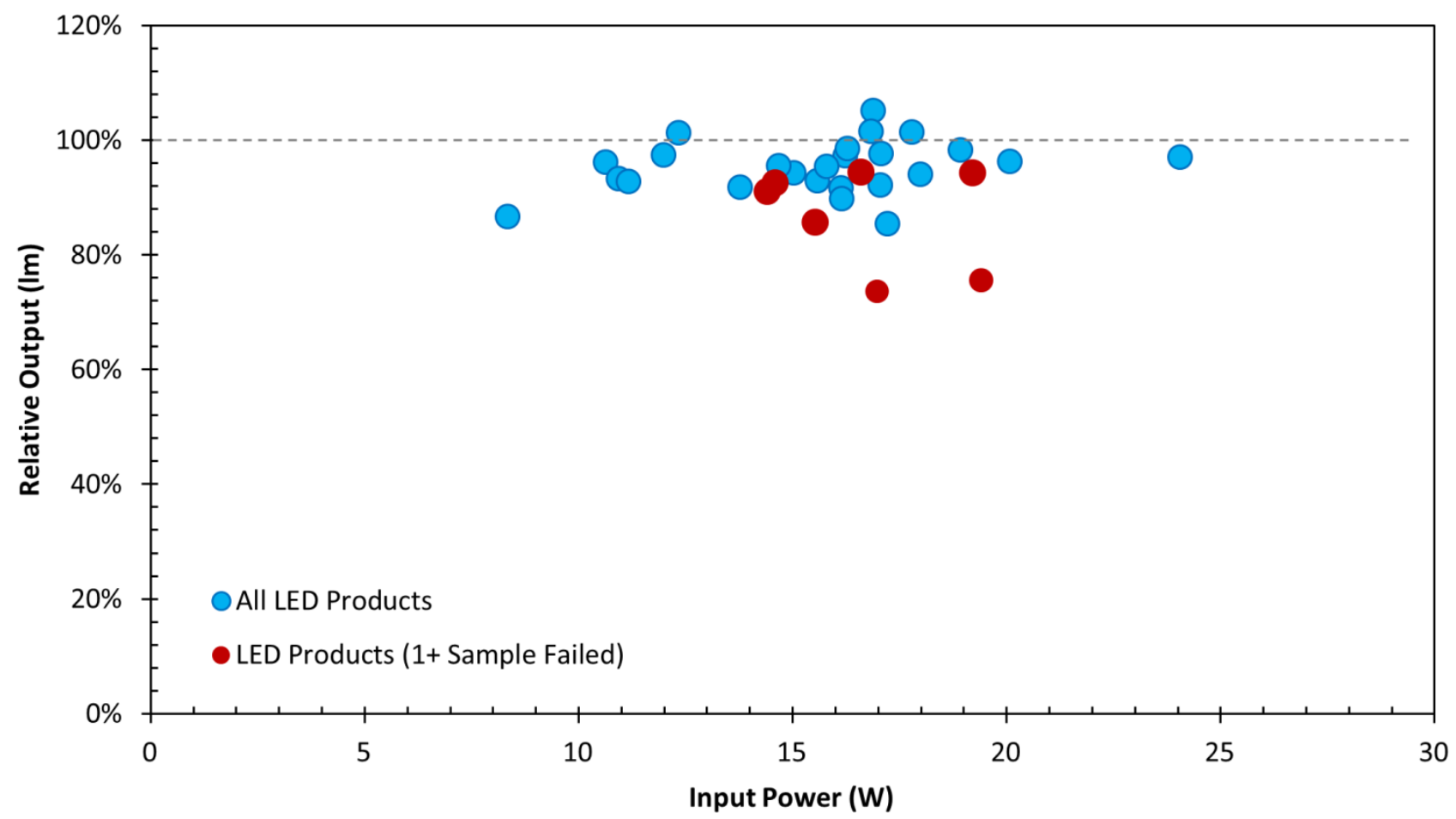

Figure 6. Lumen maintenance (final measurement) versus measured input power (average per model). There was no correlation between input power and the final measured relative output. 
greater lumen output (not shown)-did not depreciate faster. All of the lamps tested were between nominal CCTs of $2700 \mathrm{~K}$ and $3500 \mathrm{~K}$ (i.e., within a narrow range of CCTs), so evaluation of depreciation versus CCT was not possible.

Of the five lamp models with the most variation, in four cases it was due to one lamp, and in one case it was due to two lamps. In almost all cases, the lamp that deviated from the group in terms of lumen maintenance also experience substantial color shift, with three lamps exceeding a $\Delta u^{\prime} v^{\prime}$ of 0.010 . In all five cases, there was substantial difference in the CCT and/or $\mathrm{D}_{\mathrm{uv}}$ of the lamps initially. This could indicate a defective LED package or improper thermal pathway attachments.

\section{Evaluating Lifetime Claims Using ENERGY STAR Thresholds}

The following analysis is based on ENERGY STAR specifications. Specifically, it is based on the ENERGY STAR Program Requirements for Lamps (Light Bulbs) Partner Commitments, which became effective in September 2014. Critically, not all of the lamps included in this investigation were ENERGY STAR-qualified. Those that were ENERGY STAR-qualified at the time of purchase are identified in Appendix A. Importantly, even those lamps listed as ENERGY STAR-qualified in Appendix A were qualified under a different set of specifications (e.g., ENERGY STAR Program Requirements for Integral LED Lamps v1.4 Partner Commitments).

The older ENERGY STAR specifications required that directional lamps emit $70 \%$ of their initial light output at 25,000 hours, which necessitated an average output for 10 samples of at least $91.8 \%$ at 6,000 hours (following the elevated-temperature test protocol for lamps $\geq 10 \mathrm{~W}$ ). The newer requirements prescribe a variable 6,000 hour threshold based on the manufacturer's lifetime claim, ranging from $86.7 \%$ for a claimed lifetime of 15,000 hours to $95.8 \%$ for a claimed lifetime of 50,000 hours.

For comparative purposes only, Figure 7 shows each lamp's average measured lumen maintenance at 6,031 hours (the closest measurement to 6,000 hours) relative to the ENERGY STAR-required value based on its rated

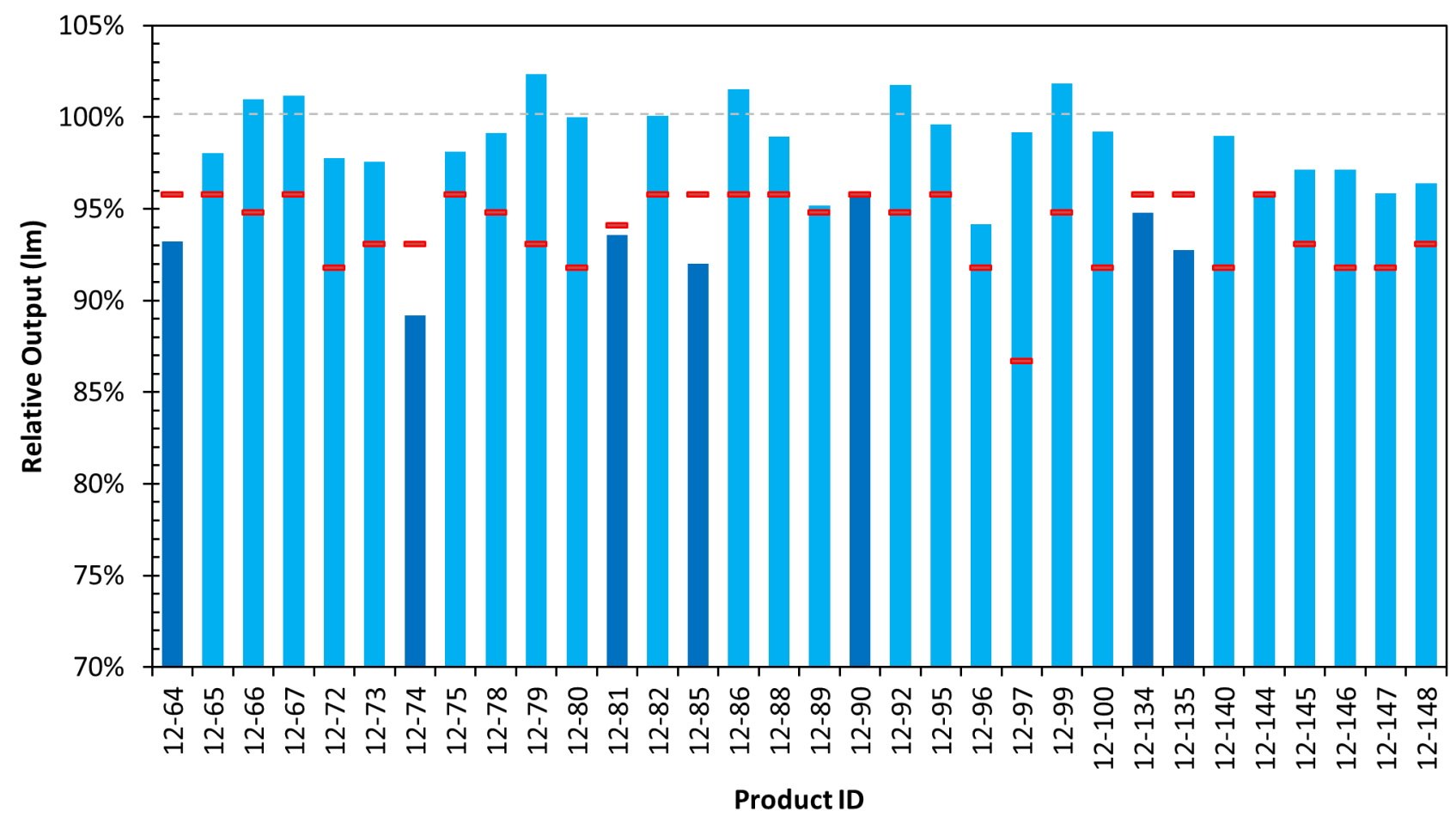

Figure 7. Relative lumen maintenance at 6,000 hours versus the current ENERGY STAR-threshold values (red lines), which are based on the rated lifetime. The darker-colored bars indicate products that failed to meet the 6,000 -hour criterion. 
lifetime. Despite no lamps reaching the $\mathrm{L}_{70}$ threshold during the test period, seven failed to meet the 6,000-hour criterion for ENERGY STAR qualification, given their rated lifetimes. Those products were 12-64, 12-74, 12-81, $12-85,12-90,12-134$, and 12-135. The current ENERGY STAR specification also includes a provision that requires lamps with rated lifetimes greater than 25,000 hours to meet an additional threshold (91.8\%) based on a longer test duration that varies from 7,500 to 12,500 hours, depending on the rated lifetime ( 30,000 to 50,000 hours). One product (12-144) that met the 6,000-hour criterion failed to meet its longer-duration criterion.

Of the seven products that failed to meet both ENERGY STAR criteria, four were in fact ENERGY STAR-qualified. However, all four of those lamps would have met the criterion that was in place at the time $(91.8 \%$ at 6,000 hours). Their rated lifetimes of 50,000 hours require a higher value at 6,000 hours (95.8\%) and 12,500 hours (91.8\%) under the new specifications. The four non-ENERGY STAR-qualified products that fell short of the criterion (12-74, 12-81, 12-85, and 12-135) had rated lifetimes of 30,000, 35,000, 50,000, and 50,000 hours, respectively.

\section{Chromaticity Maintenance}

As with lumen maintenance, high-level analysis shows that on average, the LED PAR38 lamps had greater color stability than the comparable conventional benchmarks (Figure 8). With the exception of the $\mathrm{CMH}$ benchmark, however, none of the lamp technologies performed particularly poorly. There are two important considerations when evaluating average chromaticity. First, the chromaticity maintenance for halogen and CFL productswhich are generally considered to have acceptably small levels of color shift-is actually worse than for the average LED PAR38. Yet that finding is potentially misleading, because the data was only collected for about 14,000 hours, which exceeds the lifetimes for the halogen and CFL lamps but is less than the full rated lifetime for the LED lamps. While the CFL lamps did not fail (at least in part due to the test procedure), in a typical environment they probably would have burned out and been replaced with a new lamp. The LEDs, however, are

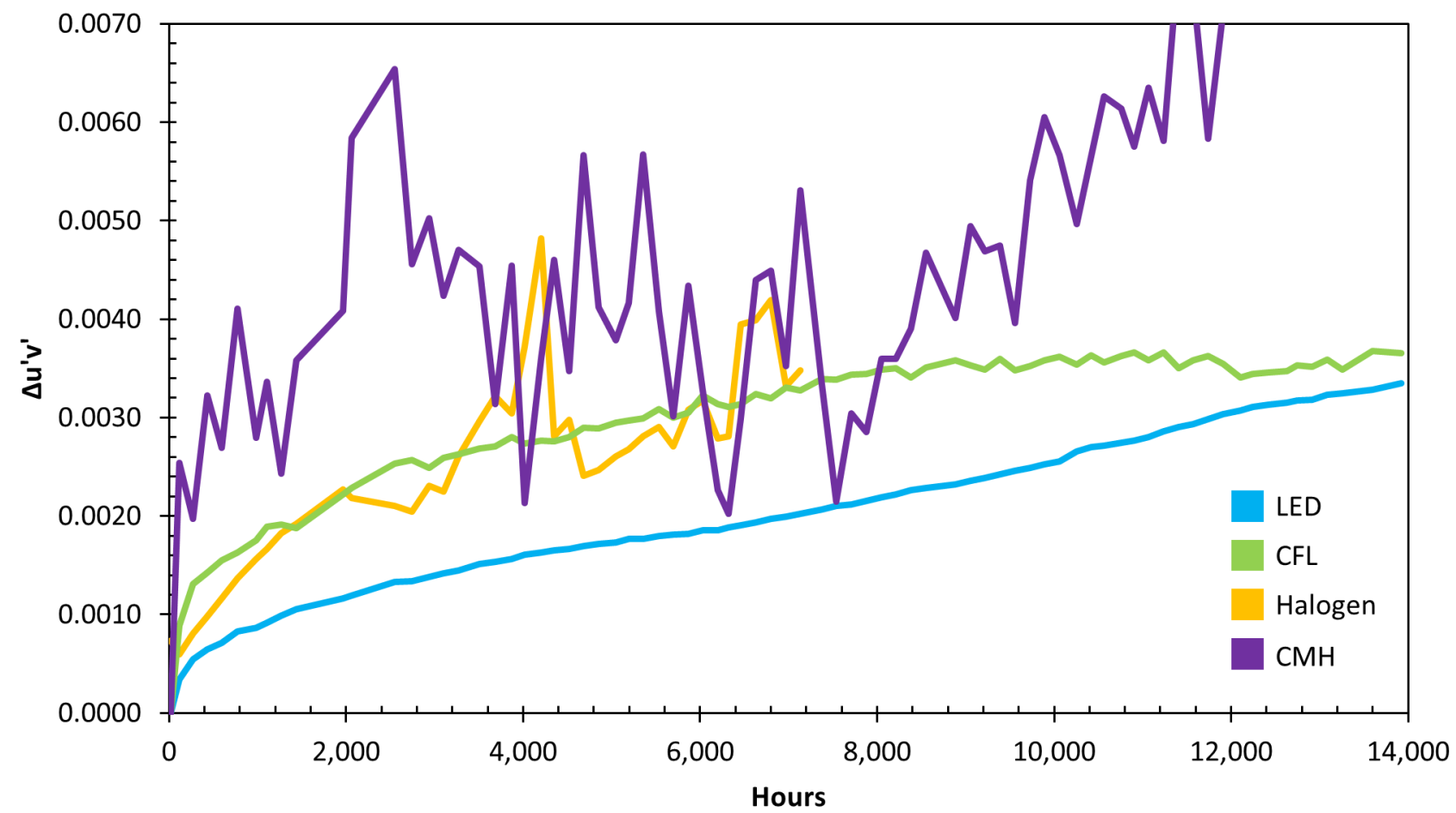

Figure 8. Average change in chromaticity for the remaining samples of each source type. On average, the LED products demonstrated less color shift than the other technologies over the same period. There was also substantial variation amongst the LED models, however, with some product types averaging much greater color shift than any of the benchmark lamps. 
likely to continue shifting in color, which occurred at a consistent rate of about $0.002 \Delta u^{\prime} v$ ' per 10,000 hours. If that rate held constant, any lamps with rated lifetimes of 40,000 hours or greater would experience parametric failure-according to the ENERGY STAR criterion of 0.007 - at less than their rated lifetimes. Importantly, there is currently no method for predicting future color shift from existing data, ${ }^{19}$ so the projections noted are speculative.

Figure 9 shows the average chromaticity maintenance for each of the 32 LED products tested. As with lumen maintenance, lamp samples that failed catastrophically were dropped from the average at the time of failure. The notable result shown in Figure 8 is that two lamps already exceeded the $\Delta u^{\prime} v^{\prime}$ parametric failure criterion (0.007) within 12,000 hours. Notably, these two products also had the worst lumen maintenance, and the cause is likely linked.

Several other products appeared to be on a consistent path to a similar failure in the near future, and in fact one sample of product $12-145$ had a $\Delta u^{\prime} v^{\prime}$ exceeding 0.016 at the final measurement point. Notably the other samples of 12-145 had below-average $\Delta u^{\prime} v$ ' values (averaging all LED lamps), which illustrates the limitations of comparing average performance. Appendix $C$ shows the $\Delta u^{\prime} v$ ' values over time for each lamp sample (arranged by lamp model). These plots can be used to examine color consistency and color shift.

$\Delta u^{\prime} v^{\prime}$ is the most appropriate measure for characterizing the magnitude of color shift, but it does not indicate the direction of the shift. Figure 10 shows plots for the average CCT and $\mathrm{D}_{\mathrm{uv}}$ of each product type over the course of the investigation. These plots demonstrate that a greater amount of the color shift was in the $D_{u v}$ axis,

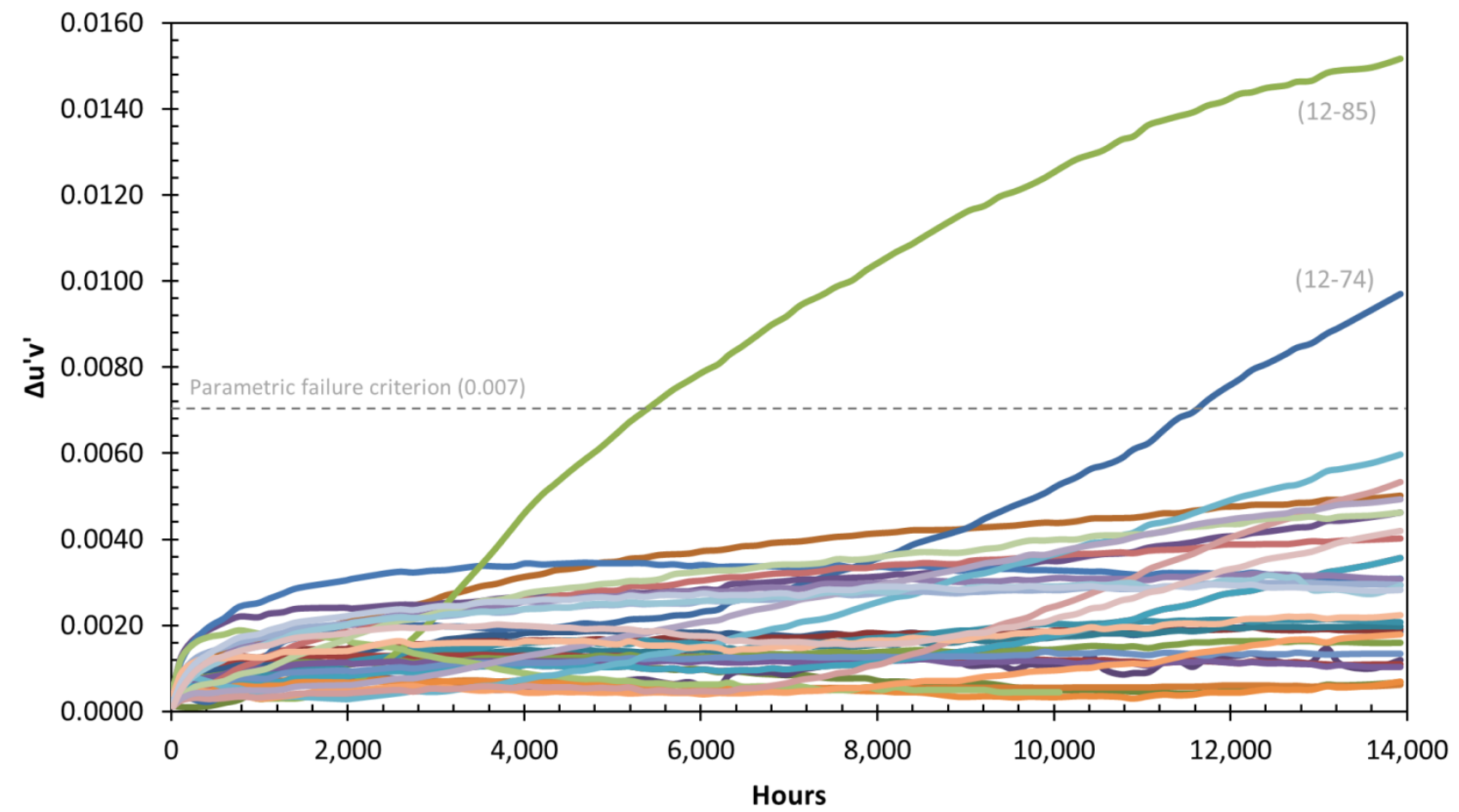

Figure 9. Average chromaticity maintenance for each LED PAR38 lamp model. Some LED products exhibited excellent color stability, but others did not.

\footnotetext{
${ }^{19}$ The IES has formed a working group (S412-13) within the SSL subcommittee of the Technical Procedures Committee (TPC) to focus on the issue of projecting color shift.
} 

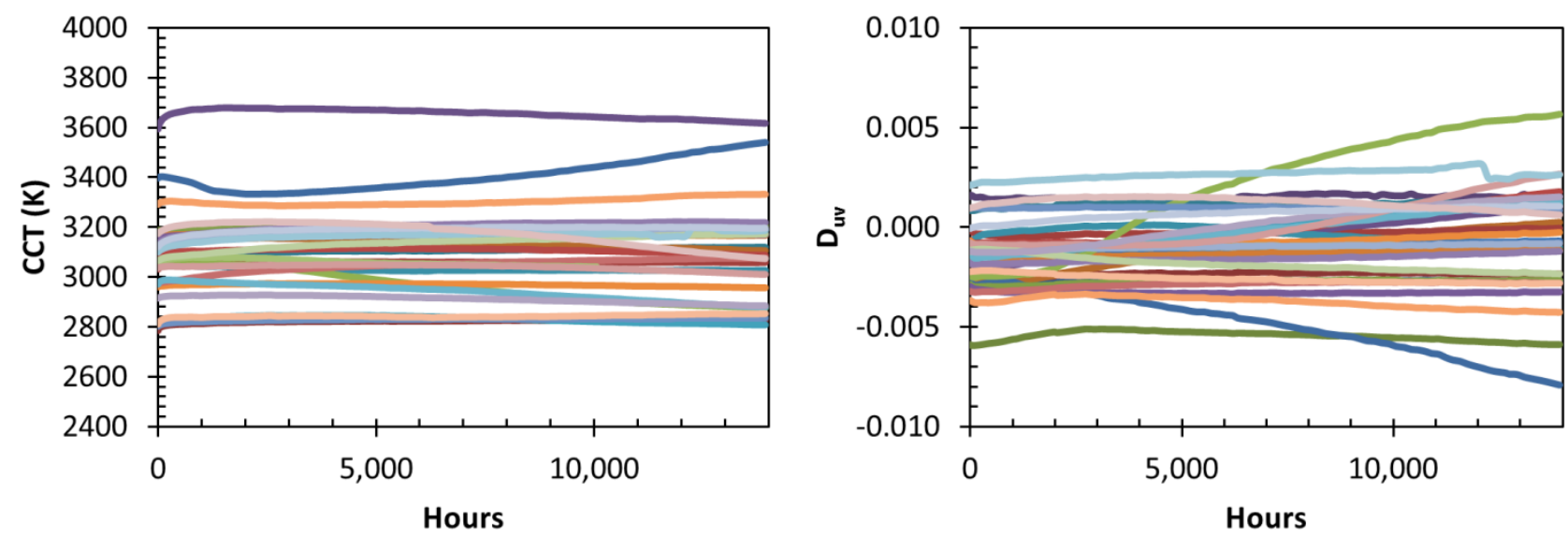

Figure 10. Average CCT and average $D_{u v}$ for each of the LED product types over the course of the investigation. There was no consistent trend in the type of color shift experienced, although the products experiencing the greatest shift typically changed in $D_{u v}$, rather than in CCT.

or moving toward/away from the black body locus, rather than along the black body locus. For these products, which were mostly $3000 \mathrm{~K}$ (nominal), these shifts are generally toward yellow if the $D_{u v}$ is becoming more positive, and toward the purple/blue if the $D_{u v}$ is becoming more negative. As Figure 10 demonstrates, the two products having the greatest color shift went in different directions, and may have been affected by the physical changes to the phosphor and/or LED chip that caused a change in the ratio of blue to yellow emission.

Alternatively, there may have been physical changes (e.g., yellowing) of other materials in the optical pathway, such as the encapsulant or refractive elements. For more discussion on the potential causes of color shift, see the GATEWAY report Color Maintenance of LEDs in Laboratory and Field Applications.

Similarly to the way Figure 4 depicts lumen maintenance, Figure 11 documents the range in $\Delta u^{\prime} v^{\prime}$ for the nonfailed samples of each product type during the last measurement. Several of the products that had a lot of variation in lumen maintenance also had a lot of variation in color maintenance (e.g., 12-73, 12-89, 12-145), but the lists of products with the most variation do not completely coincide. For example, products 12-79 and 12-92 show substantial variation in final lumen maintenance but not color maintenance, whereas product type 12-144 exhibited substantial variation in color maintenance but not in lumen maintenance. This illustrates that lumen depreciation and color shift are sometimes related, but sometimes occur independently. Figure 12 further explores this relationship, showing a moderate correlation between the final average lumen maintenance value and final average $\Delta u^{\prime} v^{\prime}$ for each of the LED PAR38 product types. Notably, the correlation coefficient of determination $\left(r^{2}=0.50\right)$ is heavily influenced by the two outlier points; without those two points, the coefficient of determination is only 0.12 . 


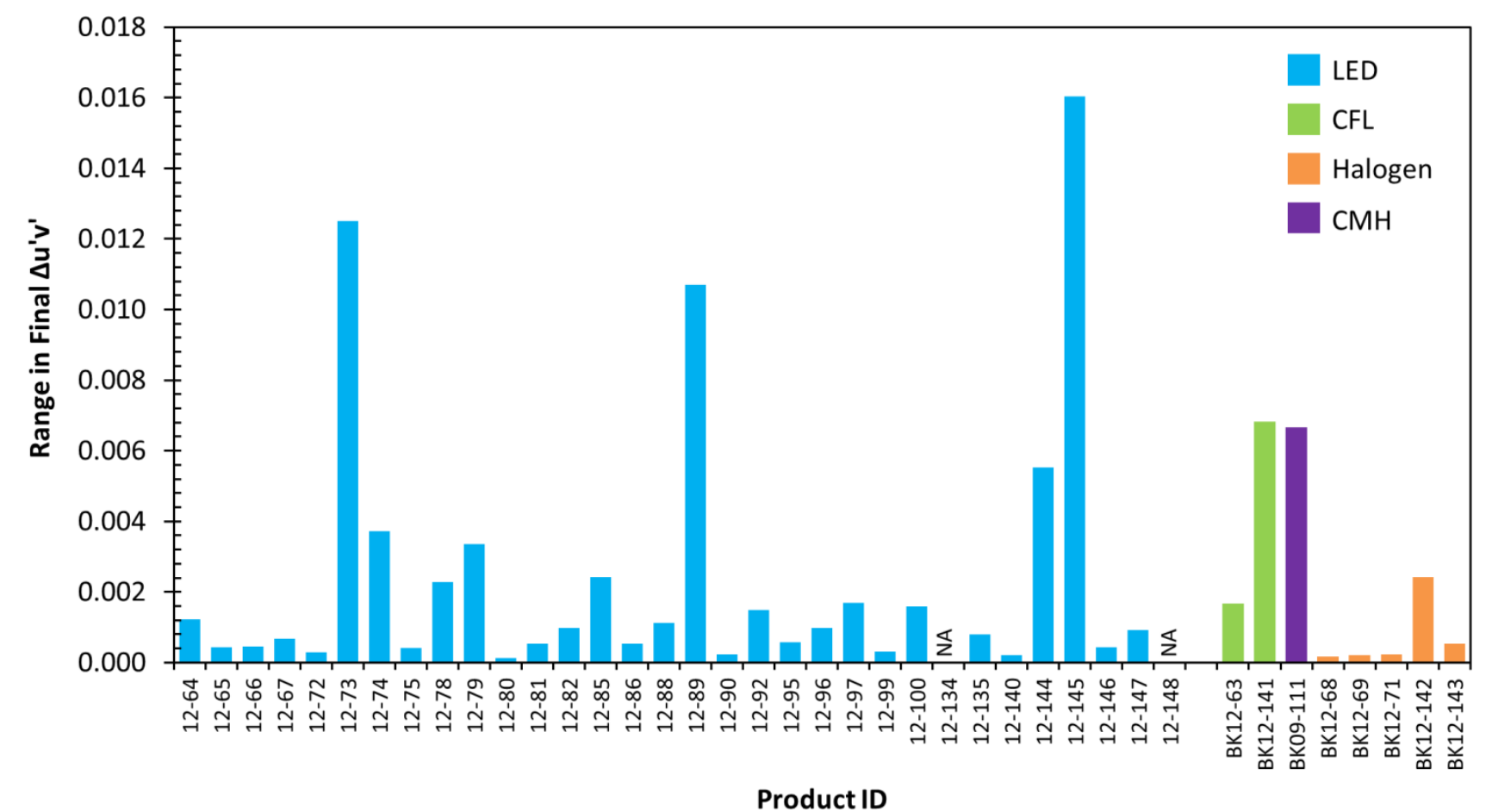

Figure 11. Range in the final measured $\Delta u^{\prime} v^{\prime}$ for the functional samples of each lamp model. The products with the largest variation tended to also have large variation in lumen maintenance, but not always.

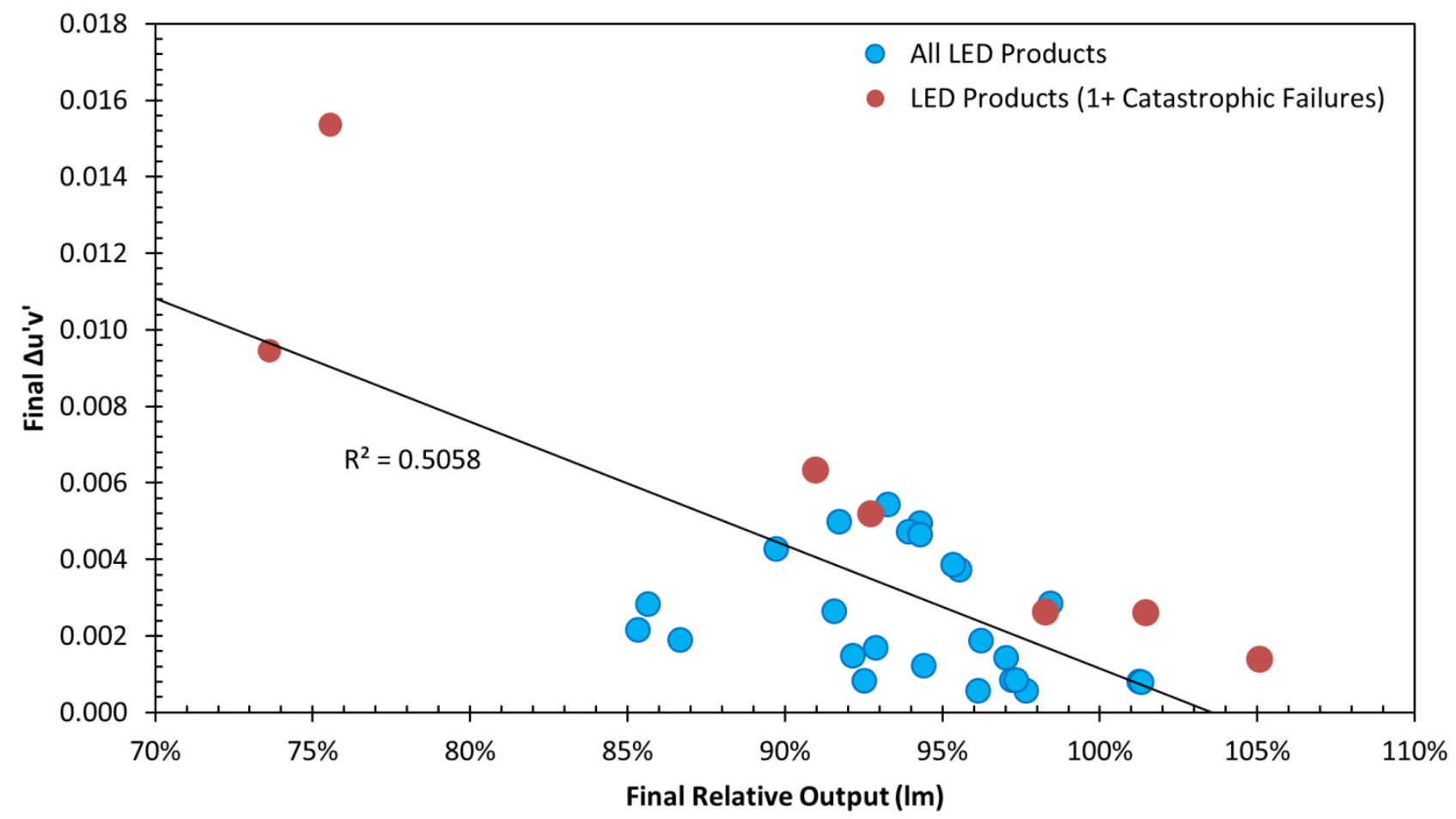

Figure 12. Final average color shift versus final average lumen maintenance. The moderate correlation indicates that the two types of degradation tend to occur simultaneously (but not always). 


\section{Conclusions}

An investigation was conducted to examine lumen depreciation and color shift of LED PAR38 lamps compared to benchmark conventional PAR38 lamps (CFL, CMH, and halogen). The 38 total products ( $32 \mathrm{LED}, 2 \mathrm{CFL}, 1 \mathrm{CMH}, 3$ halogen) were monitored in the ALTA2 for nearly 14,000 hours. Five samples of each lamp model were tested, with measurements recorded on a weekly basis. The lamps were operated continuously at an ambient temperature of $45^{\circ} \mathrm{C}$.

During the test period, 13 LED lamp samples failed catastrophically-although these failures came from only five of the 32 models of LED lamps. Five of the LED lamp catastrophic failures occurred in conjunction with a system power failure and/or the subsequent restart of the apparatus, which suggests that cycling would have led to different results (as has been shown in studies by others). All of the halogen lamps failed (but none of the CFL or $\mathrm{CMH}$ lamps failed). Importantly, the test conditions were not appropriate for inducing catastrophic failure for any of the source types and are not typical of normal use patterns. Further, the test conditions differ from those used in standardized long-term test methods (i.e., IES LM-80, IES LM-84), so the results cannot be directly compared.

On average, the lumen maintenance of the LED lamps monitored in the ALTA2 was substantially better than the average for the other lamp technologies. After nearly 14,000 hours, the average lumen output for the noncatastrophically failed LED lamps was $94 \%$. In contrast, the CFLs were at $68 \%$ and the CMH lamps were at $62 \%$. The halogen lamps typically reached about $80 \%$ of the initial output before burning out.

While the average lumen maintenance for the LED lamps was very good, there was considerable variation from lamp model to lamp model. At the end of the test period, some lamp models had an average lumen output greater than the initial average, whereas two lamp models had an average output less than $80 \%$ of the initial. All but three of the LED lamp models had average relative outputs between $87 \%$ and $101 \%$ (excluding lamps that failed catastrophically).

As with lumen maintenance, on average the LED lamps exhibited improved chromaticity maintenance compared to the conventional benchmark lamps-including the halogen lamps. However, the average $\Delta u^{\prime} v$ ' of two lamp models exceeded the ENERGY STAR limit of 0.007 and would likely be problematic in an application where color stability is important. These two lamp models also had the worst lumen maintenance, although expanded analysis demonstrates that lumen depreciation and color shift are not always coincident.

Given the methods used for this investigation-most notably, continuous operation-the results should not be interpreted as indicative of a lamp's performance in a typical environment. Likewise, these results are not directly relatable to manufacturer lifetime claims. A key takeaway is that the long-term performance of LED PAR38 lamps can vary substantially; it often exceeds that of conventional benchmark products - at least during the first 14,000 hours of operation-but some products exhibit early deterioration. Another important finding is that performance was generally not correlated to the manufacturer's rated lifetime for the product. Because lifetime is heavily affected by operating conditions, this could simply be due to that fact that the conditions in the ALTA2 did not reflect the way in which the lamps were rated. Nonetheless, this represents an important concern regarding effective communication of long-term performance. 
Table A1. Identifying information for the lamps included in the CALiPER PAR38 long-term performance investigation. For additional product performance information, see CALiPER Application Summary Report 20.

\begin{tabular}{|c|c|c|c|c|}
\hline ID & Brand & Model & $\begin{array}{c}\text { Rated } \\
\text { Lifetime } \\
\text { (hours) }\end{array}$ & $\begin{array}{c}\text { ENERGY } \\
\text { STAR }\end{array}$ \\
\hline $12-64$ & TCP & LED17E26P3830KNFL & 50,000 & Yes \\
\hline $12-65$ & Lighting Science Group & DFN 38 W27 V2 NFL 120 & 50,000 & Yes \\
\hline $12-66$ & Eiko & LEDP-11WPAR38/SP/830-DIM & 40,000 & Yes \\
\hline $12-67$ & Cree LED Lighting & LRP38-10L-30K-12D & 50,000 & Yes \\
\hline $12-72$ & Sylvania & LED21PAR38/DIM/P/930/FL30 (78745) & 25,000 & Yes \\
\hline $12-73$ & Feit Electric & PAR38/HP/LED & 30,000 & No \\
\hline $12-74$ & Satco Products, KolourOne & S8853 & 30,000 & No \\
\hline $12-75$ & GE Lighting & LED17P38S830/17 (64035) & 50,000 & Yes \\
\hline $12-78$ & Toshiba E-CORE & 19P38/835SP8 (LDRB2035NE6USD) & 40,000 & Yes \\
\hline $12-79$ & Westinghouse & 18PAR38/LED/DIM/30 (03434) & 30,000 & No \\
\hline $12-80$ & MaxLite MaxLED & SKR3817SPDLED30 & 25,000 & Yes \\
\hline $12-81$ & Halco Lighting ProLED & PAR38/16WW/NFL/LED (80034) & 35,000 & No \\
\hline $12-82$ & Litetronics & LP15566FL4D (64350) & 50,000 & Yes \\
\hline $12-85$ & LEDnovation & LED-PAR38-90-1WD-1WF & 50,000 & No \\
\hline $12-86$ & Solais Lighting & LR38/10/30K/18W/1025/GY & 50,000 & No \\
\hline $12-88$ & Lumena & MS-PAR38-120V60-27 & 50,000 & No \\
\hline $12-89$ & NuVue & NV-PAR38I20W26C (NV/PAR38/9.2 WW NFL 26 CR) & 40,000 & No \\
\hline $12-90$ & Acculamp & ALSP38 900L R9 & 50,000 & Yes \\
\hline $12-92$ & Samsung & SI-P8V181DB0US (SLA0-PAR38-75-AYD-830-25R) & 40,000 & No \\
\hline $12-95$ & MSI Solid State Lighting & IPAR3830101D & 50,000 & Yes \\
\hline $12-96$ & Array Lighting & AE26PAR38183010 & 25,000 & No \\
\hline $12-97$ & Havells & 16W/LED/PAR38/FL (48541) & 15,000 & No \\
\hline $12-99$ & LEDirect NaturaLED & LED17PAR38/DIM/NFL/30K & 40,000 & Yes \\
\hline $12-100$ & aleddra & PAR38-S-D-45-30 & 25,000 & No \\
\hline $12-134$ & Duracell & DL-P38F-60-30K-WH & 50,000 & Yes \\
\hline $12-135$ & Axiom & AP10W27V120 & 50,000 & No \\
\hline $12-140$ & Philips & BC19.5PAR38/AMB/3000K/ FL25 DIM 120V & 25,000 & Yes \\
\hline $12-144$ & Solais Lighting & LRP38/25/30 & 50,000 & Yes \\
\hline $12-145$ & Seesmart & 15W Warm White $45^{\circ}$ LED PAR 38 (180025) & 30,000 & No \\
\hline $12-146$ & Zenaro & SL-PAR38C/H/P16/50/E30/TD/26/LAC & 25,000 & Yes \\
\hline $12-147$ & Lights of America & 2213DLEDNP38 - LF3-8 & 25,000 & No \\
\hline $12-148$ & LEDWaves & LW10-NYC-008-WW-DM & 30,000 & No \\
\hline BK09-111 & Philips & CDM-i 25W/PAR38/FL/3K & 15,000 & \\
\hline BK12-63 & Philips & EL/A PAR38 23W 2PC (9292689721102) & 10,000 & \\
\hline BK12-68 & GE & 60PAR/HIR/FL30 (18626) & 3,000 & \\
\hline BK12-69 & Sylvania & 75PAR/CAP/SPL/WSP12 120V & 2,500 & \\
\hline BK12-71 & Philips & 75PAR38/HAL/SP10 & 3,000 & \\
\hline BK12-141 & Feit Electric & ESL23PAR/ECO & 10,000 & \\
\hline
\end{tabular}




\section{Appendix B: Matrix of Lamps Installed in ALTA2}

\section{Table B1. Matrix of lamp positions within the ALTA2.}

\begin{tabular}{|c|c|c|c|c|c|c|c|c|c|c|c|c|c|c|c|c|}
\hline Rest & BK12-69 & BK12-69 & BK12-69 & BK12-69 & BK12-69 & BK12-71 & BK12-71 & BK12-71 & BK12-71 & BK12-71 & BK12-68 & BK12-68 & BK12-68 & BK12-68 & BK12-68 & Empty** \\
\hline Cal & $12-64$ & $12-65$ & $12-66$ & $12-67$ & $12-72$ & $12-73$ & $12-74$ & $12-75$ & $12-92$ & $12-78$ & $12-79$ & $12-80$ & $12-81$ & $12-82$ & $12-85$ & Empty** \\
\hline Empty ${ }^{*}$ & $12-64$ & $12-65$ & $12-66$ & $12-67$ & $12-72$ & $12-73$ & $12-74$ & $12-75$ & $12-92$ & $12-78$ & $12-79$ & $12-80$ & $12-81$ & $12-82$ & $12-85$ & Empty** \\
\hline BK12-63 & $12-64$ & $12-65$ & $12-66$ & $12-67$ & $12-72$ & $12-73$ & $12-74$ & $12-75$ & $12-92$ & $12-78$ & $12-79$ & $12-80$ & $12-81$ & $12-82$ & $12-85$ & Empty** \\
\hline BK12-63 & $12-64$ & $12-65$ & $12-66$ & $12-67$ & $12-72$ & $12-73$ & $12-74$ & $12-75$ & $12-92$ & $12-78$ & $12-79$ & $12-80$ & $12-81$ & $12-82$ & $12-85$ & Empty** \\
\hline BK12-63 & $12-64$ & $12-65$ & $12-66$ & $12-67$ & $12-72$ & $12-73$ & $12-74$ & $12-75$ & $12-92$ & $12-78$ & $12-79$ & $12-80$ & $12-81$ & $12-82$ & $12-85$ & Empty** \\
\hline BK12-63 & $12-145$ & $12-88$ & $12-90$ & $12-146$ & $12-148$ & $12-95$ & $12-96$ & $12-97$ & $12-99$ & $12-100$ & $12-147$ & $12-89$ & $12-134$ & $12-135$ & $12-140$ & Empty** \\
\hline BK09-111 & $12-145$ & $12-88$ & $12-90$ & $12-146$ & $12-148$ & $12-95$ & $12-96$ & $12-97$ & $12-99$ & $12-100$ & $12-147$ & $12-89$ & $12-134$ & $12-135$ & $12-140$ & Empty** \\
\hline BK09-111 & $12-145$ & $12-88$ & $12-90$ & $12-146$ & $12-148$ & $12-95$ & $12-96$ & $12-97$ & $12-99$ & $12-100$ & $12-147$ & $12-89$ & $12-134$ & $12-135$ & $12-140$ & Empty** \\
\hline BK09-111 & $12-145$ & $12-88$ & $12-90$ & $12-146$ & $12-148$ & $12-95$ & $12-96$ & $12-97$ & $12-99$ & $12-100$ & $12-147$ & $12-89$ & $12-134$ & $12-135$ & $12-140$ & Empty** \\
\hline BK09-111 & $12-145$ & $12-88$ & $12-90$ & $12-146$ & $12-148$ & $12-95$ & $12-96$ & $12-97$ & $12-99$ & $12-100$ & $12-147$ & $12-89$ & $12-134$ & $12-135$ & $12-140$ & Empty** \\
\hline BK09-111 & BK12-141 & BK12-141 & BK12-141 & BK12-141 & BK12-141 & $12-86$ & $12-86$ & $12-86$ & $12-86$ & $12-86$ & $12-144$ & $12-144$ & $12-144$ & $12-144$ & $12-144$ & Empty** \\
\hline
\end{tabular}

* Lamp was removed due to excessive radiated heat onto sphere in rest state.

** Positions were left empty due to power supply capacity limitations. 
Appendix C: Individual Sample Performance

Product ID: 12-64
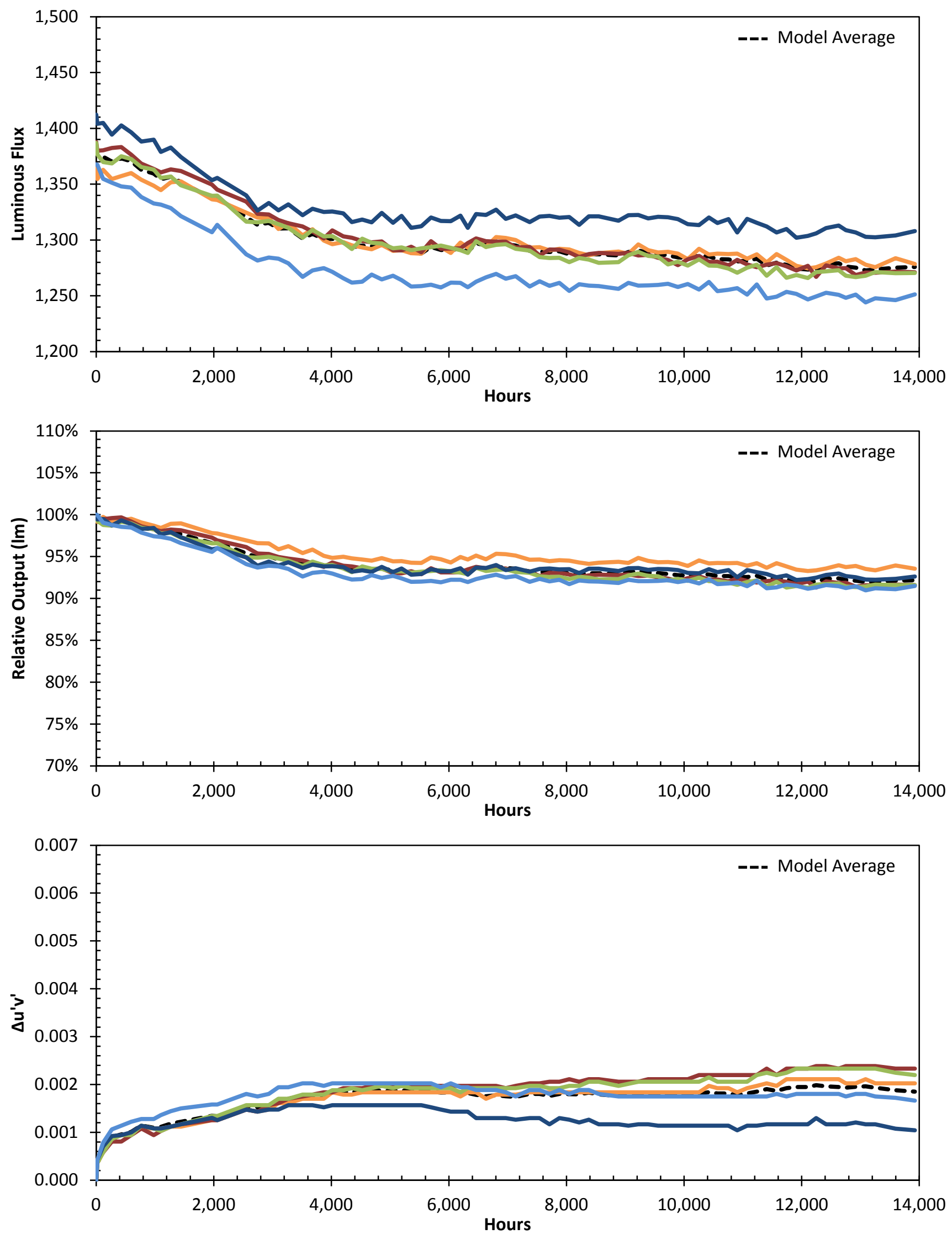
Product ID: 12-65
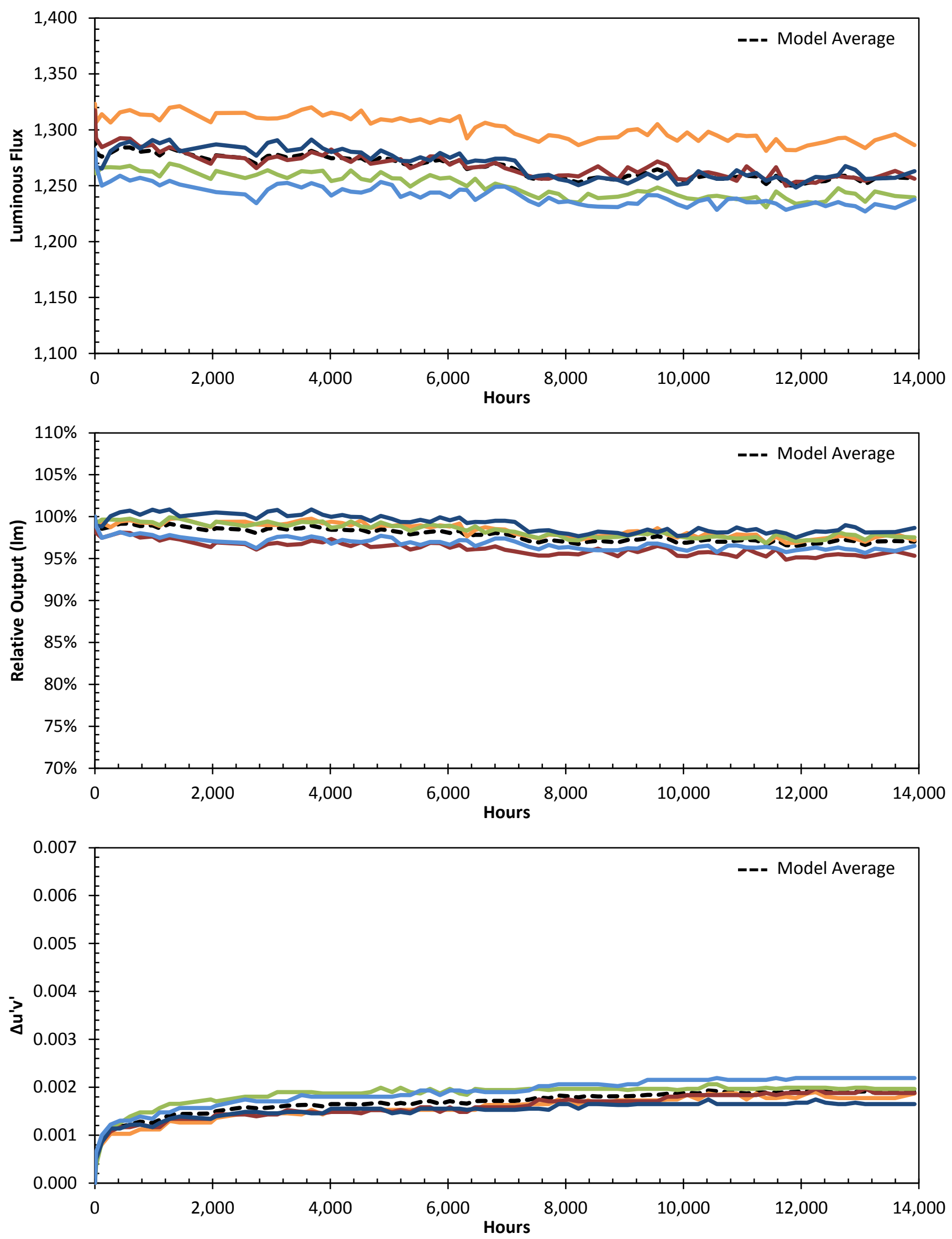
Product ID: 12-66
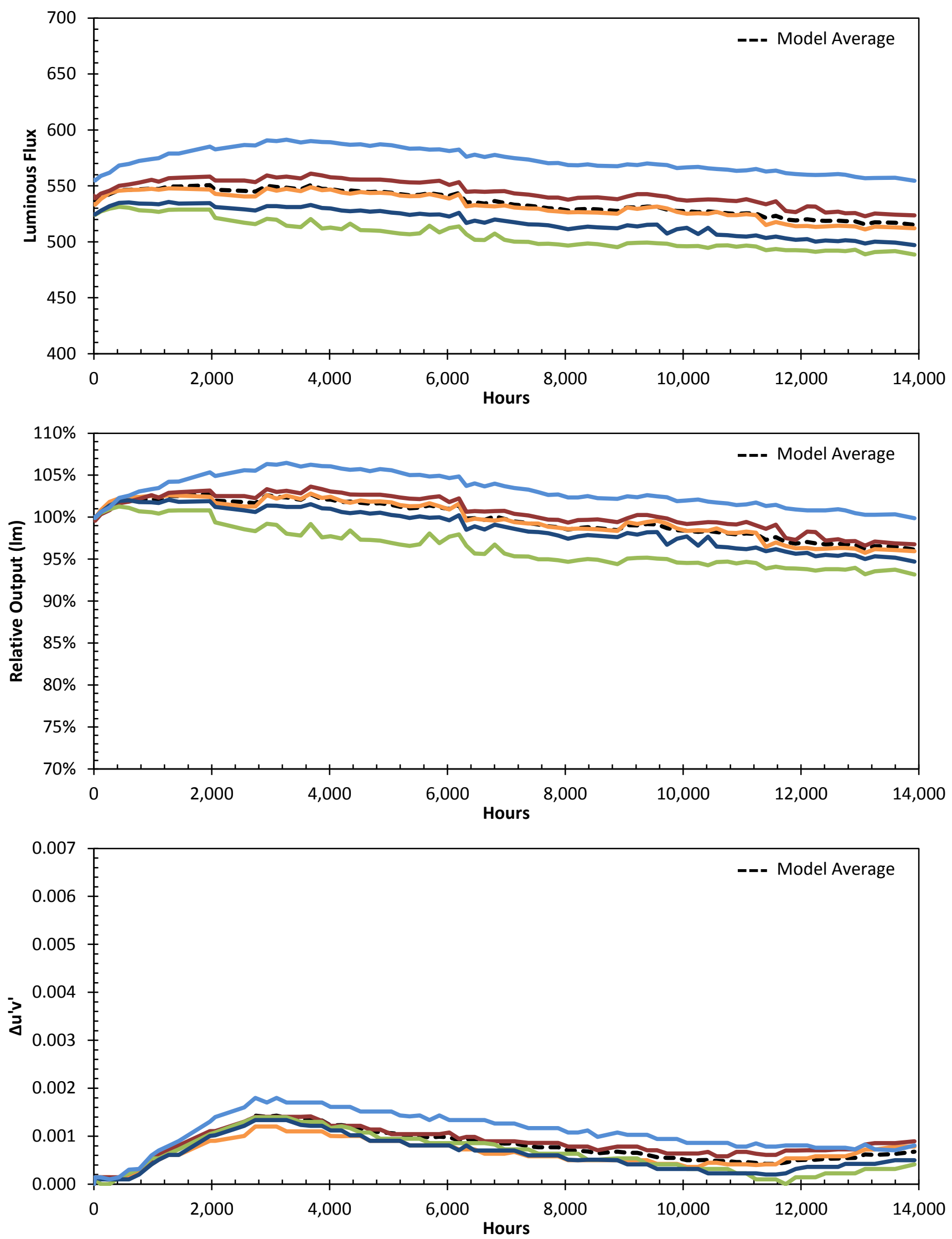
Product ID: 12-67
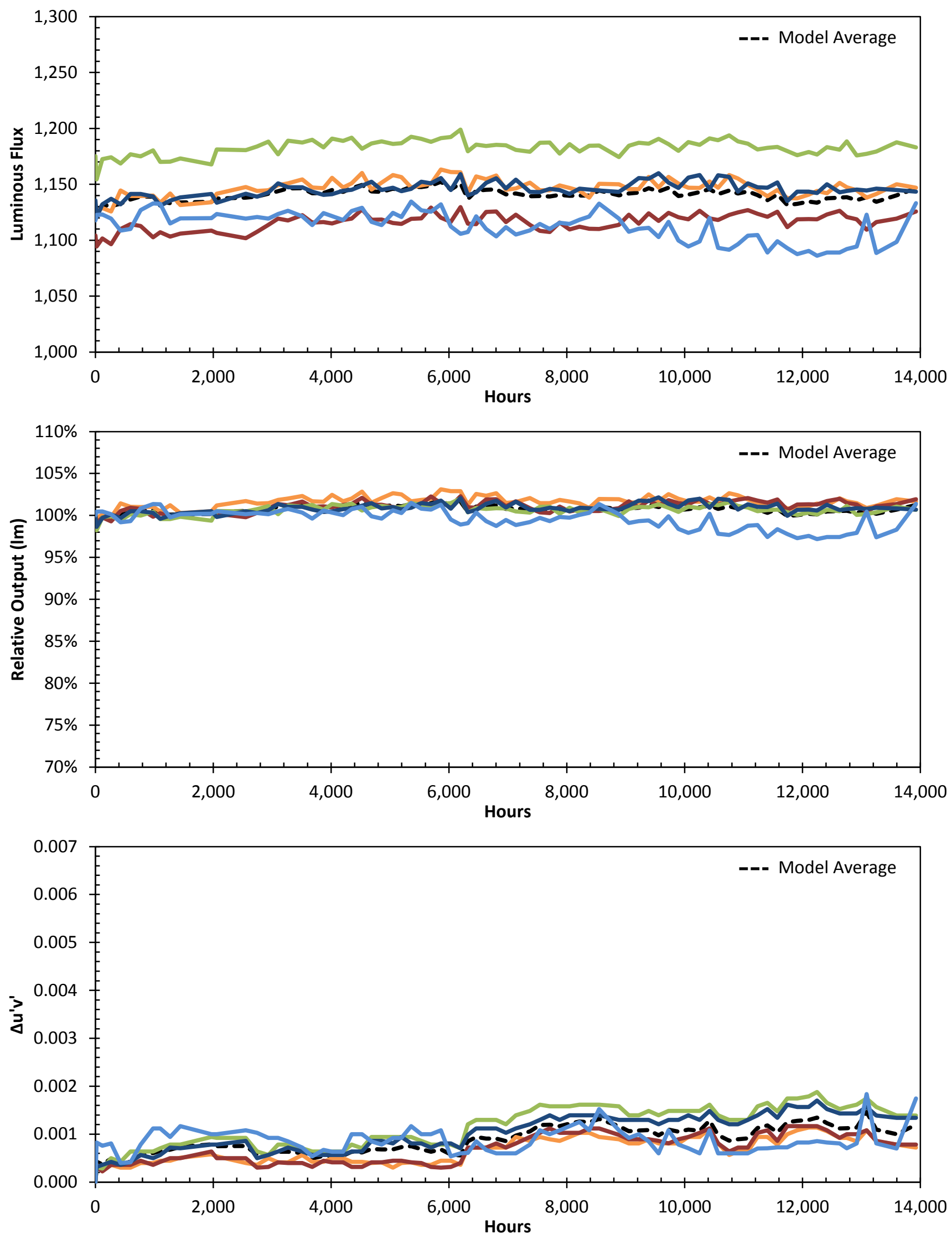
Product ID: 12-72
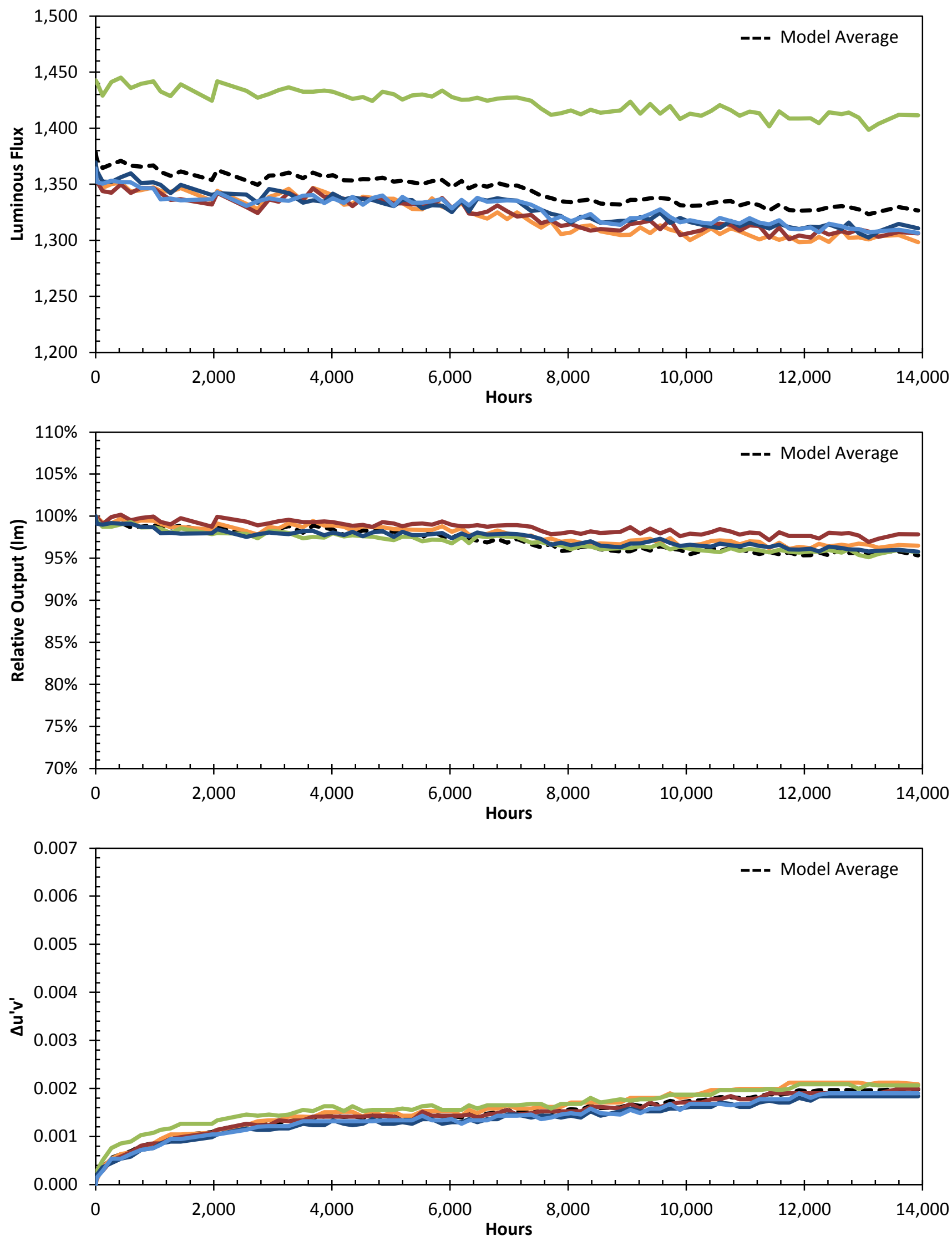
Product ID: 12-73
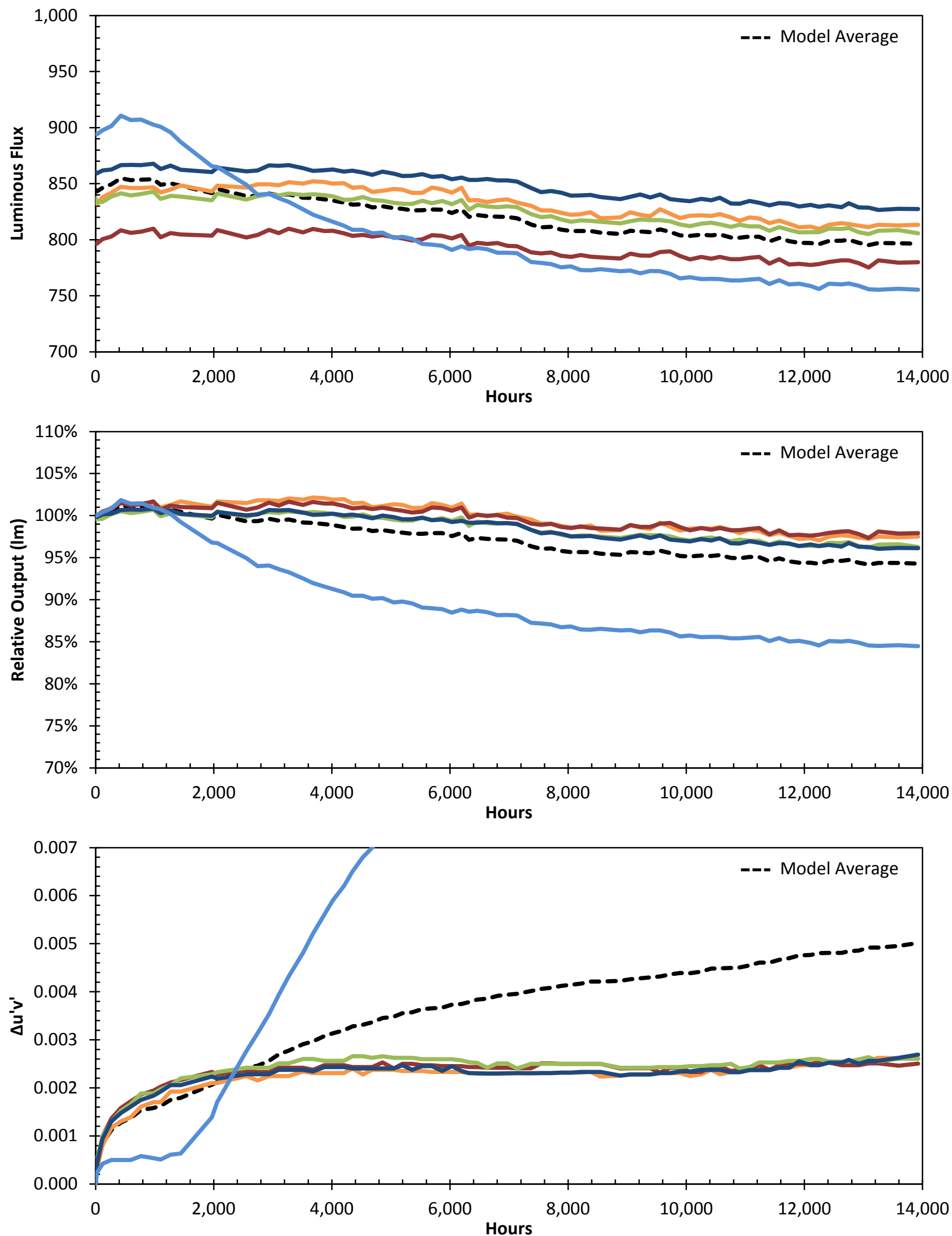
Product ID: 12-74
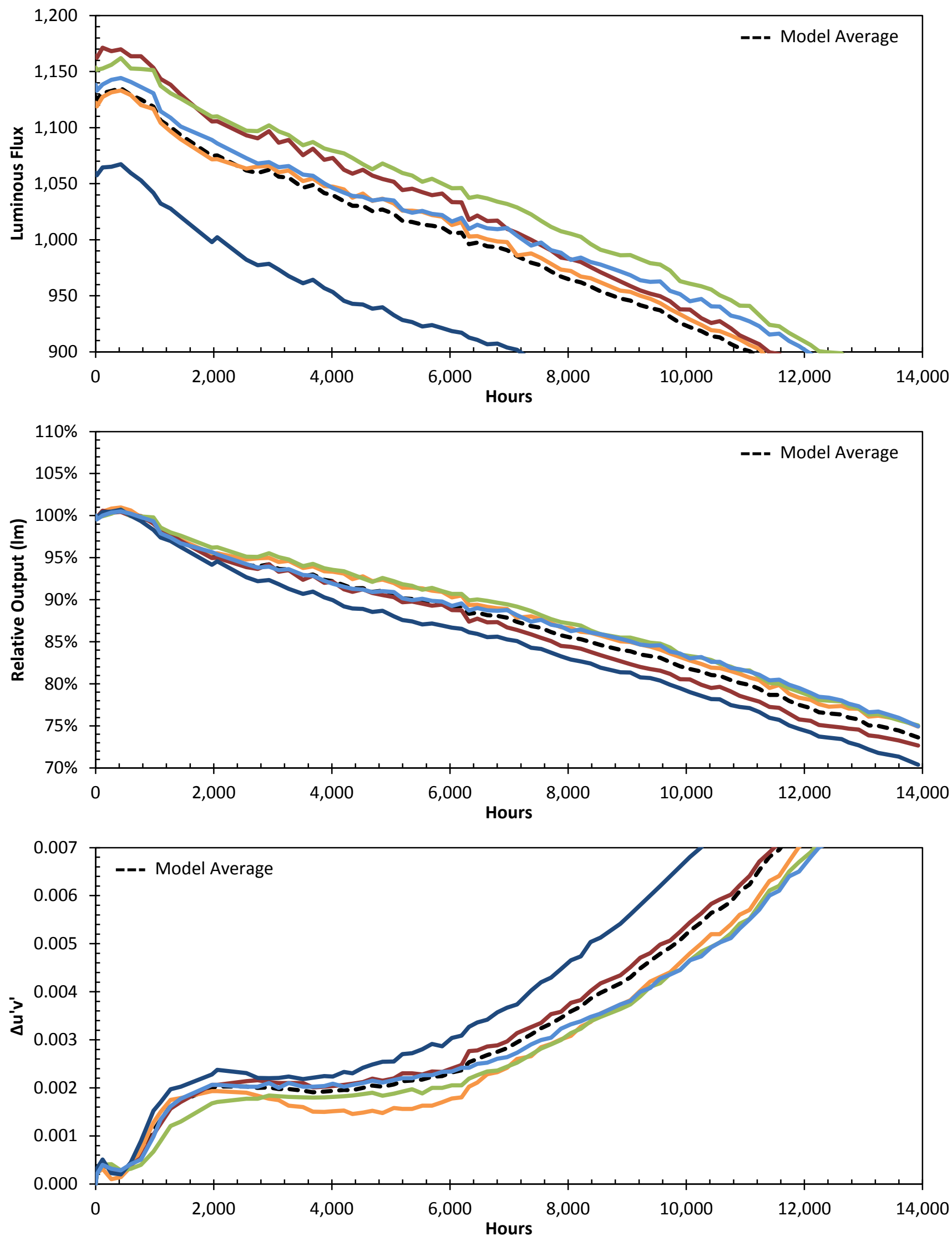
Product ID: 12-75
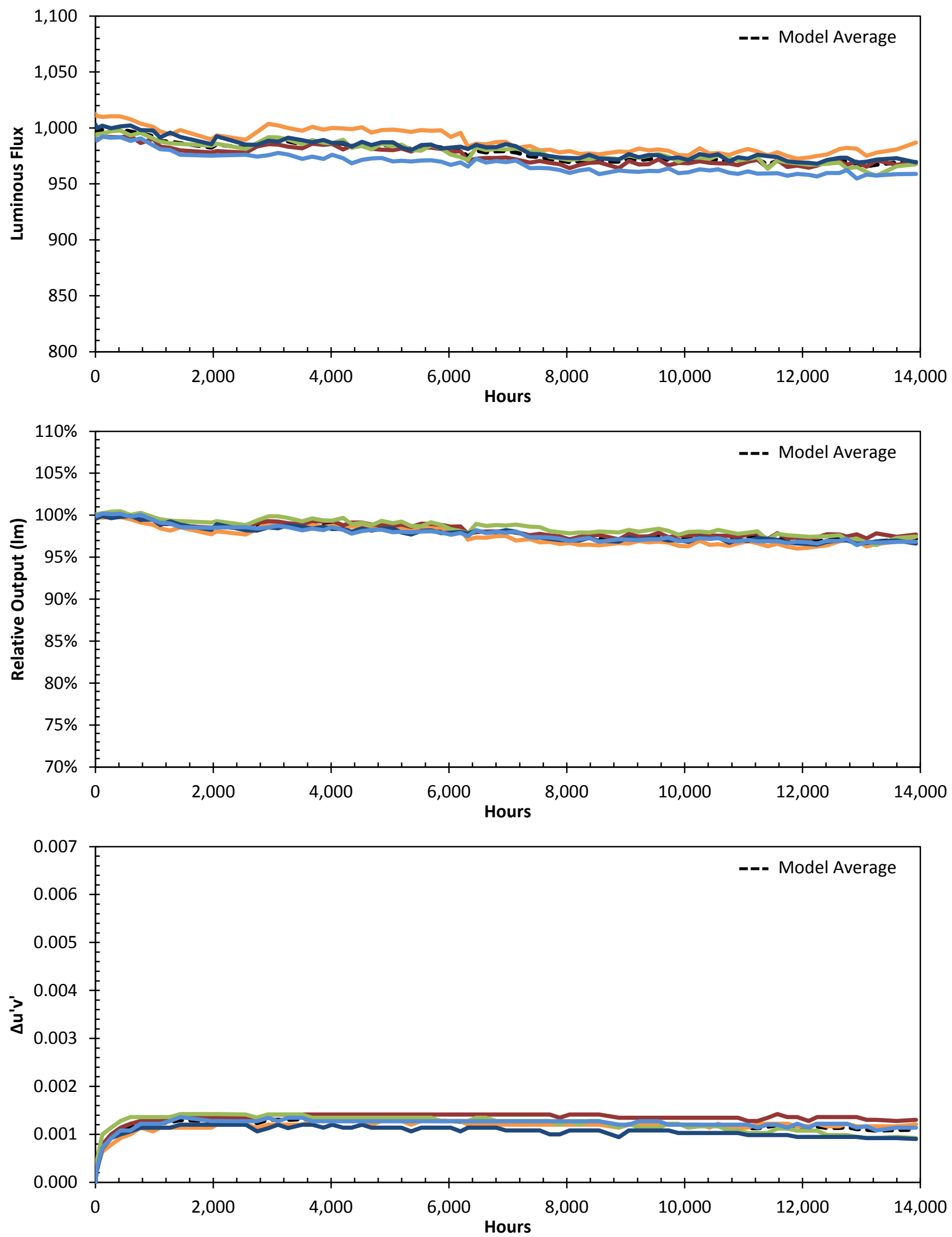
Product ID: 12-78
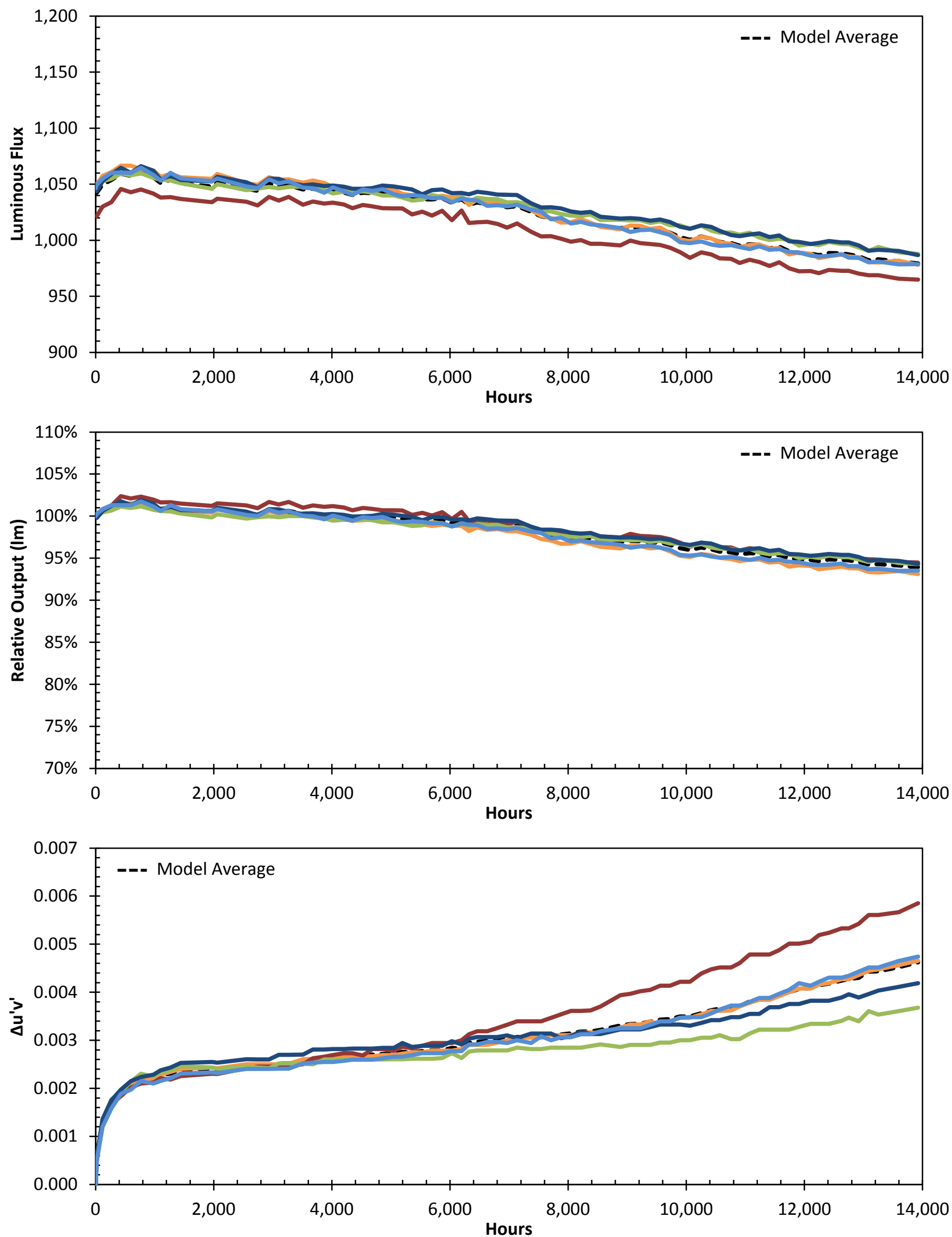
Product ID: 12-79
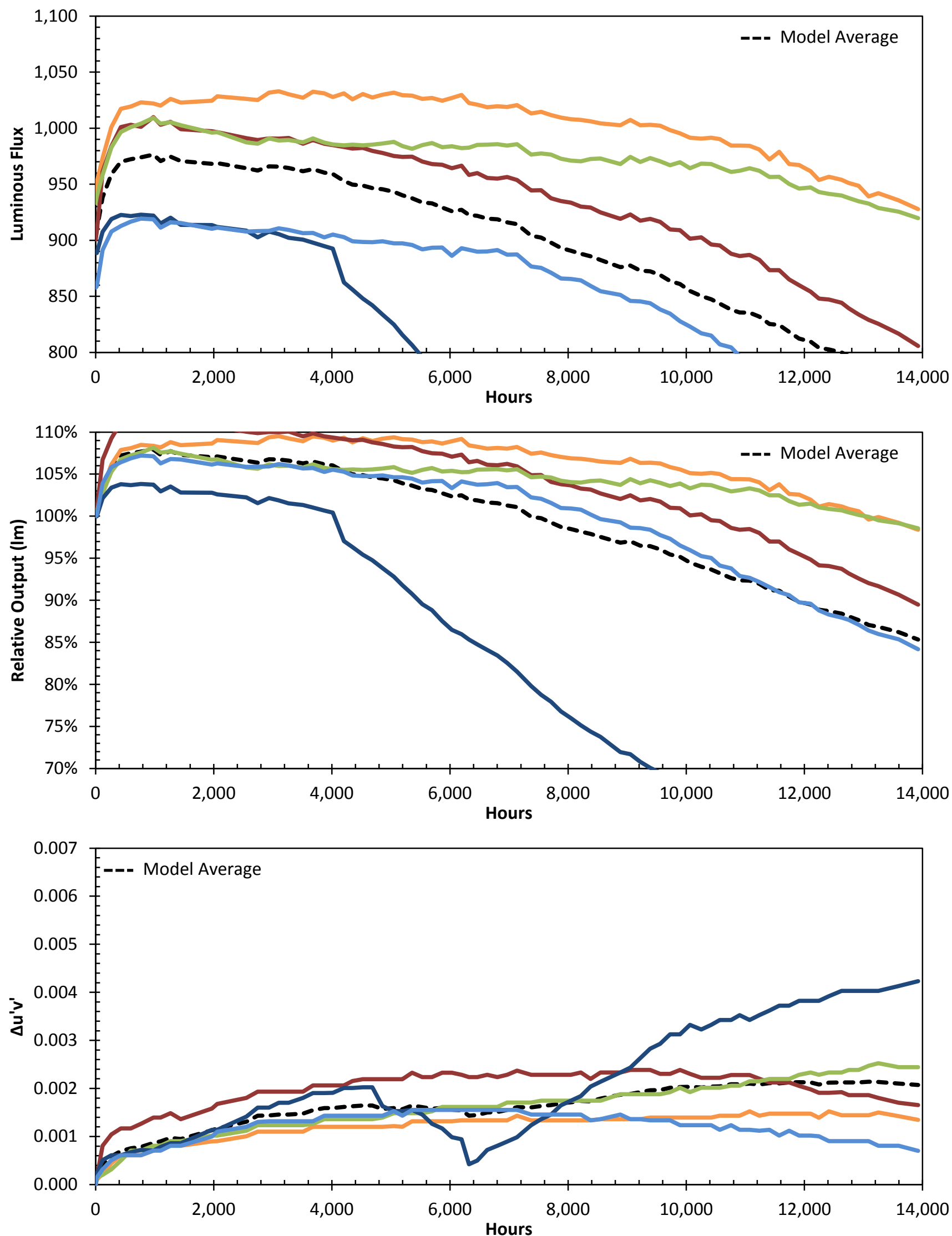
Product ID: $12-80$
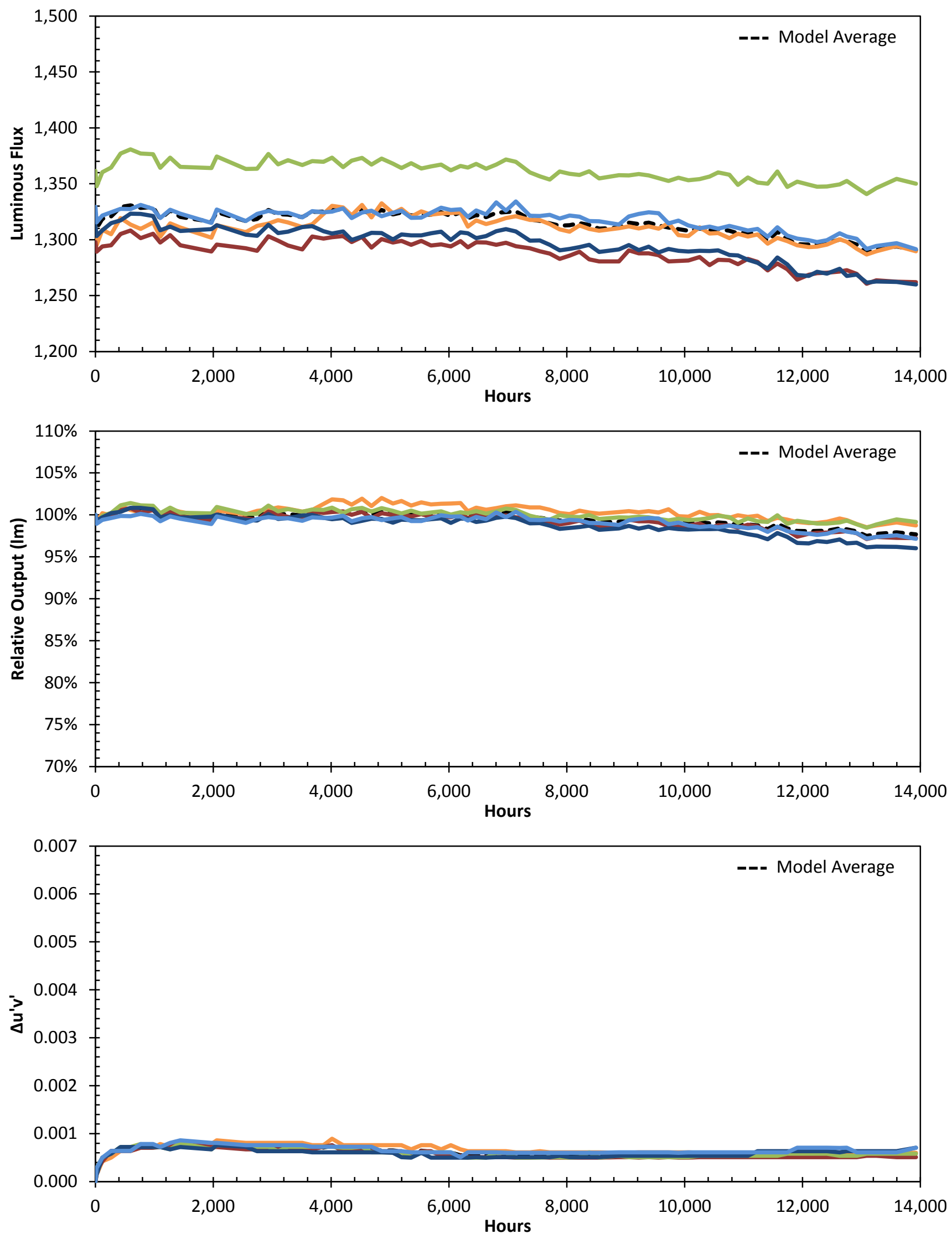
Product ID: 12-81
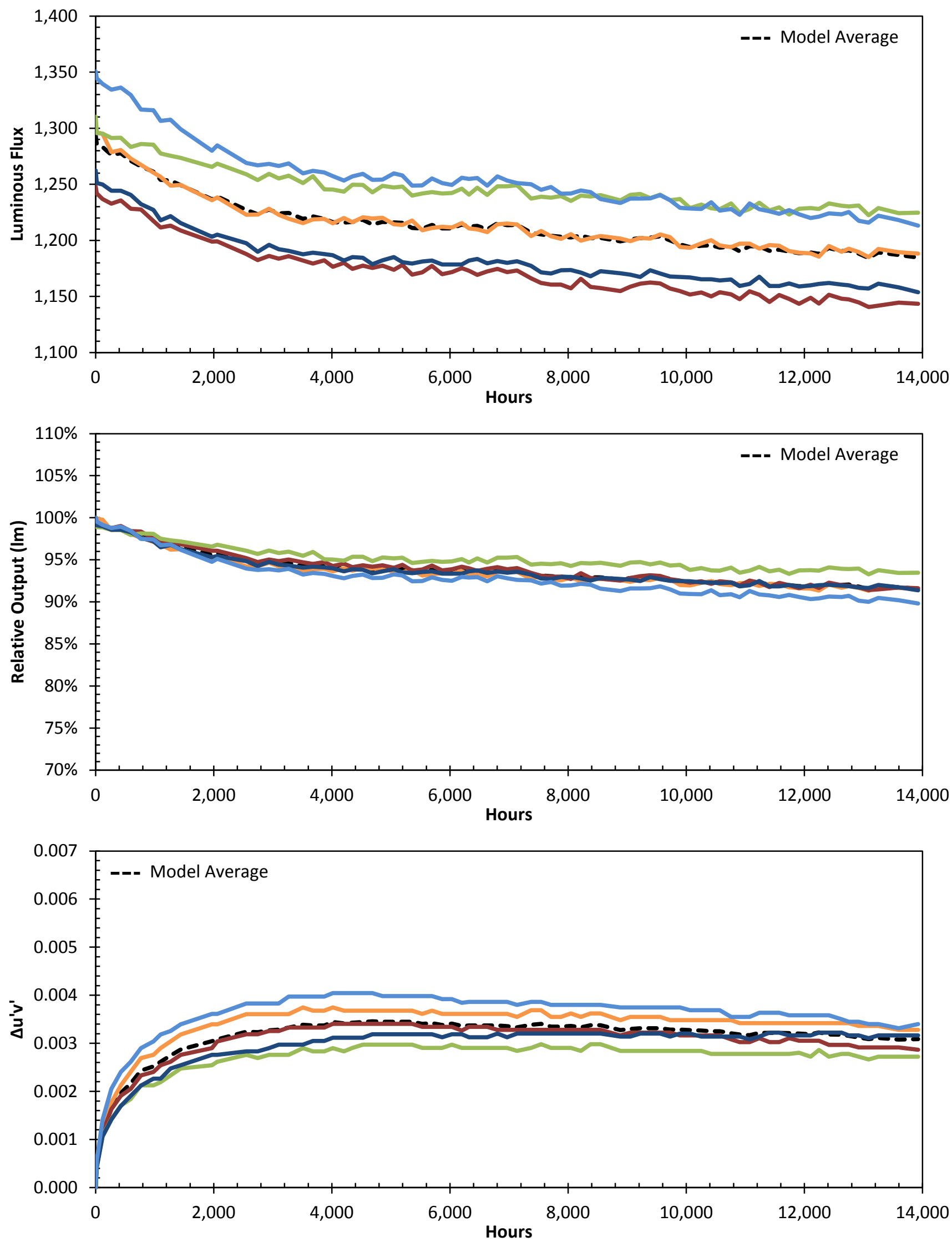
Product ID: 12-82
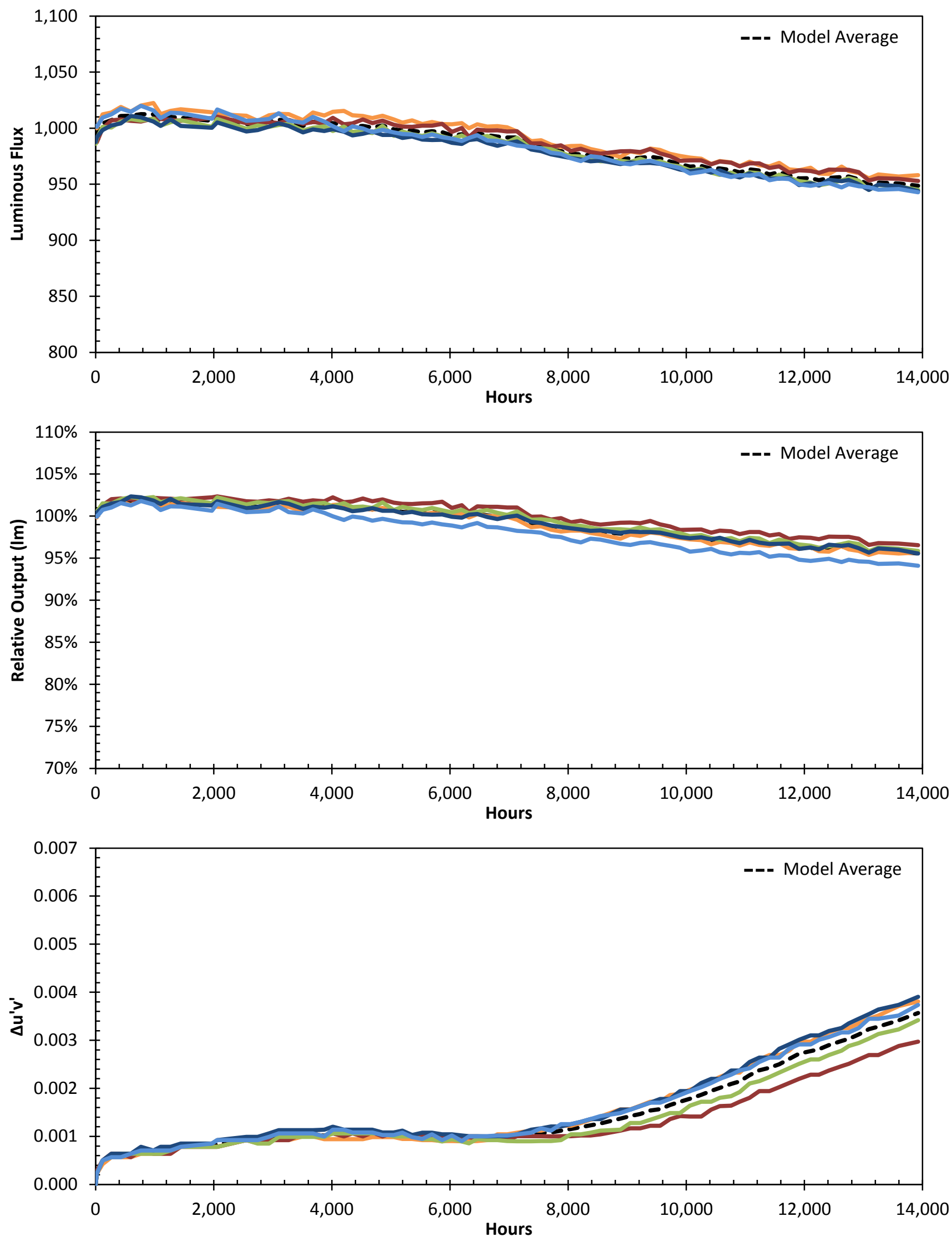
Product ID: 12-85
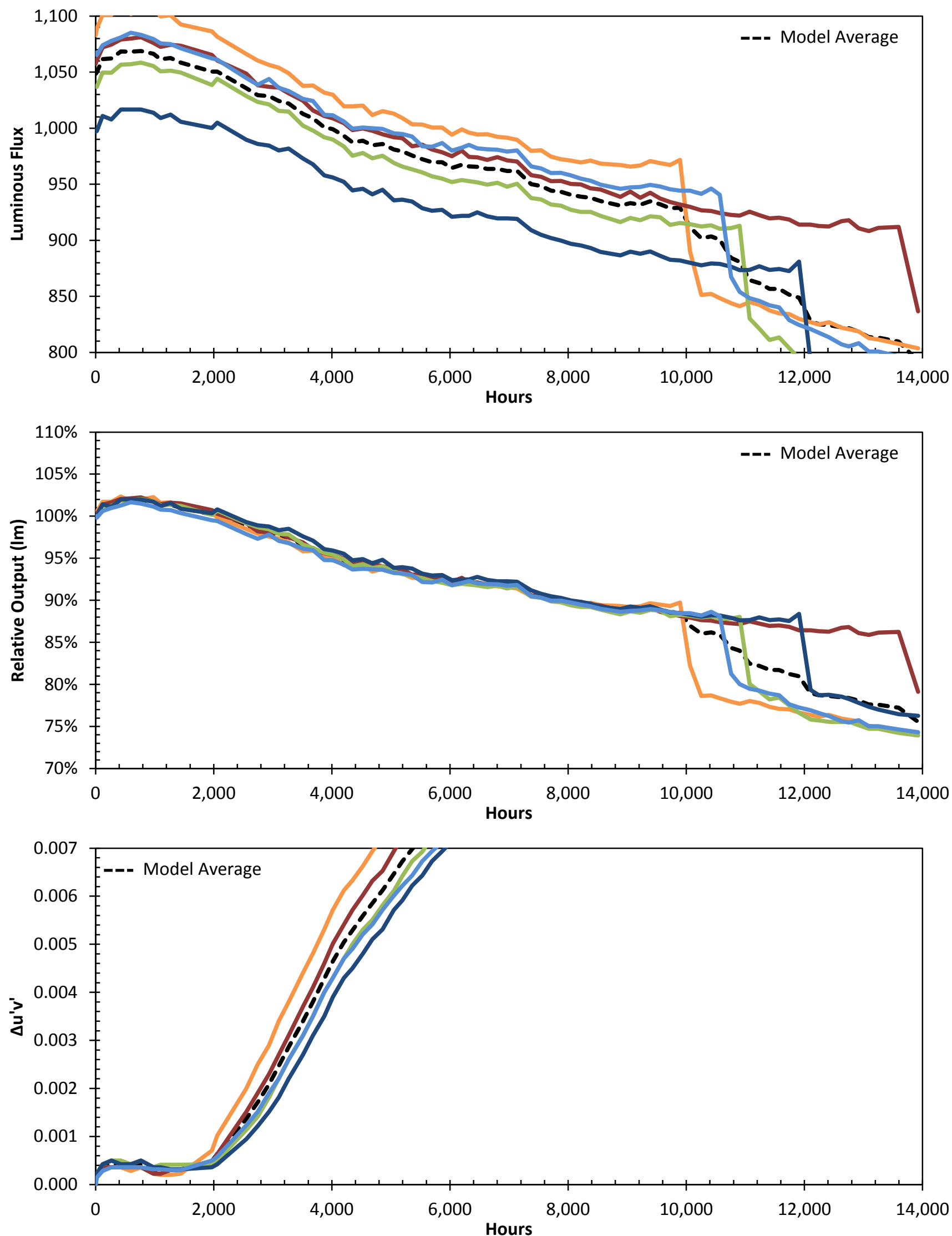
Product ID: $12-86$
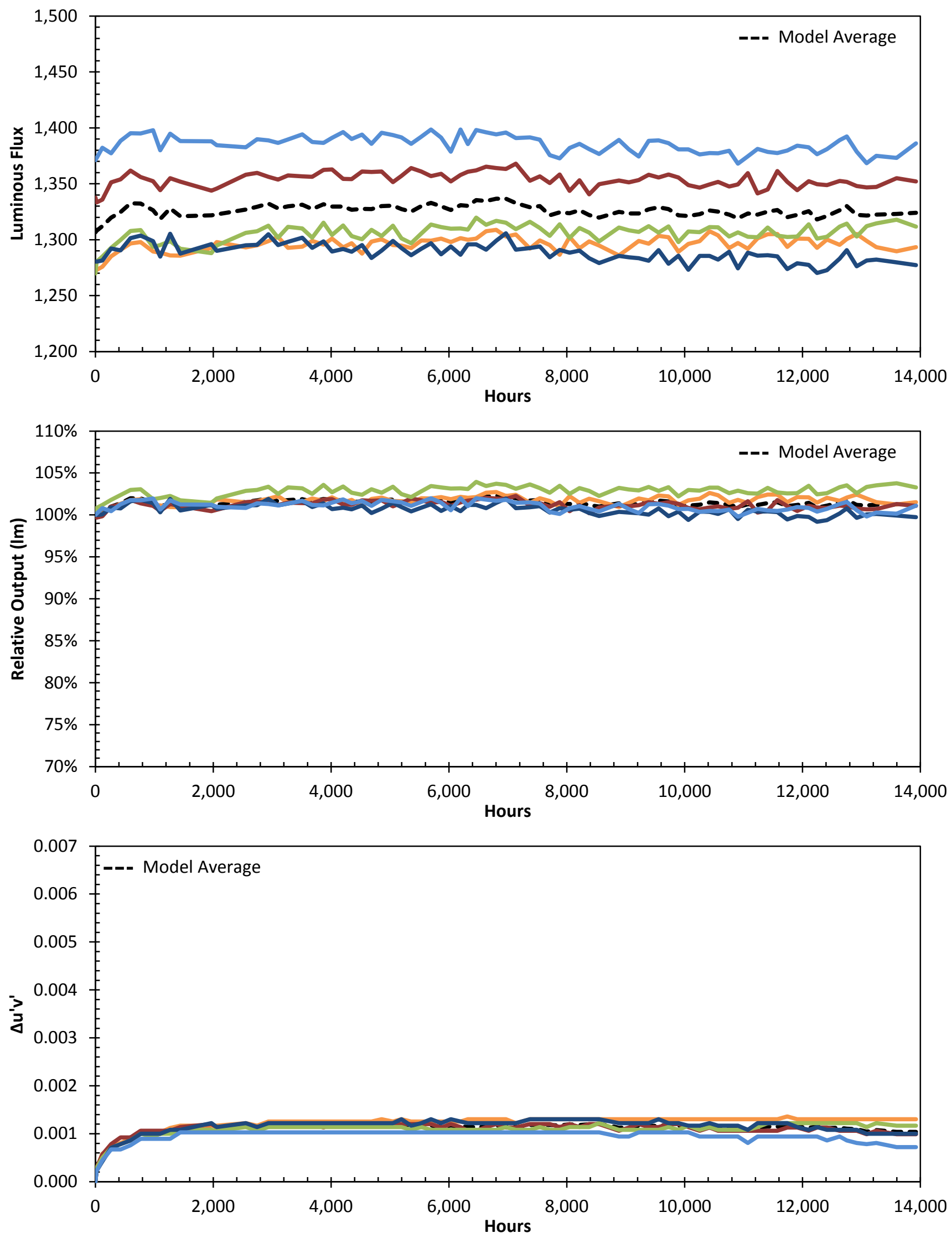
Product ID: 12-88
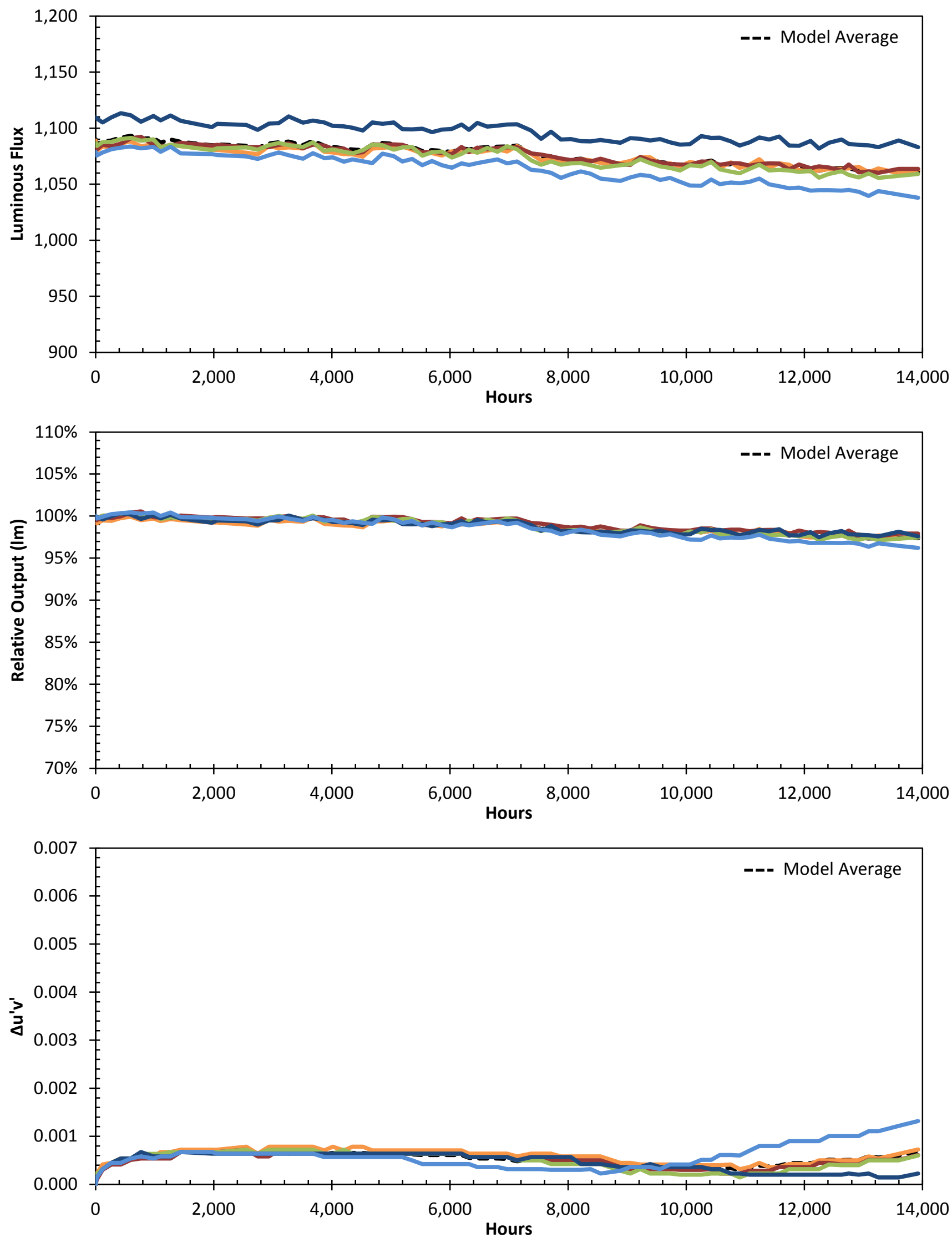
Product ID: 12-89
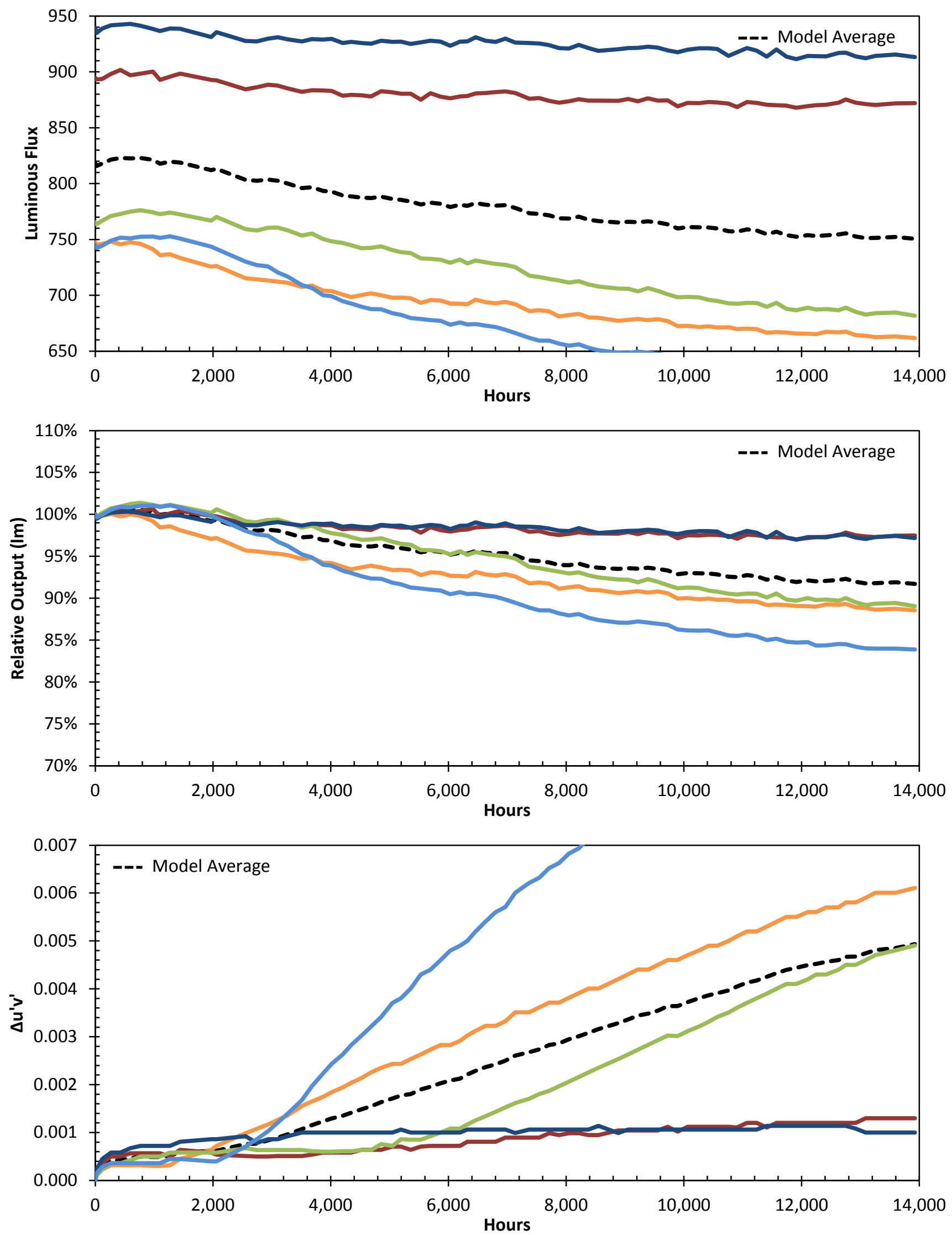
Product ID: 12-90
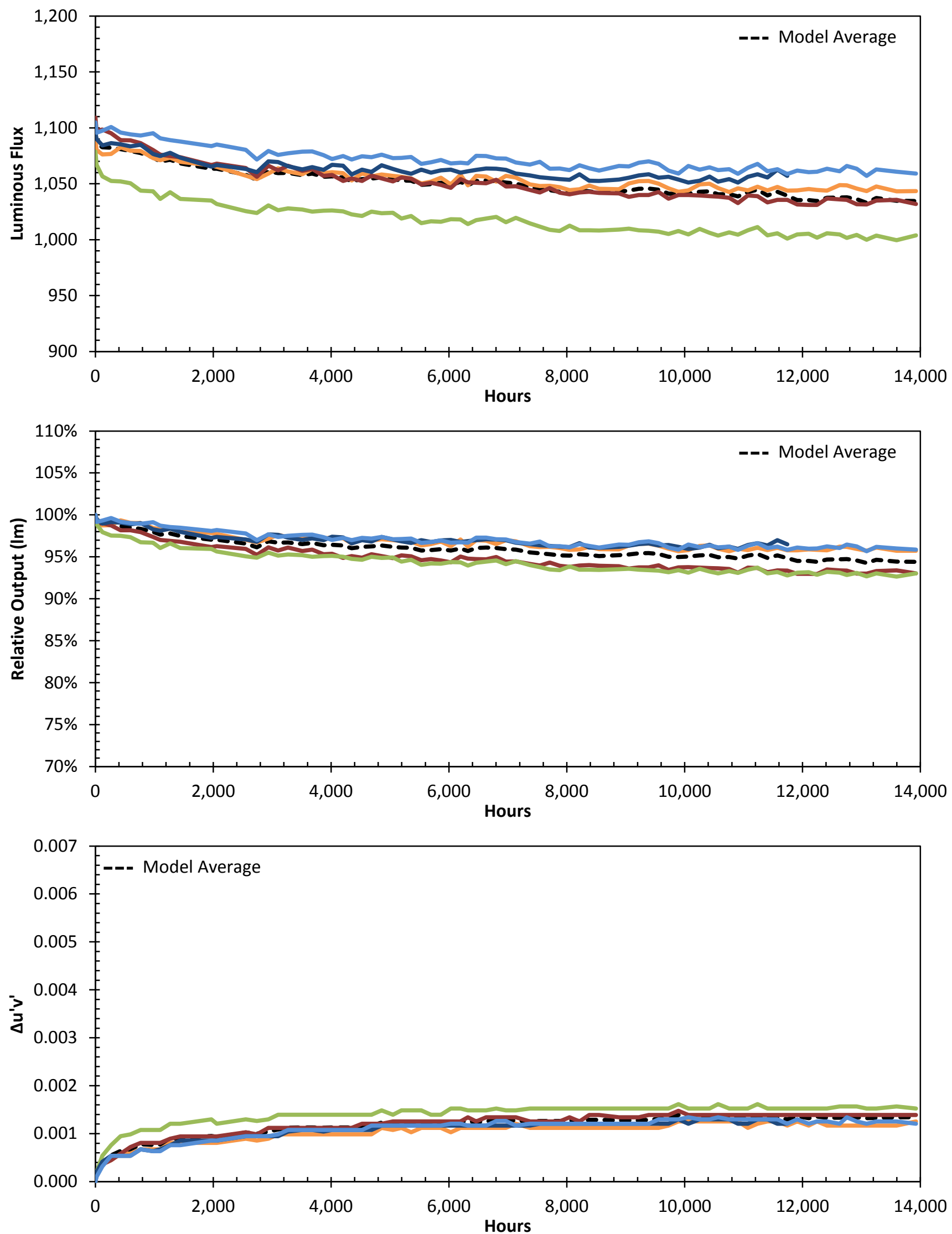
Product ID: 12-92
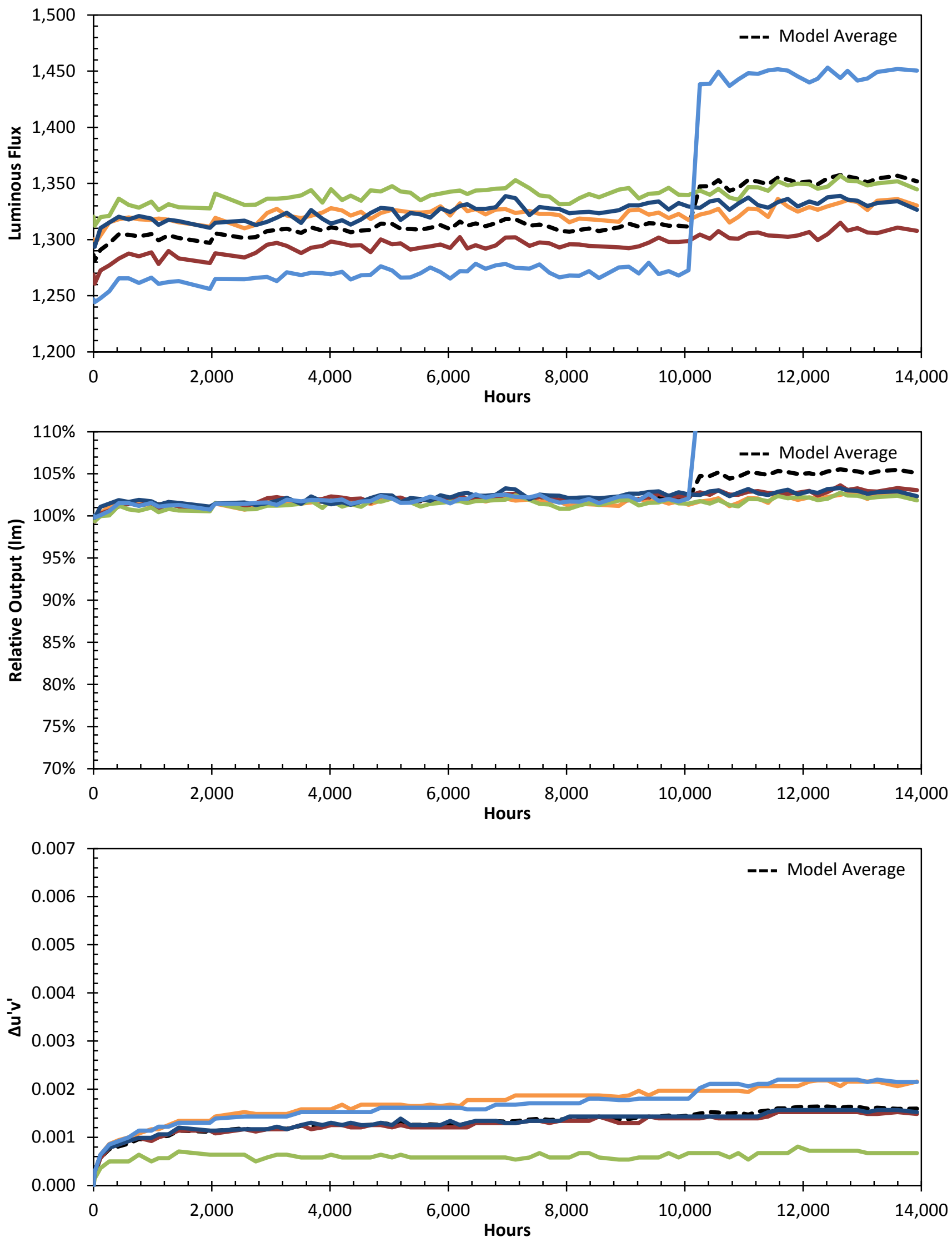
Product ID: 12-95
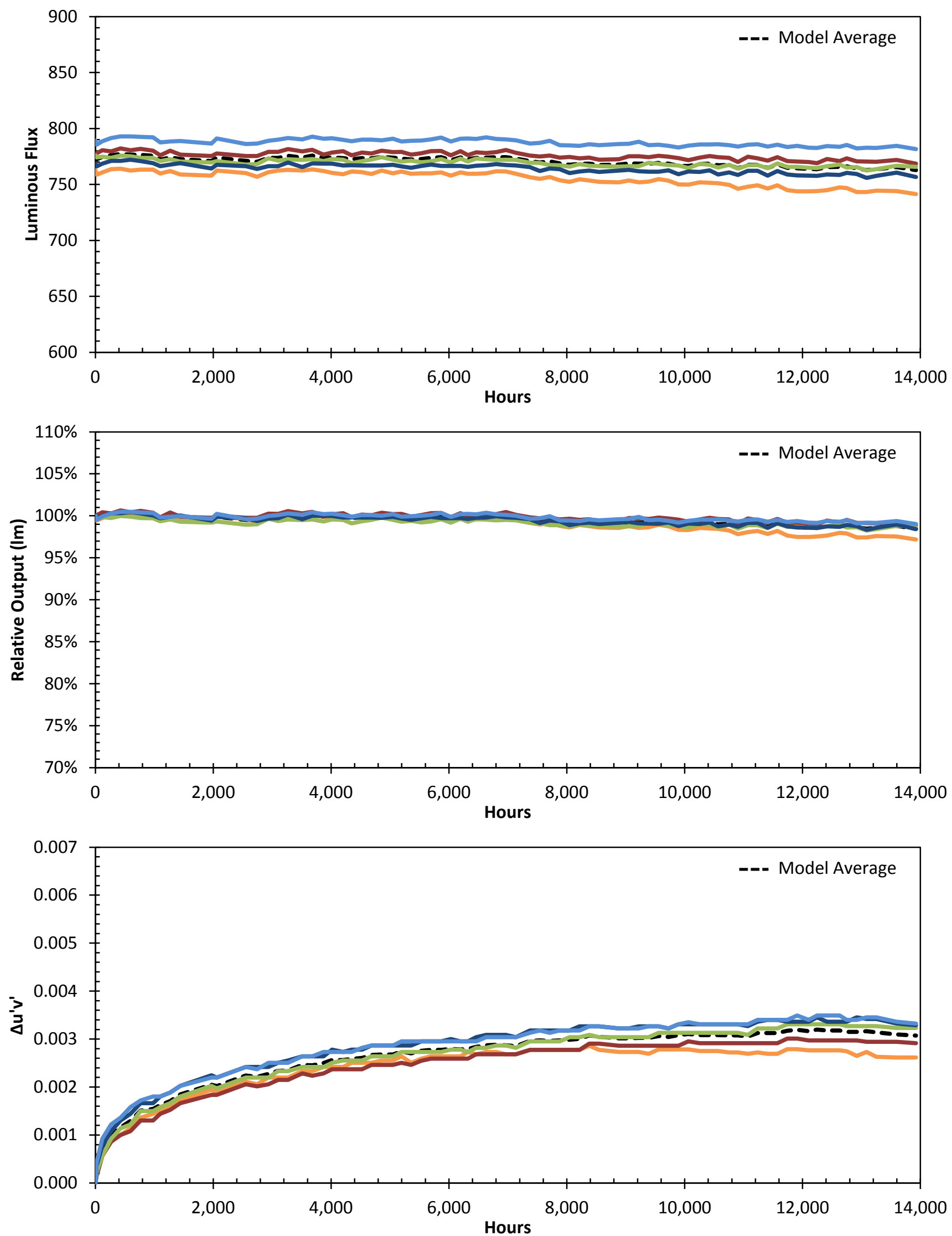
Product ID: 12-96
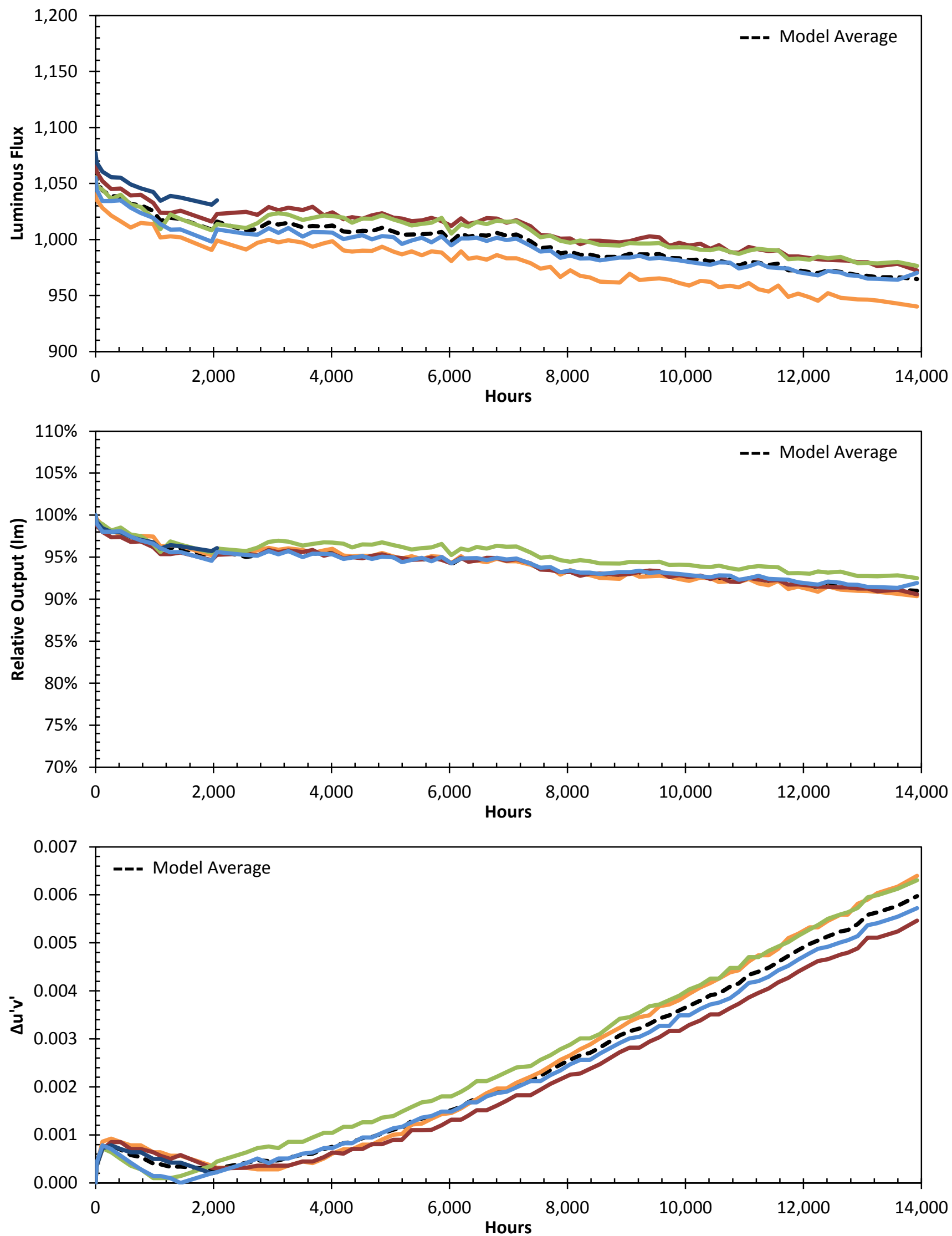
Product ID: 12-97
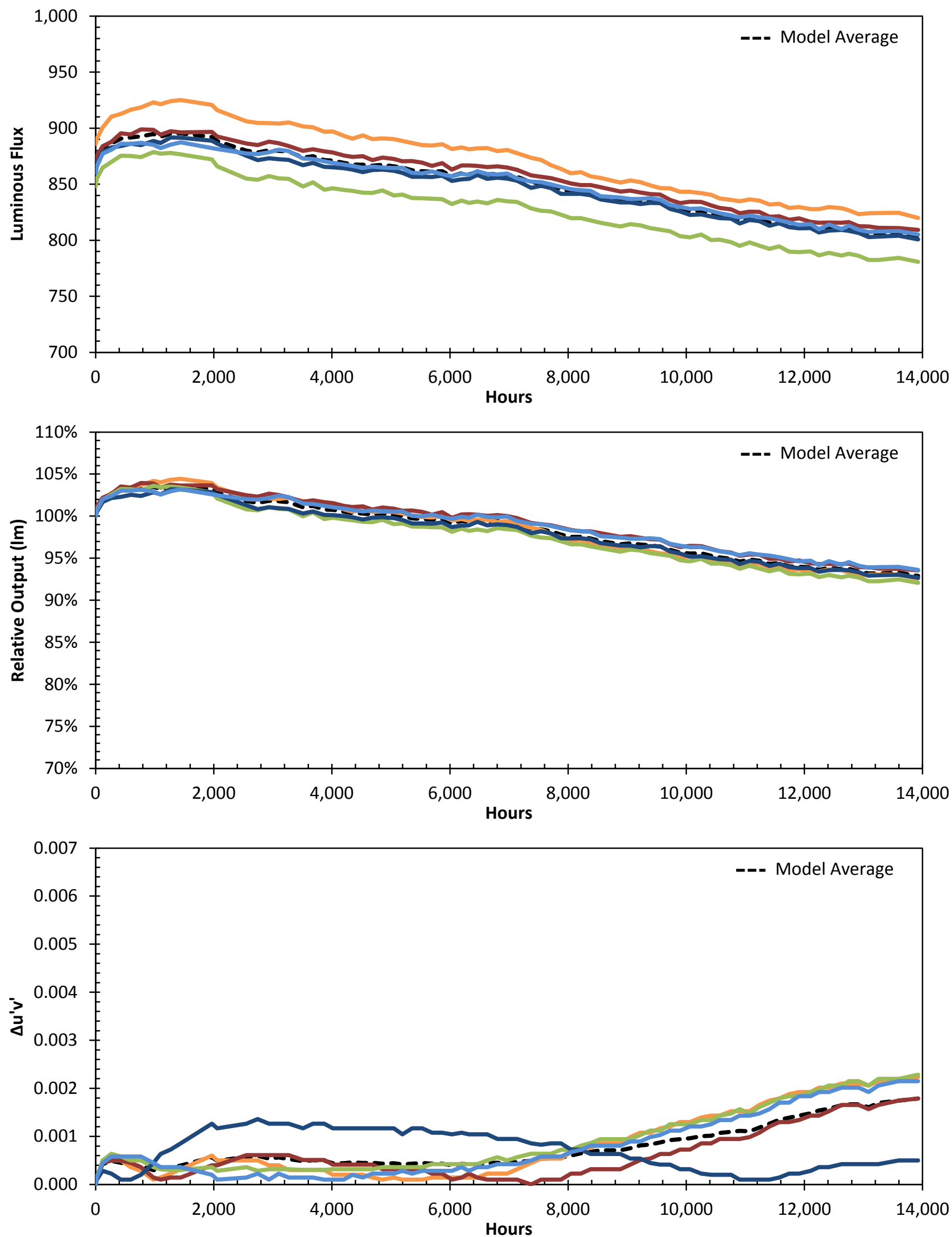
Product ID: 12-99
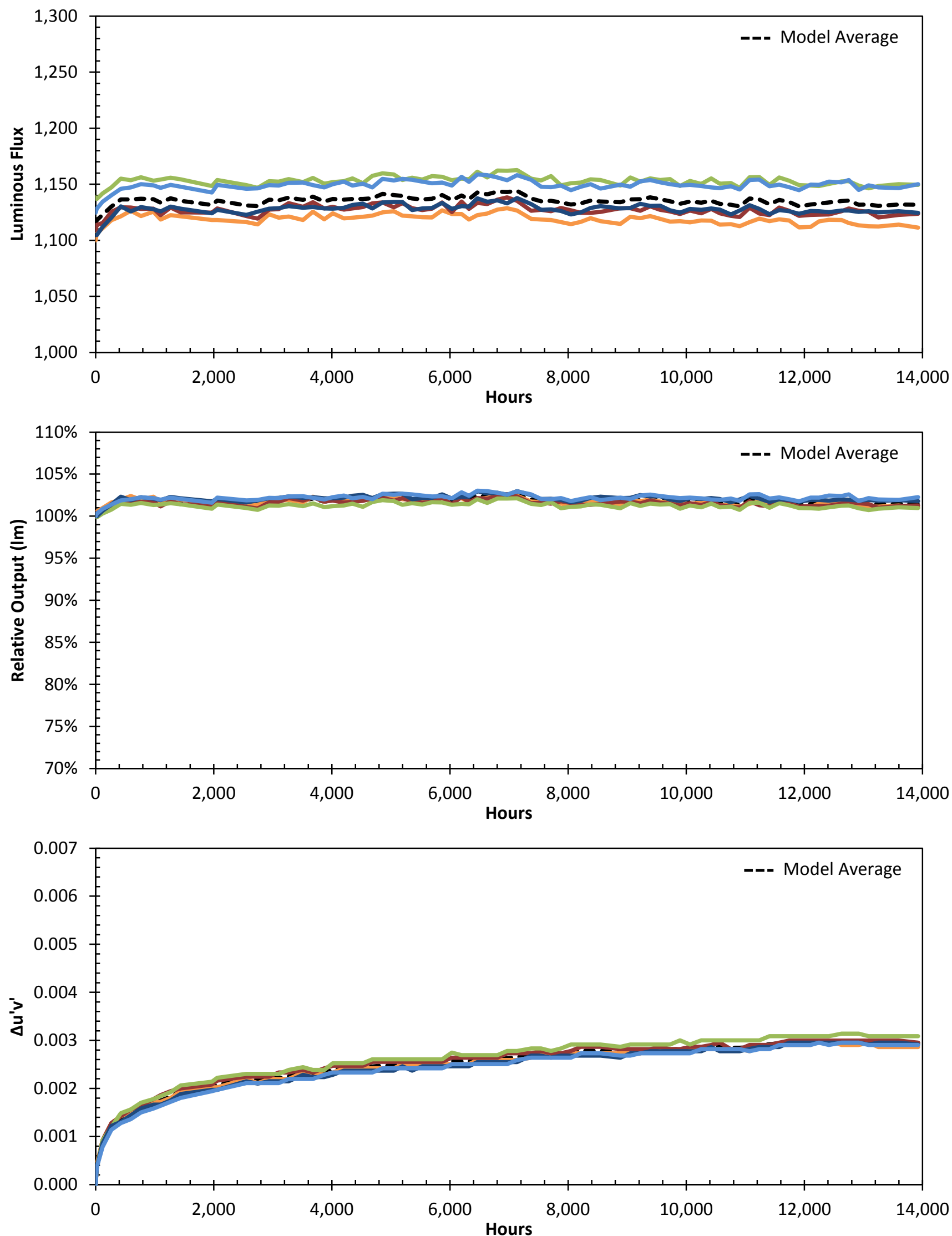
Product ID: 12-100
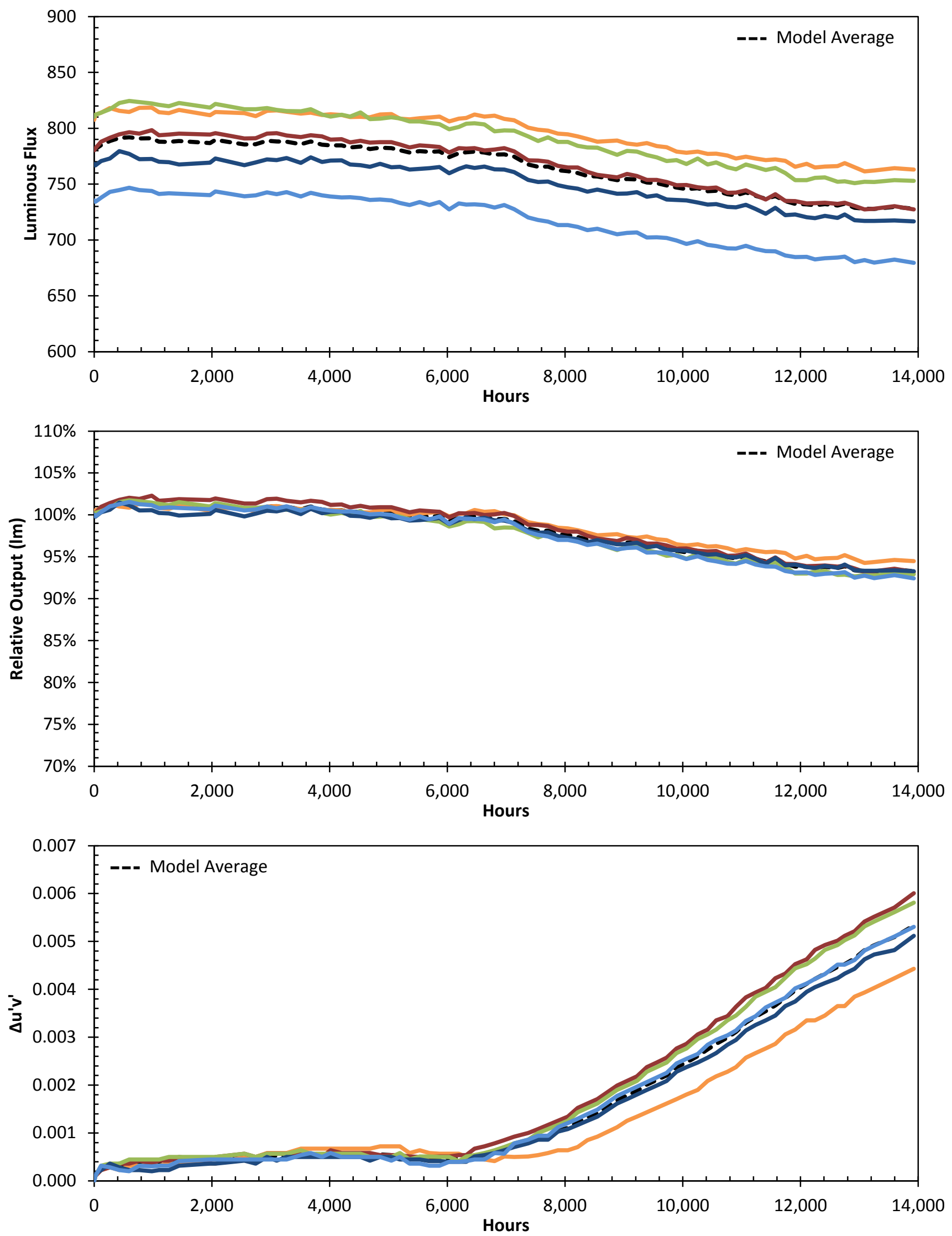
Product ID: 12-134
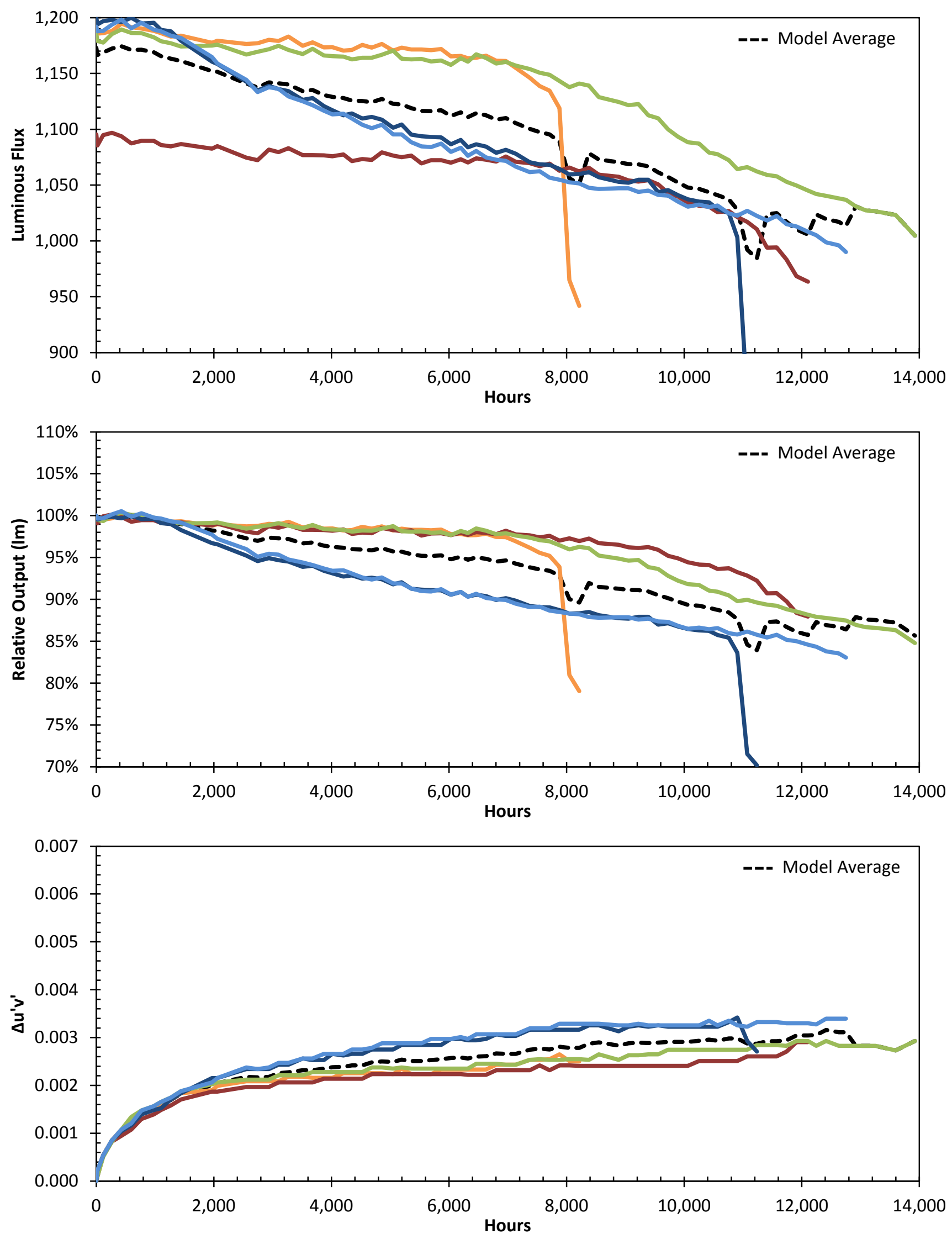
Product ID: 12-135
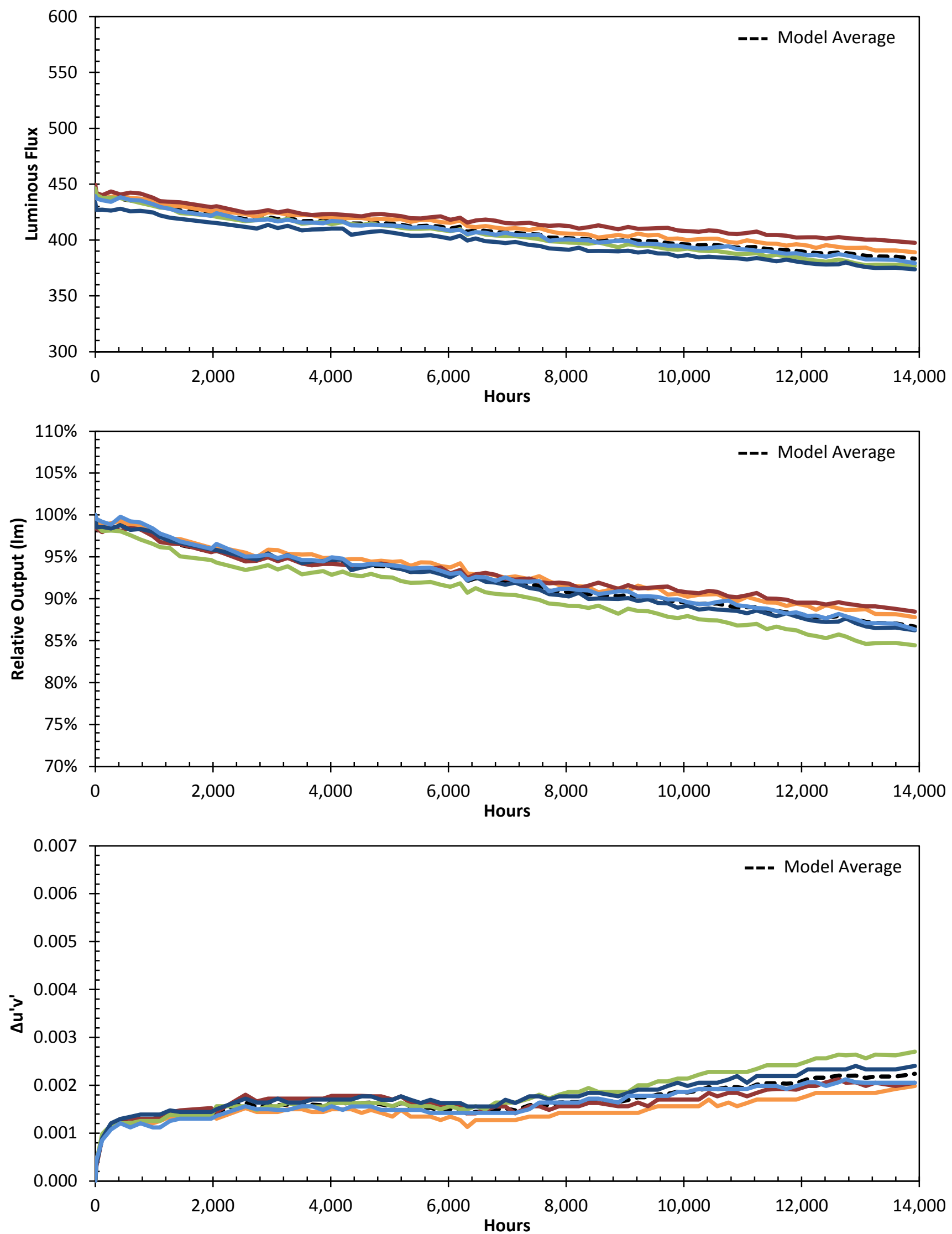
Product ID: 12-140
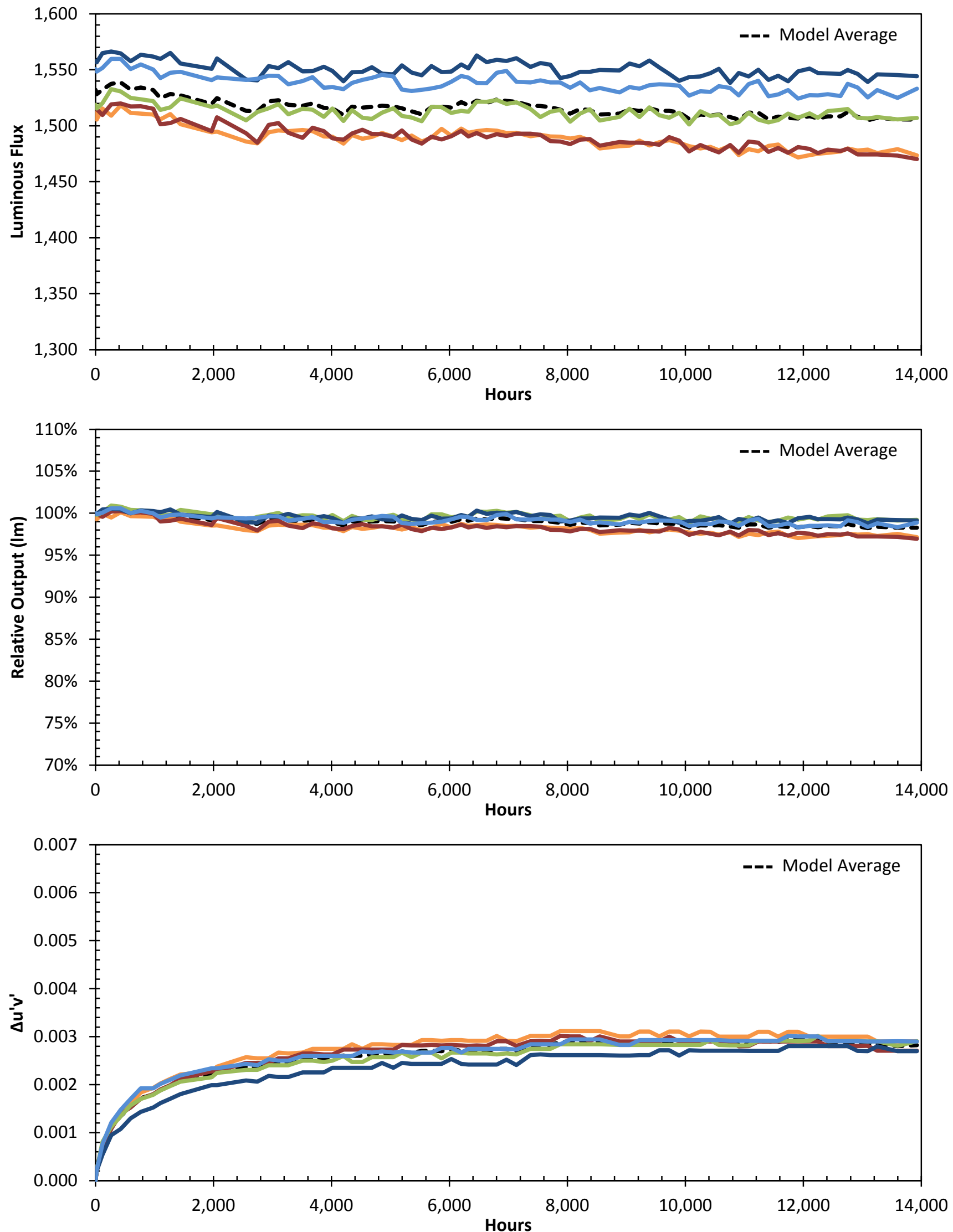
Product ID: 12-144
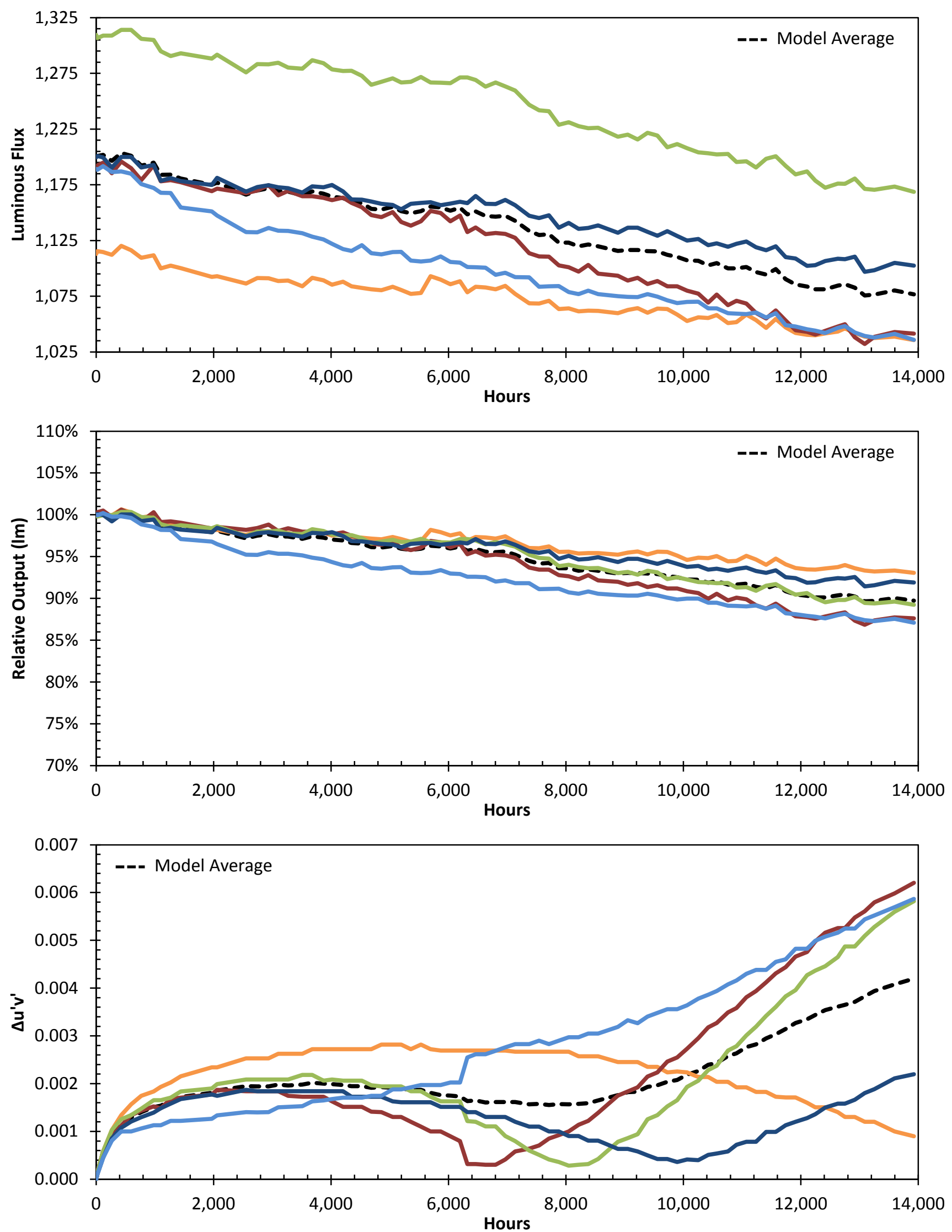
Product ID: 12-145
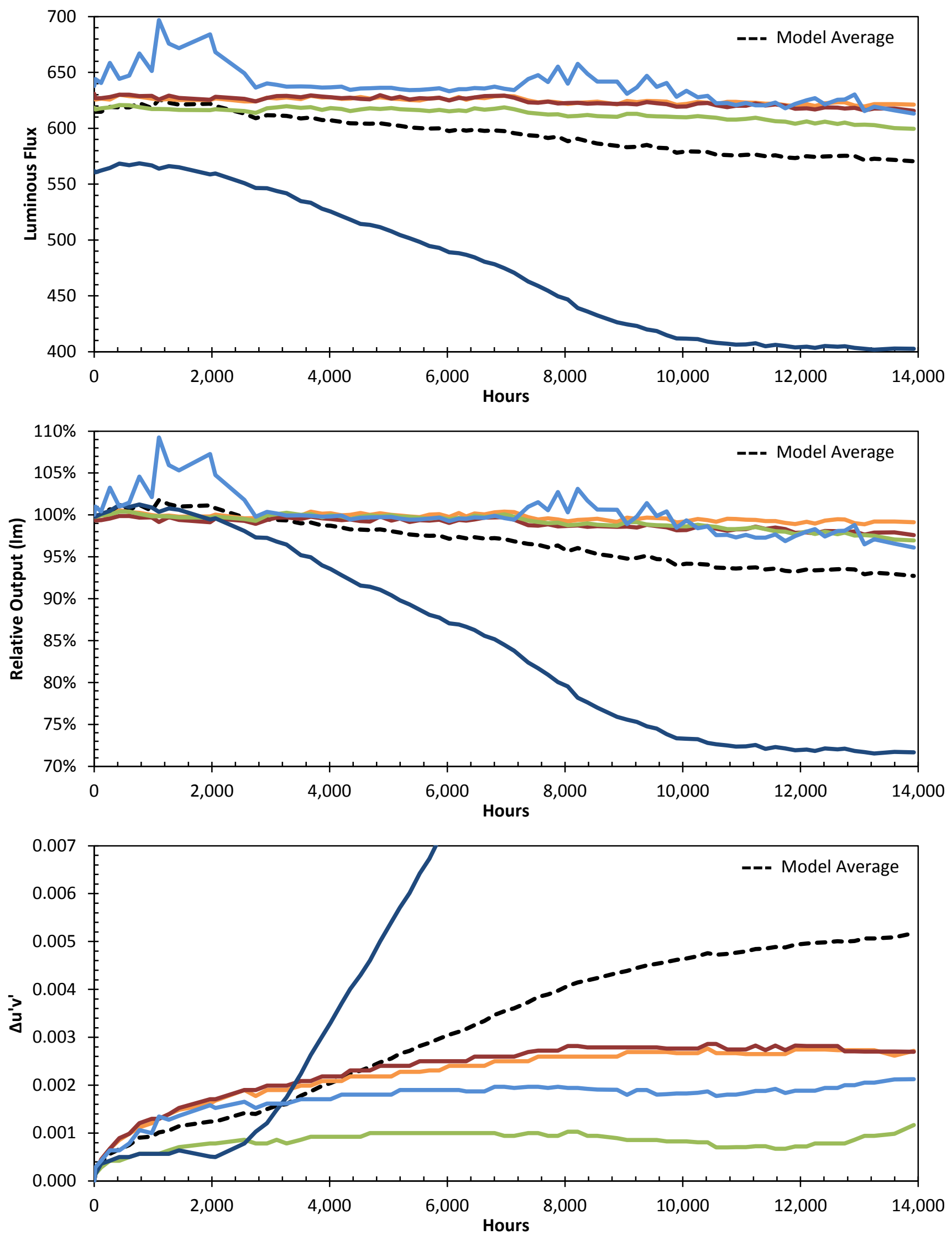
Product ID: 12-146
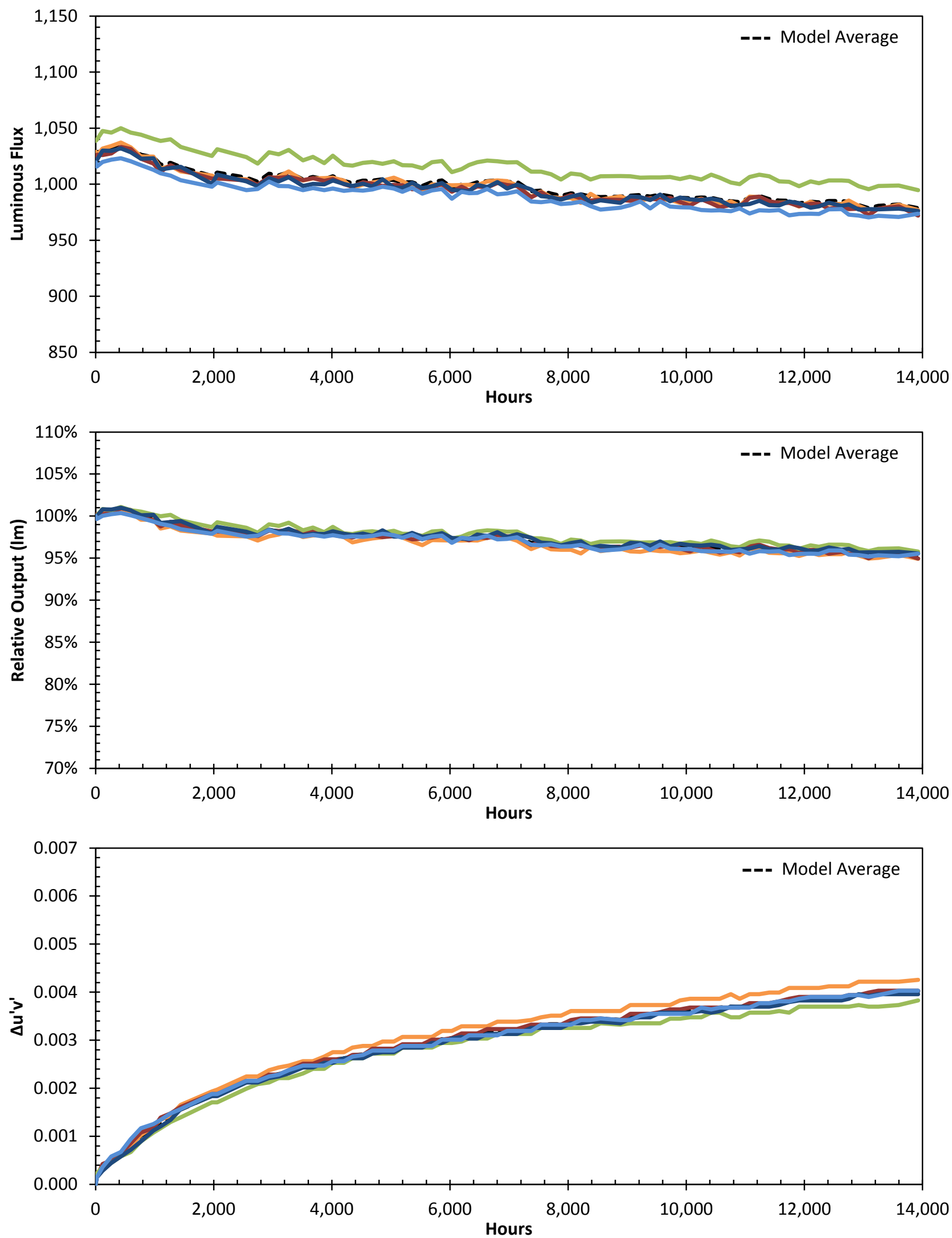
Product ID: 12-147
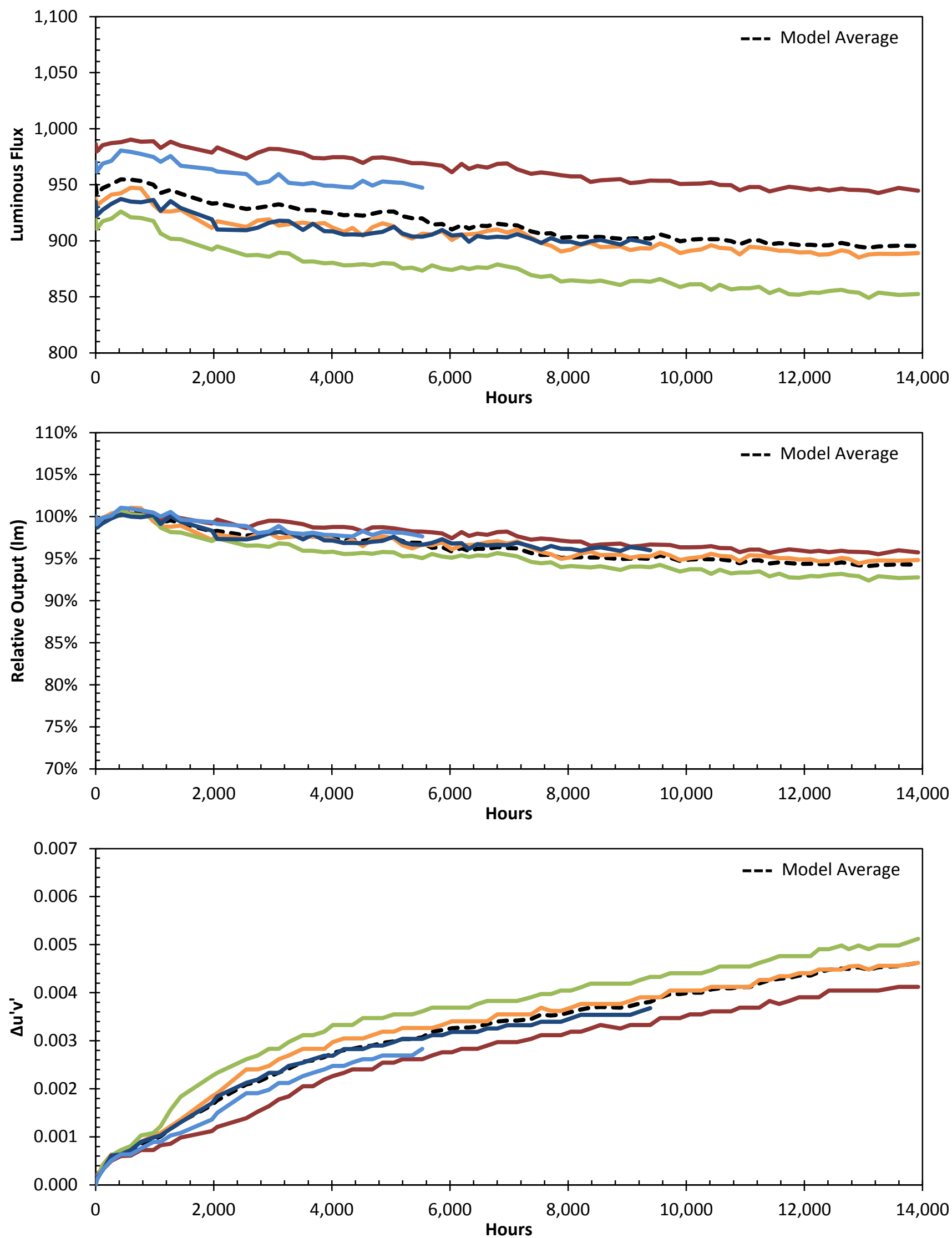
Product ID: 12-148
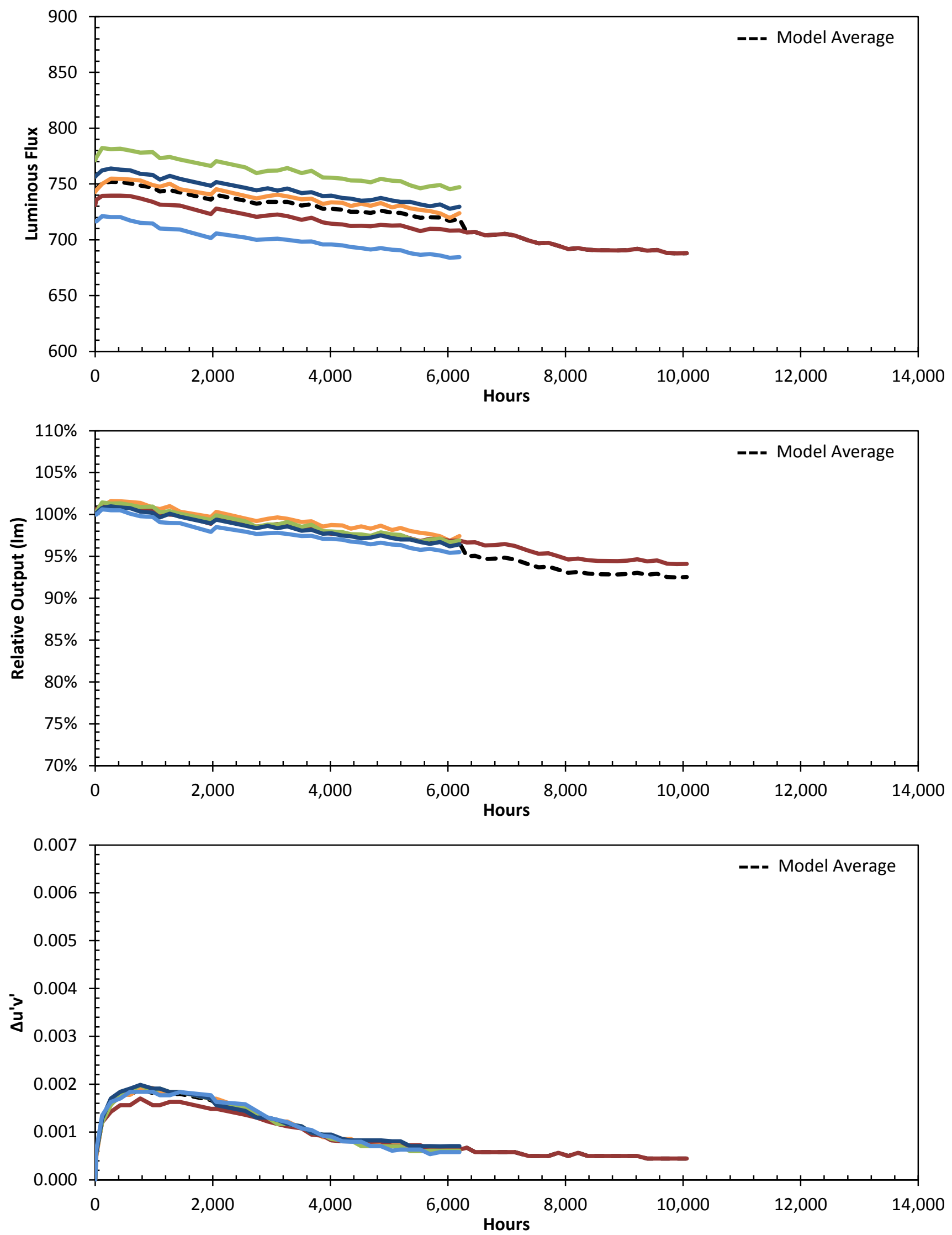
Product ID: BK12-63 (CFL)
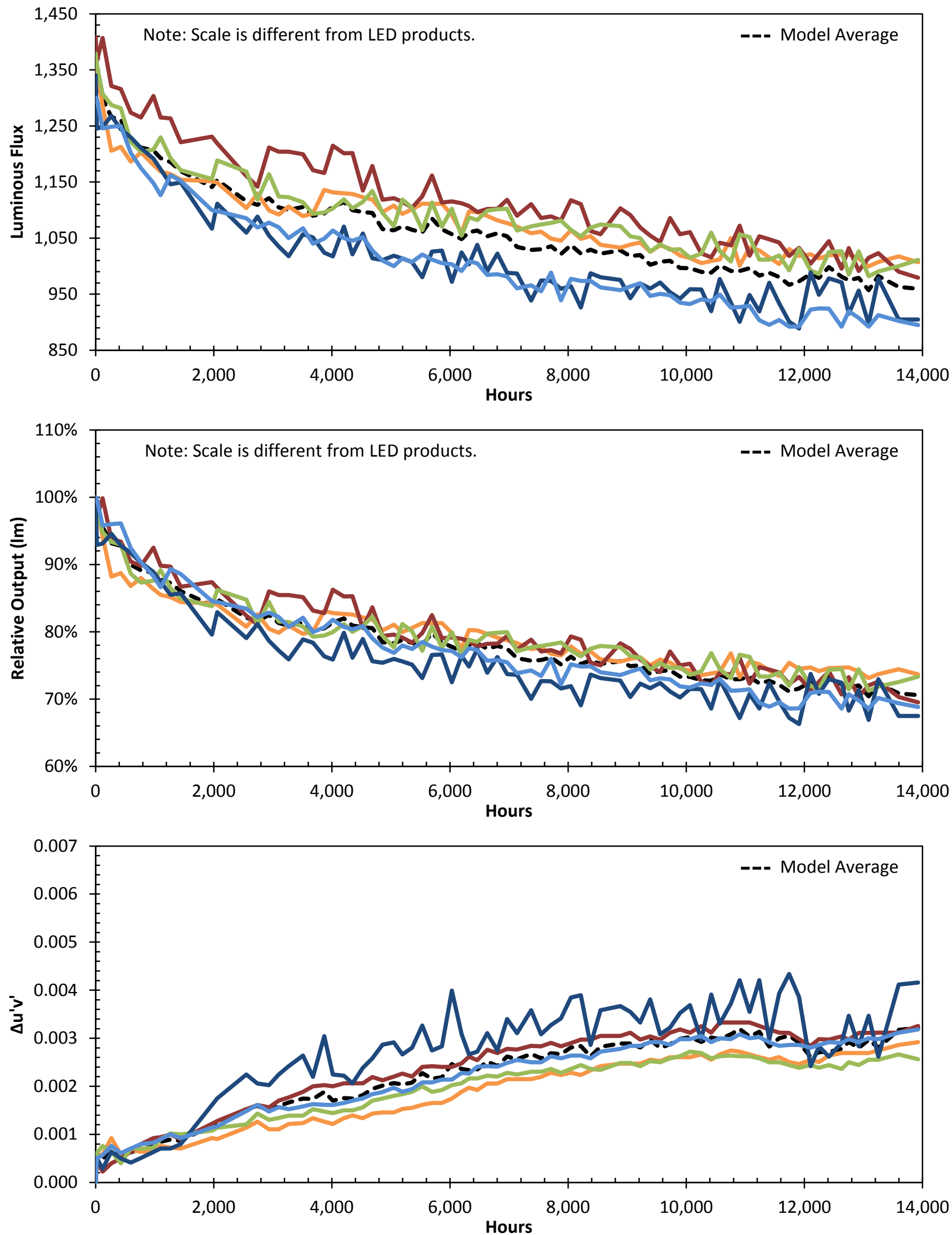
Product ID: BK12-141 (CFL)
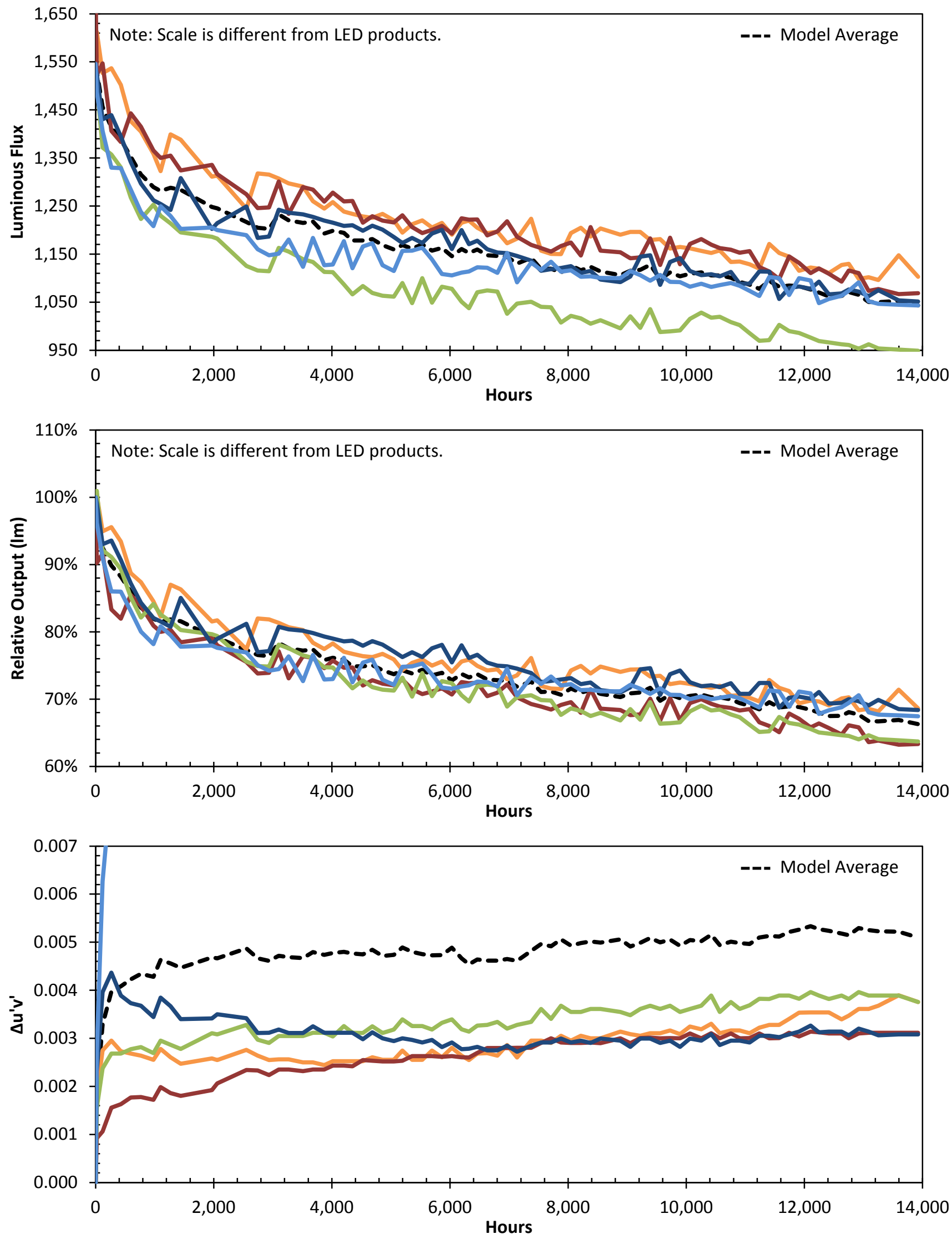
Product ID: BK09-111 (CMH)
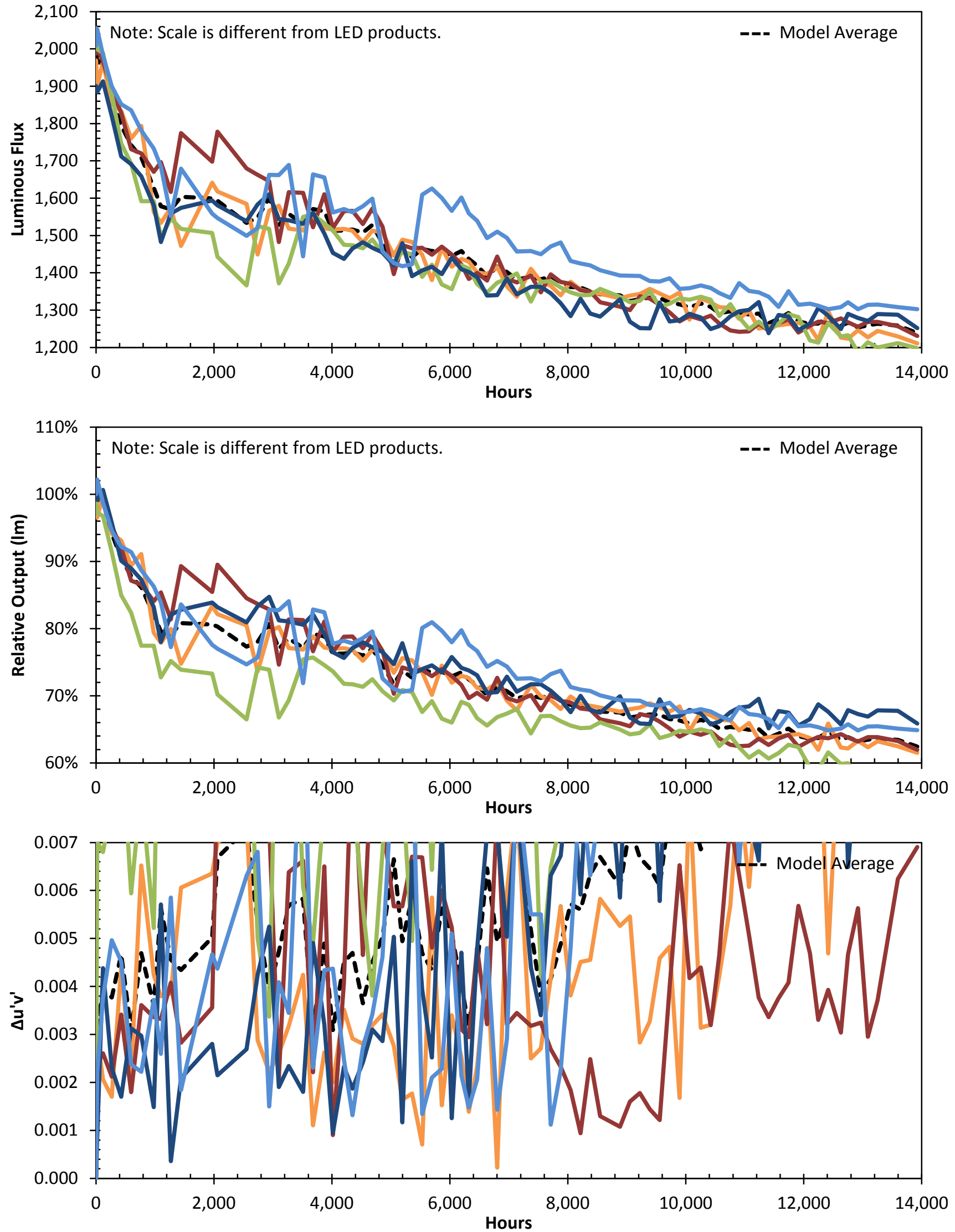
Product ID: BK12-68 (Halogen)
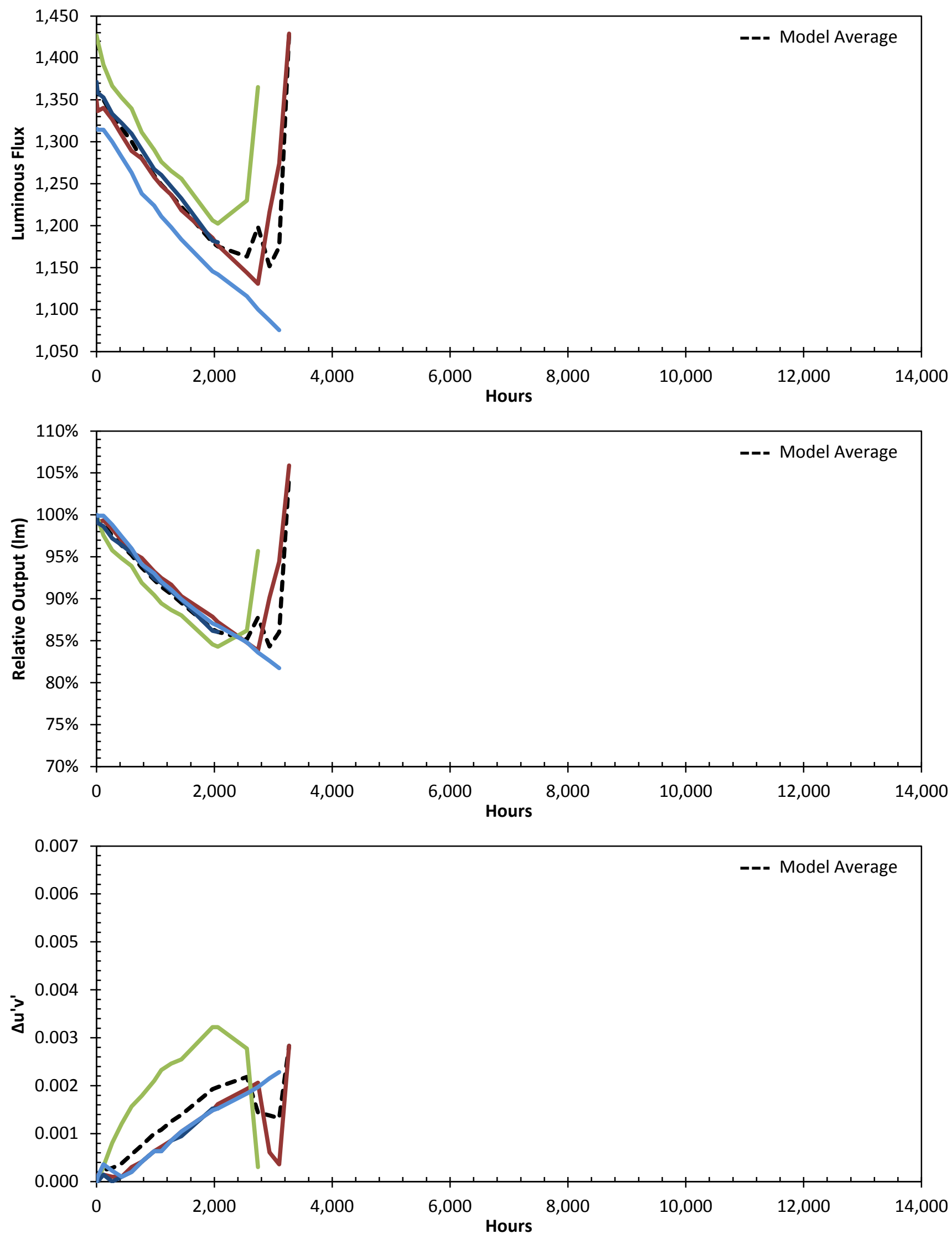
Product ID: BK12-69 (Halogen)
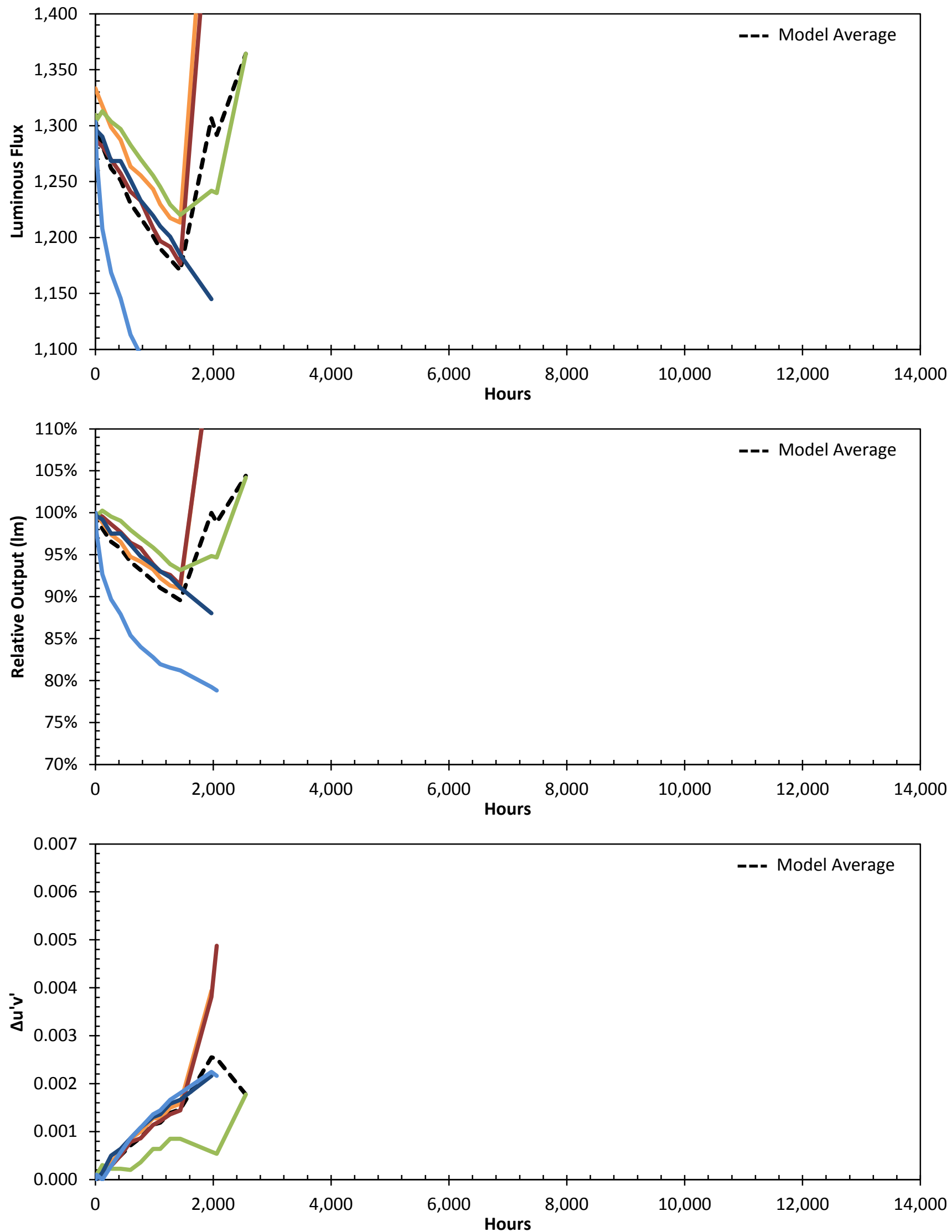
Product ID: BK12-71 (Halogen)
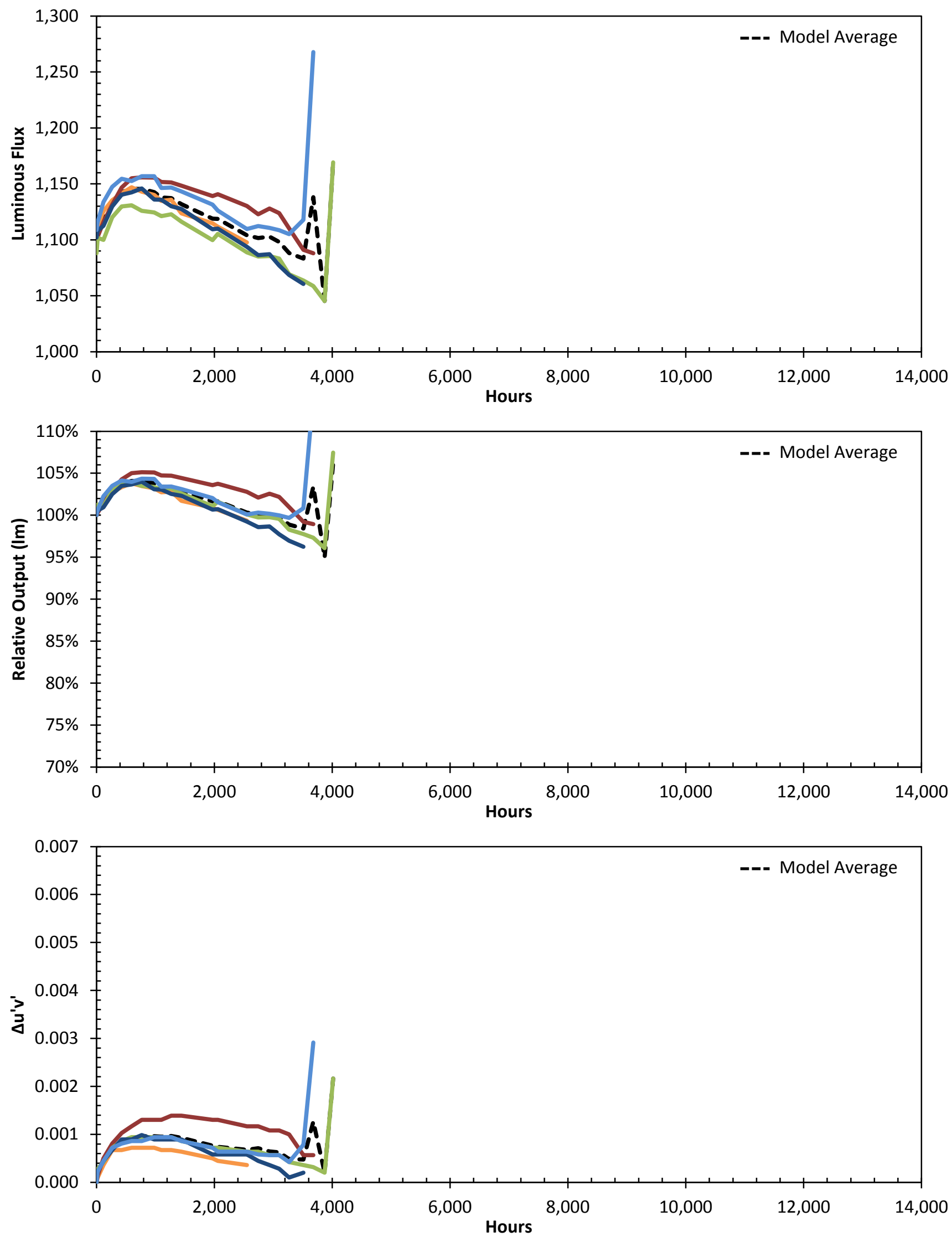


\section{DOE SSL Commercially Available LED Product Evaluation and Reporting Program NO COMMERCIAL USE POLICY}

The U.S. Department of Energy (DOE) is a federal agency working in the public interest. Published information from the DOE SSL CALiPER program, including test reports, technical information, and summaries, is intended solely for the benefit of the public, in order to help buyers, specifiers of new SSL products, testing laboratories, energy experts, energy program managers, regulators, and others make informed choices and decisions about SSL products and related technologies.

Such information may not be used in advertising, to promote a company's product or service, or to characterize a competitor's product or service. This policy precludes any commercial use of any DOE SSL CALiPER Program published information in any form without DOE's express written permission. 
